\title{
Health problems in people with intellectual disability : aspects of morbidity in residential settings and in primary health care
}

Citation for published version (APA):

de Valk - van Schrojenstein Lantman, H. M. J. (1998). Health problems in people with intellectual disability : aspects of morbidity in residential settings and in primary health care. [Doctoral Thesis, Maastricht University]. Universiteit Maastricht. https://doi.org/10.26481/dis.19980313hv

Document status and date:

Published: 01/01/1998

DOI:

10.26481/dis.19980313hv

Document Version:

Publisher's PDF, also known as Version of record

\section{Please check the document version of this publication:}

- A submitted manuscript is the version of the article upon submission and before peer-review. There can be important differences between the submitted version and the official published version of record. People interested in the research are advised to contact the author for the final version of the publication, or visit the DOI to the publisher's website.

- The final author version and the galley proof are versions of the publication after peer review.

- The final published version features the final layout of the paper including the volume, issue and page numbers.

Link to publication

\footnotetext{
General rights rights.

- You may freely distribute the URL identifying the publication in the public portal. please follow below link for the End User Agreement:

www.umlib.nl/taverne-license

Take down policy

If you believe that this document breaches copyright please contact us at:

repository@maastrichtuniversity.nl

providing details and we will investigate your claim.
}

Copyright and moral rights for the publications made accessible in the public portal are retained by the authors and/or other copyright owners and it is a condition of accessing publications that users recognise and abide by the legal requirements associated with these

- Users may download and print one copy of any publication from the public portal for the purpose of private study or research.

- You may not further distribute the material or use it for any profit-making activity or commercial gain

If the publication is distributed under the terms of Article $25 \mathrm{fa}$ of the Dutch Copyright Act, indicated by the "Taverne" license above, 
HEALTH PROBLEMS IN PEOPLE

WITH INTELLECTUAL DISABILITY

Aspects of morbidity in residential settings and in primary health care 
The study presented in chapters 2 through 4 was conducted in a cooperation project between the Department of Epidemiology at Maastricht University and the Pepijn Centre for people with Intellectual Disability, Echt.

The study presented in chapter 6 and 7 was conducted at the Research Institute for Extramural and Transmural Health Care (EXTRA) which participates in the Netherlands School of Primary Care Research (CaRe), acknowledged in 1995 by the Royal Dutch Academy of Science (KNAW).

HEALTH PROBLEMS IN PEOPLE WTTH INTELLECTUAL DISABILITY.

Aspects of morbidity in residential settings and in primary health care/

Schrojenstein Lantman - de Valk van, Henrica Maria Jacoba. Thesis Maastricht

With Ref, - with summary in Dutch.

ISBN nr. 90-5681-029-4

Subject headings: intellectual disability/health problems/residential care/primary health care

Book preparation: Unigraphic Maastricht

Lay-out: Jean Mathijssen - It's Different, Maria-Hoop

Cover Design: Ben Zegwaard

Printing: Unigraphic Maastricht 


\section{HEALTH PROBLEMS IN PEOPLE \\ WITH INTELLECTUAL DISABILITY}

Aspects of morbidity in residential settings and in primary health care

Proefschrift

ter verkrijging van de graad van doctor

aan de Universiteit Maastricht

op gezag van de Rector Magnificus

Prof. Dr. A. C. Nieuwenhuijzen Kruseman

volgens het besluit van het College van Decanen

in het openbaar te verdedigen

op vrijdag 13 maart 1998 om 16.00 uur

door

Henny van Schrojenstein Lantman - de Valk 


\section{Promotores}

Prof. Dr. H.F.J.M. Crebolder

Prof. Dr. M.J. Haveman (Universităt Dortmund, D.)

\section{Copromotor}

Dr. J.F.M. Metsemakers

\section{Beoordelingscommissie}

Prof. Dr. A. C. Nieuwenhuijzen Kruseman (voorzitter)

Prof. Dr. J. A. Knottnerus

Prof. Dr. E. Schadé (Universiteit van Amsterdam)

Prof. W.I. Fraser (University of Wales, Cardiff)

Dr. J. Diederiks

The study presented in the chapters 2 through 4 was supported by a grant from the Ministry of Health, Welfare and Sports.

The study presented in chapter 6 and 7 was supported by a grant from the Stichting voor Onderzoek en Ontwikkeling van de Maatschappelijke Gezondheidszorg STOOM (Foundation for the Development and Scientific Study of Health Care) and by the Pepijn Centre. 
Voor Esther, Merel en Jonas 


\section{CONTENTS}

\section{CHAPTER 1}

General introduction and key questions

\section{CHAPTER 2}

Prevalence and incidence of health problems in people with intellectual disability

\section{CHAPTER 3}

The need for assessment of sensory functioning in ageing persons with mental handicap.

\section{CHAPTER 4}

Use of medication by people with intellectual disability in residential facilities

\section{CHAPTER 5}

Comorbidity in people with Down's syndrome: a criteria-based analysis

\section{CHAPTER 6}

People with intellectual disability in general practice: case definition and case finding

\section{CHAPTER 7}

Health problems in people with intellectual disability in general practice: a comparative study

\section{CHAPTER 8}

General discussion

\section{CHAPTER 9}

Summary

\section{CHAPTER 10}

Samenvatting.

Appendix: questionnaire casefinding

Dankwoord 


\section{GENERAL INTRODUCTION AND KEY QUESTIONS}

The care of people with intellectuall disability (ID) has changed considerably over the past 50 years as the result of paradigm shifts in the shared vision of the needs of people with ID. Related to this paradigm shift was the simultaneous change in definition of ID itself. The way a society views a person with $\mathrm{ID}$ is to some extent influenced by the model of residential and other care provisions for people with such needs. This is also applicable for the perception of health problems of people with ID and the health care which is provided to these people.

\section{Changing visions}

During the twentieth century, people with $\mathrm{ID}$ have been regarded at various times as burdens on the public purse, suitable cases for charity, medical patients, recipients of social care, objects of scrutiny, users of social services and exiles in institutions (Walsh 1997). As time went on, they were seen as patients who needed treatment and who, sometimes, could recover. Hospital-like institutions were built to accommodate these people who were viewed as being sick albeit these hospitals were located outside society, both physically and socially. This model of care provision was called 'the medical model'. This philosophy and treatment model was followed by the "normalisation model" between 1960 and 1970 (Van Gennep 1997). The intent at this time was to offer people with ID a life with patterns and circumstances that were similar to those in the mainstream of society. People with ID were to experience a normal dayweek - and year-rhythm, the normal phases of the life cycle, and a bi-sexual world. Their wishes and choices were to be respected, and the facilities in which they were to reside were to be as similar to those of people without ID. This normalisation model led to the discharge of people with $\mathrm{D}$ from institutions into small scale living facilities in or near communities.

Quite a few of these smal-scale living facilities, however, did not stimulate integration, but rather maintained the old institutional culture. This model resulted in people with mild ID being placed into a community facility while people with severe ID and those with challenging behaviour despite their level of ID remaining in the old institutes. The acceptance of this population by other members of society remained low.

Gradually it became clear that people with ID indeed should be accepted as normal citizens. In fact, these people were autonomous and had the same rights and responsibilities as other people but they needed support in order to participate in society. Service planning needed to be person-centered (Henning 1993). Support may be given by family and friends or by professionals. The aims of the support should be to enable the person with ID to live as normally as possible within the limitations imposed upon him by his disability and assist the person to create an existence with which he is content. This means that a person with ID should live as independently as possible with truly individualized support mechanisms. This has been called the new paradigm (van Gennep 1997) and could best be considered personcentered care. 


\section{Changes in the definition of ID}

It is not surprising that, as a consequence of these changing visions, the definition of $I D$ also changed over time. The generally accepted definition, which is in line with this new paradigm, and has been used as the basis for this thesis is the definition of the American Association on Mental Retardation (AAMR 1992). This definition states that people considered to have ID are those who have significantly subaverage intellectual functioning which manifested itself before age 18 and exists concurrently with limitations in two or more adaptive skill areas, i.e. communication, self-care, home living, social skills, community-skills, self-direction, health and safety, functional academics, leisure and work. Assumptions underlying this definition are that a valid assessment considers both cultural and linguistic diversity as well as differences in communication and behavioral factors. The limitations in adaptive skills are considered in the context of the community environments typical of the individual's age peers. Specific adaptive limitations often coexist with strengths in other adaptive skills or personal capabilities.

\section{Changes in the living arrangements for people with ID in the Netherlands}

Living facilities for people with ID in the Netherlands are primarily a mixture of a design emanating from the times of the medical model combined with physical plant renovations based on the principles of the normalization model. Maas et al. (1988) counted the clients of all possible care facilities for people with ID in four regions of the Netherlands excluding the age groups 0-4 years and those older than 70. Based on the numbers of people identified as having ID in these regions, the total number of people with ID in the Netherlands was estimated te be 120,000 .

About 30,000 people with ID live in institutions. These are residential facilities where 150 1,000 people live on the same grounds, mostly in groups of 6-12 people. Some of these facilities are located in urban areas or village centers while quite a few are located in the woods or other 'healthy' surroundings at a distance from other Dutch citizens. The care provided in these facilities includes board and lodging, work and leisure, and a full spectrum of special care required for a person with ID. This service includes health care.

A further 15,000 people with ID live in group homes, that is to say, living facilities with about of 24 inhabitants in subgroups of $4-10$ persons. These facilities are generally located in nomal neighbourhoods of villages or in the suburbs.

About 75,000 people with ID live with their families or on their own. In the Netherlands, there is no formal registration of people with ID living outside institutes or group homes, so that number is an estimate. Governmental policy in the last several years has been to reduce as many residential places as possible and to relocate people in to small living facilities in the community. By the year 2000 , thirty percent of the people who now live in institutions should be housed in groups of no more than 6 persons in normal homes integrated into normal neighbourhoods (Ministry of Health, Welfare and Sports 1995). Separating the functions of the current multimodal service delivery model is to be one of the aims to be achieved. The person with ID should, as much as possible, use the care facilities used by other Dutch 
citizens. Special care, adjusted to the needs of the person with ID should only be used if necessary. Nomal care practices should be applied wherever possible:

\section{Changes in health care provision}

Health care for most people with ID in the Netherlands is organized in the same way as for other Dutch citizens. People with ID living outside of institutions are registered with a general practitioner (GP) and whenever they experience any health problems, they may seek the advice of their GP. The GP, who serves as the gatekeeper for all other health care facilities, then either provides the necessary health care or refers the patient to another health care facility (Schrijvers 1997). GPs have no special training in the health problems of people with ID.

People with ID who live in large residential care facilities have their own GP, who belongs to the staff of the facility. This GP is generally a person who has been trained as a GP but who has more expertise and who has completed a pastgraduate training program for this job. People living in group homes are registered with a GP, but the staff of the group home is free to request assistance from a physician who may assist the staff directly or assist the assigned GP in health problems specifically related to ID.

Until some twenty years ago, most people with ID who had serious health problems, were admitted to institutions. People with ID who stayed with their families were said to be more healthy (Centerwall \& Centerwall 1960). Unfortunately, in the Netherlands, the health problems of people with ID living at home were never studied. Currently, governmental policy is to keep at least children with ID with their families as long as possible. The number of places in day care facilities for children has increased considerably. The fact that children with ID stay with their families means that GPs are confronted with the health problems related to ID more than in the past. Furthermore, the people with ID who now are being discharged from large residential facilities to live in smaller community-based facilities will increasingly register with the local GP.

\section{Consequences of these changes}

Looking from the health care perspective it becomes clear that GPs and home care agencies will become more involved in care provision of people with ID. There are several reasons that justify the special attention for the provision of medical care for people with ID.

\section{Multi-morbidity vulnerability}

The first reason is that the actual cause of the ID quite often causes other health problems as well. This manifests itself as comorbidity or multimorbidity. Comorbidity refers to additional health problems that may occur during the course of an index disease. Multimorbidity refers to any simultaneous occurence of health problems in the same person where nothing is known about an interrelation of the disorders (van den Akker et al. 1996). As yet we are not sure to what extent health problems are interrelated, so the term multimorbidity is used.

Perinatal problems may cause epilepsy, cerebral palsy and ID (Pope 1992). People with Down's syndrome quite often develop sensory impaiments; children with Prader Willi 
syndrome are hypotonic and have feeding disorders as a baby and often develop severe eating problems, obesity, daytime sleepiness and psychoses in later life (Clarke 1993). A clear aetiological diagnosis may offer red flags for the physician to anticipate and attend to such health issues to prevent additional health problems. The knowledge of health problems that are likely to occur with certain aetiological diagnoses is growing fast (Carey 1992). If recovery is not feasible, such as in people with cerebral palsy who already have epilepsy and are nonambulatory or bedridden, a health plan should aim to prevent secundary and tertiary complications such as pressure sores or joint deformities (Pope 1992). Vulnerability to disease may be increased by medication usage. Epilepsy, psychiatric problems and quite a few other health problems related to the cause of ID require pharmacological treatment. People with ID frequently use medication and thus are more at risk for medication interactions, side effects and overdosage (Searle et al. 1989, Luchins et al. 1993).

\section{Life expectancy}

The second consideration is that the life expectancy of people with ID is increasing (Maaskant et al. 1995). The birth rate for people with $\mathrm{ID}$ is stable. Therefore an increasing life expectancy means that the number of people with $I D$ is also increasing. Most striking is the increase of the life expectancy of people with Down's syndrome. While beween 1942-1952 less than $50 \%$ of the children with Down's syndrome survived their first year, in $1988,80 \%$ of thern was still alive at 5 years and $44 \%$ survived to age 60 (Sadovnik \& Baird, 1992). The combination of 'normal' ageing disorders with lifelong conditions such as epilepsy, cerebral palsy or psychiatric problems might lead to different expressions of the ageing experience. Ageing people with ID not only have a higher risk for health problems, but also may find that the symptoms of 'normal' ageing disorders may be different than in ageing people without ID.

\section{Communication}

The third issue is that of people with ID experiencing problems in their attempts to communicate with their physicians, both in verbalizing their health problems and worries and in understanding the examination techniques such as blood tests or gynaecological exams. On the other hand, physicians are untrained in non-verbal communication and very often do not understand what the person with ID tries to express (Howells et al 1993, Day \& Jancar 1994). Another barrier in communication is formed as the result of unrecognized visual or auditory impairments (Welsh Health Planning Forum 1992, Evenhuis 1995a, 1995b). Once it is known that a person is visually or auditively impaired, communication might well be possible. If these conditions remain unrecognized, however, both the doctor and the patient have a serious problem. Communication problems may also lead to misinterpretations of behavioural symptoms: challenging behaviour is often interpreted as a psychiatric condition. People with ID showing such challenging behaviour often do not fit the criteria for diagnosable psychiatric conditions (Turner \& Moss 1996). At the same time, if a person, due to his limited verbal capacities cannot be interviewed, psychiatric disorders such as panic disorders or phobias are particularly difficult to detect (Moss et al. 1996). 


\section{Purpose of this study}

The purpose of this study is to explore the health problems both of people with ID who live and receive services in residential care and those who receive services from general practitioners. As described above, vulnerability and increased life expectancy might cause more health problems in people with ID than in the general population. At the same time, due to communication problems, part of these health problems may remain unnoticed.

The study started with developing an overview of the health problems of people with ID living in residential facilities in the Netherlands. The author of this thesis participated in a 5-year prospective cohort study on the consequences of the ageing process on the care needs and the provision of care for people with ID receiving residential services in the Netherlands (Maaskant et al. 1995). Health problems were among the aspects that were considered in this study. The study consisted of 4 data collections, each with an interval of one year. In this way prevalence data and 3-years incidence data were obtained.

While discussing the results of this initial study, it became apparent that these results were not representative of the health problems of people with ID who lived with their families. At that same time, van Berkum \& Haveman (1995) reported on the discrepancies between need for and the provision of care to those people with ID who continued to live with their families.

Subsequently, this highlighted the need for this current study to focus on the differences between the health problems experienced by people with and without ID who were registered in general practices and to focus on home care supports'. This part of the study was performed within the Registration Network. Family Practices (RNH) of Maastricht University. The database contained information of about 62.500 patients (Metsemakers et al. 1992).

\section{Study questions.}

\section{The key questions of this study were:}

Health problems of people with ID in residential facilities

- What is the prevalence and incidence rate of the most frequent health problems?

- What is known about two important health problems in these facilities, those being sensory impairments and medication usage?

2. Which multimorbidity is found in people with ID due to circumscript aetiology such as Down's syndrome?

\section{Health problems of people with ID in general practice}

- To what extent are people with ID who are living with their families or living on their own registered in general practices?

- What are the characteristics of these people?

- Do people with ID have different health problems from people without ID?

\footnotetext{
"In the Netherlands, home care, that is nursing, help with activities of datly living and household assistanice, are important to support the family systems requiring special care
} 


\section{Overview of the chapters}

In the following paragraphs an overview of the separate chapters of this thesis has been prowided.

After an introduction of the theme and the study questions in this chapter (chapter 1), the first question regarding the health problems of people with ID in residential settings is answered in chapters 2,3 and 4 . The results presented in these chapters were among the products of the above mentioned study on the changes in the needs for and the provision of care that might be related to ageing in people with ID (Maaskant et al. 1995).

Chapter 2 deals with the prevalence and incidence of health problems in people with ID living in residential facilities, i.e. institutions and group homes.

Chapter 3 describes in more detail the sensory impairments in people with ID. The differences between age groups and the differences between people with Down's syndrome and those with ID due to other aetiologies are discussed.

Chapter 4 discusses medication use in people with ID. The questions in this chapter are: what medication is used most often? Is the medication use related to age and level of disability? Do people living in large residential care facilities receive more medication than people living in group homes?

The second question: which multimorbidity is found in people with ID with a clear aetiological diagnosis is dealt with in chapter 5 . It was decided to study health problems in people with Down's syndrome as people with Down's syndrome are probably the largest subgroup of people with ID for whom the aetiology is known. The study was done by a criteria-based analysis of literature search on articles in which health problems in people with Down's syndrome were compared to those in other people.

The third question is discussed in chapters 6 and 7 . To study the health problems of people with ID who live at home or on their own, these people should first be identified. However, no case registers or other formal registrations of people with ID living outside institutions or group homes in the Netherlands exist. This need served as the basis of the following chapters.

Chapter 6 describes the process of case definition and case finding of the people with ID that were registered within a GP data base. The differences in demographic characteristics between the people with and without ID in this sample and available information about home care supports were also described in this chapter.

In Chapter 7, the differences in health problems between people with and those without ID in general practice were studied. The study focused on the number of health problems (multimorbidity) in both groups and the prevalence of health problems that are reported frequently in people with ID. 
In Chapter 8, the results are discussed within the framework of the study questions. Subsequently, recommendations for health care provision for people with ID are formulated. Issues that warrant further study are outlined.

Chapter 9 contains a summary of the thesis as a whole. In Chapter 10 a Dutch summary (samenvatting) is presented.

The chapters 2 through 7 are adaptations of articles that have either already been published in refereed journals or have been submitted for publication. Hence there is inevitably some overlap among these chapters. 


\section{REFERENCES}

AAMR (1992) Mental Retardation: Definition, classification and systems of supports. AAMR: Washington DC, USA.

Akker M. van den, Buntinx F. \& Knottnerus J.A. (1996) Comorbidity or multimorbidity: What's in a name? A review of literature. European Joumal of General Practice 2, 65-70.

Berkum H.W. van \& Haveman M.J. (1995) Zorg aan huis. Behoefte aan zorg gebruik van zorg en discrepantie tussen wraag en aanbod onder ouders van verstandelijk gehandicapten in Zuid-Nederland. Department of Epidemiology, Uniwersity of Limburg, Maastricht.

Carey J.C. (1992) Health supervision and anticipatory guidance for children with genetic disorders (including specific recommendations for trisomy 21 , trisomy 18 and neurofibromatosis. 1). Pediatric Clinics of North America 39, 25-53.

Centerwall S.A. \& Centerwall W.R. (1960) A study of children with mongolism reared in the home compared with those moved away from the home. Paediatrics $25,678-85$.

Clarke D.J. (1993) Prader Willi syndrome and psychoses. British Journal of Psychiarry 163,680-4.

Day K.A. \& Jancar J. (1994) Mental and physical health and ageing in mental handicap: a review. Journal of Inrellectual Disability Research 38, 241-50.

Evenhuis H.M. (1995) Medical aspects of ageing in a population with intellectual disability: $\mathbb{I}$. Visual inpairment. Journal of Intellectual Disability Research 39, 19-25.

Evenhuis H.M. (1995) Medical aspects of ageing in a population with intellectual disability: Il. Hearing impairment. Journal of Intellectual Disability Research 39, 27-33.

Gennep A.Th.G van (1997) Paradigmaverschuiving in de visie op zorg voor mensen met een verstandelijke handicap. Inaugurale Rede. Maastricht University.

Howells G., Kerr M. \& Lervy B. (1993) Learning Disabiliny (Mental Handicap). Distance learning workbook for general practitioners. University of Wales College of Medicine.

Henning D.B. (1993) A paradigm shift: A look at the new person-centered community services in the US. In: Haveman M.J. \& Buntinx W.H.E. (Eds) Family needs and family support in mental retardation. An international perspective. SWIHC, Maastricht 13-24.

Luchins D.J., Dojka D.M. \& Hanrahan P. (1993) Factors associated with reduction in antipsychotic medication dosage in adults with mental retardation. American Joumal on Mental Revardation 98, 165-72.

Maas J.M.A.G., Serail S. \& Janssen A.J.M. (1988) Frequentie-onderzoek geestelijk gehandicapten 1986. Tilburg: IVA, Instituut voor sociaal-wetenschappelijk onderzoek van de Katholieke Universiteit Brabant 1988.

Maaskant, M.A., Haveman M.J., Schrojenstein Lantman-de Valk H.M.J. van, Uirlings H.F.J., Akker M. van den \& Kessels A.G.H. (1995) Veroudering bij mensen mer een verstandelijke handicap. Versiag van een longitudinaal onderzoek. University of Limburg, Maastricht/Pepijn Centre, Echt.

Maaskant M.A., Sturmans F., Haveman M.J. \& Frederiks C.M.A. (1995) Life expectancy of institutionalized people with mental handicap in the Netherlands. European Journal on Mental Disability 5,5-13.

Metsemakers J.F.M., Hoppener P., Knottnerus J.A., Kocken R.J. \& Limonard C.B. (1992) Computerized health information in the Netherlands: a registration network of family practices. British Journal of General Practice $42,102-16$

Ministry of Health Welfare and Sports (1995) Meerjarenprogramma intersectoraal gehandicaptenbeleid 19951998, De perken te buiten. Tweede Kamer 1994-1995, 24710,nrs 1-2.

Moss S., Prosser H., Ibbotson B. \& Goldberg D. (1996) Respondent and informant accounts of psychiatric symptoms in a sample of patients with learning disability. Journal of Intellectwal Disability Research 40,57-65.

Pope A.M. (1992) Preventing secondary conditions. Mental Retardation 30, 347-54. 
Pope A.M. (1992) Preventing secondary conditions. Mental Retardation 30, 347-54.

Sadovnik A.D. \& Baird P.A. (1992) Life expectancy. In: Pueschl S.M.\& Pueschel J.K.(eds) Bromedical concerns in people with Down syndrome. Paul Brookes Publ. Comp. Baltimore, $47-57$.

Schrijvers A.J.P. (ed). (1997) Health and health care in the Netherlands. A critical self-assessment by Dutch experts in the medical and health sciences. De Tijdstroom, Utrecht.

Searle G.F., Berelowitz G.J. \& Wright C.E. (1989) The use of drugs for physical conditions in adults with mental retardation. Journal of Mental Deficiency Research 33, 69-79.

Turner S. Moss. S. (1996) The health needs of adults with learning disabilities and the Health of the Nation strategy. Journal of Intellectual Disability Research 40,438-50.

Walsh P.N. (1997) Old world-new territory: European perspectives on intellectual disability. Journal of Intellectual Disability Research 41, 112-9.

Welsh Health Planning Forum (1992). Protocol for Investment in Health Gain Mental handicap (learing disabilities). University of Wales, Cardiff. 


\section{CHAPTER 2}

\section{PREVALENCE AND INCIDENCE OF HEALTH PROBLEMS IN PEOPLE WITH INTELLECTUAL DISABILITY}

\section{Summary}

The objective of this study was to determine the prevalence and incidence of the most frequent chronic health problems in relation to age in people with intellectual disabilities living in residential facilities in the Netherlands.

A prospective cohort study was done with four data collections, each with an interval of one year. Data were collected by means of questionnaires, which were completed by each person's physician. Striking results included the reported high prevalence and incidence of visual and hearing impairment, which was even more pronounced in people with Down's syndrome than in people with intellectual disabilities resulting from other causes. Gastrointestinal problems also appeared to have high incidence rates. Dementia was reported frequently in people with Down's syndrome aged 40 years and older.

The results reflect the need for a more predictive policy which can anticipate health problems in people with intellectual disabilities.

Published as: Schrojenstein Lantman-de Valk H.M.J. van, Akker M. van den, Maaskant M.A., Haveman M.J., Urlings H.F.J, Kessels A.G.H., Crebolder H.F.J.M. (1997) Prevalence and incidence of health problems in people with intellectual disability. Journal of Intellectual Disability Research 41, 42-51. 


\section{Introduction}

The chance of people with intellectual disabilities (ID) being affected by health problems is higher than that of people without ID. In fact, some conditions may be related to the aetiology of a person"s ID. As people age, "normal" ageing problems add to these congenital disorders (Welsh Health Planning Forum 1992). Life expectancy is increasing for people with ID as well as for the general population (Maaskant et al. 1995). This means that the risk for health problems increases with age in people with ID. Haveman \& Maaskant (1989) found that symptoms of ageing were present in people with severe ID from the age of 50 years onward.

Furthermore, people with Down's syndrome (DS) appeared to have ageing problems more often than people with ID resulting from other causes (Haveman et al. 1989). Moss et al. (1993) found that health problems were more frequent in people with severe or profound ID than in people with mild or moderate ID.

Because of a lack of verbal capacities in people with ID (Day \& Jancar 1994) and the lack of non-verbal communication skills in medical staff, people with ID have difficulties in expressing complaints. For the same reason, cooperation with examination procedures, such as the collection of blood samples or the administration of (neuro-)imaging techniques may be extremely difficult. These diagnostic problems may hamper the provision of good medical care to people with ID. For these reasons, medical care providers should be informed about the most prevalent health problems and health risks in people with ID and how to anticipate on first signs of such conditions.

Quite a few authors (Janicki \& Jacobson 1986, Day 1987, Hogg et al. 1988, Badry et al. 1989, Maaskant \& Haveman 1988) have reported on the prevalence of health disorders in this group. All these studies were cross-sectional in design, were based on information given by direct care staff, and compared younger and older persons at one moment in time. However, because of the changing circumstances over time, older people in those studies might be the healthy survivors, while the younger people may represent a more handicapped population.

No references could be found that dealt with incidence rather than prevalence of hevalth pro blems in people with ID. However, to develop an adequate policy for the prevention and treatment of health problems, data on incidence are necessary.

The authors of the present study performed a time-limited ( 4 years) cohort study on the agerelated changes in the need for and the supply of care for persons with ID in the Netherlands. (Maaskant et al. 1995).

This paper deals with the following questions:

1. What is the age-specific prevalence of health problems in a sample of people with ID? Are there differences between people with DS and those with other aetiologies of ID? Is there a rellation between level of ID and prevalence data?

2. What is the age-specific incidence of health problems? Are there differences between people with DS and those with other causes of ID? 


\section{MATERIALS AND METHODS}

\section{Subjects}

The study sample consisted of 1602 people with ID living in institutions or group homes in North Brabant and Limburg, the two southern provinces of the Netherlands. Ninety two per cent of the institutions and $96 \%$ of the group homes in these regions participated in this study. The sample covered about $15 \%$ of the people in these residential facilities. In the Netherlands, institutions have $300-1000$ residents, while group homes have 20 - 30 residents.

People with ID living with their families were not included in this study because there is no formal registration of these people in the Netherlands. Furthermore, it appeared that in the Netherlands, only $2-5 \%$ of the people with ID older than 50 years live with their family in the Netherlands (van Berkum \& Haveman 1995).

The sample was stratified according to age and aetiological diagnosis, i.e. DS vs. other causes of ID. This was done to make sure that sufficient older residents, and especially older residents with DS, were selected to study special health risks at older age.

In each institution within the age groups, 30 persons were randomly chosen, while in each group home, 10 persons were randomly chosen. In the sample, some extra people with DS were included to ensure that sufficient cases were available to study health problems in people with DS. The so-called extra people with DS were identifiable via a special code and were included in analyses only when comparing people with DS to people with ID from other aetiologies. Within the age groups, the sample is considered to be representative of people with ID living in residential services in the Netherlands.

\section{Data collection}

In this longitudinal study, data were collected by means of questionnaires over a 3-year period (1990-1993) with a one year interval between each data collection. Each data collection consisted of two questionnaires per person. The gerontological questionnaire contained questions about subjects such as mobility, behavioural issues, vocational training and integration. This questionnaire had to be completed by direct care staff. The medical questionnaire contained questions about chronic health problems, medication use, aetiology of ID and hospital referrals. The medical questionnaire was designed by the authors, and was discussed in a panel of experts on ID. For each question, criteria were specified whether or not to include a patient in a given category. Chronic health problems could be noted as present when any form of care provision including medication was given. Actual screening of the person at the moment of completing the questionnaire was not required. The questionnaire had to be completed by the person's general practitioner. In the Netherlands, these physicians have a fixed list of patients and know them rather well. The interrater reliability of the medical questionnaire was satisfactory (Maaskant et al. 1995).

The retum rate for medical questionnaires was $89 \%$ at the first data collection, and $72 \%$ for the last collection. Non-response for the last data collection was $21 \%$. Five per cent of the persons had died, and $2 \%$ had moved and information could no longer be obtained. Non-response 
analysis revealed that non-responders were less intellectually disabled and slightly older [46 versus 42 years old $(p=0.06)]$ than responders. Not all questionnaires were completed totally. Subsequently, the response rates somestimes fluctuated between different variables. The total number is always given in the table concerned.

\section{Analyses}

In this paper prevalence rates are presented from the last data collection (1993). This decision was made because of the reliability of the data.

Prevalence rate is defined as the number of persons suffering from a given health problem, divided by the total number of persons regarding whom data were available. Prevalence rate is expressed as a percentage.

The age groups $0-19,20-29,30-39,40-49,50-59$, and 60 years and older were chosen to analyse the data in relation to age.

To calculate age-specific risks for certain conditions, a backward stepwise regression analysis was performed on the prevalence data from the last data collection (1993). The dependent variable was the presence or absence of a certain condition in each person. Independent variables were age, level of ID and aetiological diagnosis (DS or other cause of ID). A model was constructed so that the variables level of ID and DS were excluded when their influence was not statistically significant $(p>0.10)$. The variable of age was not excluded from analysis since this was the central variable in the study. For epilepsy, a slightly different model was constructed. In addition to age, level of ID and DS, the variable of dementia was added to the study because it had been demonstrated from other studies that epilepsy is a symptom of dementia, especially in people with DS (Lai \& Williams 1989, Stafstrom 1993, McVicker et al. 1994).

The least affected groups were chosen as reference groups. With regard to age, this appeared to be the group 30-39 years of age For level of ID, those with mild ID were chosen as a reference group, and for DS and dementia, the reference groups were those who did not suffer from the condition. Data analyses were performed with the BMDP program (Dixon et al. 1990).

Incidence rate was defined as the number of new cases of a given condition within 3 years divided by the persons who did not have this condition at the first data collection. The incidence rate again is presented as a percentage. The absolute numbers of cases were too small to provide one-year incidence rates. The data presented in this study are calculated as 3 year-incidence rates. The relation between prevalence rate/incidence rate and age was tested with the help of the chi-square test for linear trend. The data are presented separately for disorders in which incidence and/or prevalence rates in people with DS were clearly different than in people without DS. 


\section{RESULTS}

\section{Prevalence rates}

The prevalence of each of the most frequent disorders in relation to age is shown in Table 1.

Table I Prewalence of chronic diseases in relation to age in 1020 persons with ID (in \%)

\begin{tabular}{|c|c|c|c|c|c|c|c|c|c|}
\hline Age (years) & $0-19$ & $20-29$ & $30-39$ & $40-49$ & $50-59$ & $60-69$ & $>70$ & total & $\mathrm{p}$ \\
\hline$N=$ & 101 & 197 & 129 & 136 & 278 & 146 & 33 & 1020 & \\
\hline Affective disorder & 2.0 & 3.1 & 3.9 & 7.3 & 6.8 & 8.3 & 5.9 & 5.7 & ** \\
\hline Dementia & 1.0 & - & 0.8 & 5.1 & 5.4 & 6.2 & 17.6 & 3.8 & * \\
\hline Cerebral palsy & 29.0 & 15.7 & 11.0 & 8.7 & 7.6 & 13.0 & 13.0 & 11.8 & $* *$ \\
\hline Epilepsy & 27.0 & 22.6 & 19.4 & 17.4 & 12.0 & 6.9 & 11.8 & 16.4 & ** \\
\hline Visual impairment & 15.2 & 11.2 & 17.2 & 18.1 & 23.4 & 21.9 & 38.2 & 19.0 & $* *$ \\
\hline Hearing impairment & 6.9 & 6.6 & 6.3 & 10.9 & 16.7 & 17.1 & 32.4 & 12.3 & ** \\
\hline Hypertension & - & 1.5 & 0.8 & 6.5 & 9.7 & 1.1 .6 & 14.7 & 6.1 & $*$ \\
\hline other cardiovascular disorders ${ }^{\| * * *}$ & 1.0 & 1.5 & 0.8 & 1.5 & 6.6 & 11.9 & 31.3 & 5.2 & ** \\
\hline Diabetes & - & - & 1.6 & 2.9 & 4.7 & 8.9 & 9.1 & 3.4 & $* *$ \\
\hline Cronic urinary tract infections & 3.0 & 2.1 & 0.8 & - & 4.3 & 6.2 & 8.8 & 3.1 & ** \\
\hline Ostheoarthitis & - & 0.5 & 2.3 & 3.6 & 7.5 & 6.3 & 17.6 & 4.4 & ** \\
\hline Back- and neck disorders & 6.9 & 3.1 & 1.6 & 4.3 & 4.3 & 8.3 & 15.2 & 4.9 & * \\
\hline other psychiatric disorders ${ }^{2}$ & 9.9 & 16.8 & 17.1 & 21.2 & 18.3 & 14.4 & 14.7 & 16.7 & ns \\
\hline COPD & 8.9 & 4.1 & 3.1 & 1.4 & 6.5 & 9.6 & 5.9 & 5.6 & ns \\
\hline Gastric and esophageal diseases & 6.9 & 5.6 & 1.6 & 8.8 & 7.5 & 11.0 & 11.8 & 7.1 & ns \\
\hline
\end{tabular}

'These are: angina pectoris, infarction, arthytmias, claudicatio, cerebrowascular accident and other signs of atheroselerosis

2Other than affectiwe disonder and dementia

The disorders selected were known to be frequent in the general Dutch population (Ruwaard \& Kramers 1993). In addition, data on epilepsy and cerebral palsy were presented as these disorders more frequently occur in people with ID. Prevalence is increasing in every older age group for some disorders (e.g. visual and hearing disorders, dementia, affective disorders, hypertension and other cardiovascular disorders). For other disorders e.g. epilepsy and cerebral palsy, prevalence was diminishing in older age groups. No relationship between prevalence and age group was noted for gastric and oesophageal disorders, constipation, Chronic Obstructive Pulmonary Disorders (COPD) and psychiatric disorders other than dementia or affective disorders. Substantial differences were seen for eight of the above mentioned disorders when comparing the prevalence of disorders in people with DS and in people with ID due to other causes. The prevalences of visual and hearing disorders, cerebral palsy, epilepsy, hypertension, dementia, affective disorders and other psychiatric conditions in people with DS and in people with ID resulting from to other causes is shown in Table 2. Salient results are the differences in prevalence of dementia, visual and hearing disorders, and hypertension. 
Table 2 Prevalence of chronic diseases in relation to age in people with Down's syndrome (DS*" $N=243$ ) and people with mental handicap due to other causies (DS-; N -849$)$ in percentages

\begin{tabular}{|c|c|c|c|c|c|c|c|c|}
\hline $\begin{array}{l}\mathrm{DS}+/ \mathrm{DS}- \\
\text { Age (years) }\end{array}$ & $0-19$ & $20-29$ & $30-39$ & $40-49$ & $50-59$ & $>60$ & total & pht \\
\hline \multicolumn{9}{|l|}{ Dementia } \\
\hline $\mathrm{DS}+$ & - & - & - & 22.2 & 45.7 & 72.7 & 16.9 & $*$ \\
\hline DS- & 1.3 & - & 1.1 & - & 1.7 & 15.2 & 2.0 & $*$ \\
\hline \multicolumn{9}{|l|}{ Epilepsy } \\
\hline DS* & 4.9 & - & 2.1 & 16.7 & 21.7 & 36.4 & 10.7 & $*$ \\
\hline DS- & 33.3 & 24.3 & 21.9 & 18.5 & 122 & 7.2 & 17.4 & $* *$ \\
\hline \multicolumn{9}{|c|}{ Visual impaïrment } \\
\hline DS+ & 15.0 & 23.3 & 36.2 & 31.5 & 59.1 & 63.6 & 34.7 & *** \\
\hline DS- & 14.9 & 8.8 & 11.6 & 17.6 & 20.2 & 25.7 & 17.2 & $* *$ \\
\hline \multicolumn{9}{|c|}{ Hearing impairment } \\
\hline DSt & 14.6 & 14.0 & 12.8 & 24.1 & 37.0 & 72.7 & 23.1 & *** \\
\hline DS- & 3.9 & 5.8 & 6.3 & 6.5 & 15.2 & 19.2 & 11.0 & *** \\
\hline \multicolumn{9}{|c|}{ Hypertension } \\
\hline DS + & - & - & - & 1.9 & 4.3 & - & 1.2 & n.s. \\
\hline DS- & - & 1.8 & 1.1 & 7.4 & 9.9 & 12.5 & 6.6 & $* *$ \\
\hline \multicolumn{9}{|c|}{ Affective disordler } \\
\hline DS+ + & - & 4.7 & - & 3.7 & - & - & 1.7 & n.s. \\
\hline DS- & 2.7 & 4.1 & 5.3 & 8.4 & 8.2 & 8.2 & 6.6 & wh \\
\hline \multicolumn{9}{|c|}{ other psychiatric disorders } \\
\hline DS+ & 4.9 & 14.0 & 2.1 & 13.0 & 4.3 & 9.0 & 7.8 & m.s. \\
\hline DS- & 13.2 & 17.0 & 21.9 & 20.6 & 19.4 & 14.8 & 17.9 & n.s. \\
\hline \multicolumn{9}{|c|}{ Cerebral palsy } \\
\hline DS+ + & 2.4 & - & - & 1.9 & - & - & 0.8 & m.s. \\
\hline DS- & 33.3 & 16.4 & 12.8 & 9.3 & 9.1 & 12.5 & 13.8 & * * \\
\hline
\end{tabular}

\section{Logistic regression analysis}

The results of the logistic regression analyses are shown in Table 3. Only the significant results $(p<0.10)$ are shown. The chance of COPD for example, was higher in the youngest age group $(\mathrm{OR}=6.5)$ than in the reference group. The same was found for older people, aged 5059 years, or 60 years and older ( $O R=4.1$ and $O R=9.2$, respectively).

Older people were more likely to suffer from some somatic disorders (e.g. cardiac disorders, gastric disorders, back and neck disorders and urologic disorders) than people aged 30-39 years, when adjusting for the other independent variables in this model. The youngest age group was also more likely to be affected by cardiac disorders, congenital cardiac disorders included $(O R=3.3$ ), and cerebral palsy $(O R=2.0)$ than people in the reference age group. The youngest age group was less likely to be affected by visual impairments $(\mathrm{OR}=0.5)$ or by other psychiatric disorders $(O R=0.5)$. 
Table $3 \quad \mathrm{OR}$ and $90 \% \mathrm{Cl}$. with respect to chronic conditions according to age, level of ID and aetiological diagnosis. Results of backward stepwise logistic regression analysis.

\begin{tabular}{|c|c|c|c|c|c|c|c|c|c|}
\hline \multirow{3}{*}{$\begin{array}{l}\text { disorder / } \\
\text { impaiment }\end{array}$} & \multirow{2}{*}{\multicolumn{4}{|c|}{ Age (years) }} & \multirow{2}{*}{\multicolumn{3}{|c|}{ level of ID }} & \multirow[b]{3}{*}{$\begin{array}{l}\text { profound } \\
\text { vs. } \\
\text { mild }\end{array}$} & \multirow[b]{3}{*}{$\begin{array}{l}\text { DS:- } \\
\text { vs. } \\
\text { DS- }\end{array}$} \\
\hline & & & & & & & & & \\
\hline & $\begin{array}{c}0-19 \\
45 \\
30-39 \\
\end{array}$ & $\begin{array}{c}20-29 \\
\text { vs. } \\
30-39 \\
\end{array}$ & $\begin{array}{c}40-49 \\
\text { vs. } \\
30-39 \\
\end{array}$ & $\begin{array}{c}50-59 \\
\text { vs. } \\
30-39 \\
\end{array}$ & $\begin{array}{c}60+ \\
\text { vs. } \\
30-39 \\
\end{array}$ & $\begin{array}{c}\text { moderate } \\
\text { ws. } \\
\text { mild }\end{array}$ & $\begin{array}{l}\text { severe } \\
\text { vs. } \\
\text { mild }\end{array}$ & & \\
\hline$\overline{C O P D}$ & $\begin{array}{c}6.5 \\
(2.2-18.9)\end{array}$ & & & $\begin{array}{c}4.1 \\
(2.2-18.9)\end{array}$ & $\begin{array}{c}9.2 \\
(3.3-25.5)\end{array}$ & $\begin{array}{c}2.3 \\
(1.11-4.7)\end{array}$ & & $\begin{array}{c}3.0 \\
(1.5-6.2)\end{array}$ & \\
\hline $\begin{array}{l}\text { Cardiac, } \\
\text { including } \\
\text { congenital }\end{array}$ & $\begin{array}{c}3.3 \\
(1.6-6.7)\end{array}$ & & & & $\begin{array}{c}7.1 \\
(3.5-14.2)\end{array}$ & & & & $\begin{array}{c}5.5 \\
(3.8-8.0)\end{array}$ \\
\hline $\begin{array}{l}\text { Cardiac; } \\
\text { excluding } \\
\text { congenital }\end{array}$ & & & & $\begin{array}{c}5.5 \\
(1.6-19.0)\end{array}$ & $\begin{array}{c}14.0 \\
(4.1-48.0)\end{array}$ & & & & $\begin{array}{c}3.9 \\
(1.8-4.9)\end{array}$ \\
\hline $\begin{array}{l}\text { Gastric } \\
\text { disorder }\end{array}$ & & & & & $\begin{array}{c}2.0 \\
(1.1-3.8)\end{array}$ & & & $\begin{array}{c}3.5 \\
(1.9-6.4)\end{array}$ & \\
\hline $\begin{array}{l}\text { Back } \\
\text { disorder }\end{array}$ & & & & $\begin{array}{c}2.4 \\
(1.1-5.1)\end{array}$ & $\begin{array}{c}3.6 \\
(1.7-7.9)\end{array}$ & & & & \\
\hline $\begin{array}{l}\text { Genito } \\
\text { urinary } \\
\text { disorder }\end{array}$ & & & $\begin{array}{c}2.6 \\
(1.1-5.9)\end{array}$ & $\begin{array}{c}3.5 \\
(1.7-7.4)\end{array}$ & $\begin{array}{c}6.0 \\
(2.8-12.8)\end{array}$ & & & & \\
\hline $\begin{array}{l}\text { Visual } \\
\text { impairment }\end{array}$ & $\begin{array}{c}0.5 \\
(0.3-0.9)\end{array}$ & & & $\begin{array}{c}1.8 \\
(1.1-2.7)\end{array}$ & $\begin{array}{c}2.3 \\
(1.4-3.7)\end{array}$ & $\begin{array}{c}2.5 \\
(1.4-4.4)\end{array}$ & $\begin{array}{c}3.0 \\
(1.8-5.2)\end{array}$ & $\begin{array}{c}5.3 \\
(3.1-9.2)\end{array}$ & $\begin{array}{c}2.8 \\
(2.1-3.8)\end{array}$ \\
\hline $\begin{array}{l}\text { Hearing } \\
\text { impairment }\end{array}$ & & & & $\begin{array}{c}3.3 \\
(1.9-6.0)\end{array}$ & $\begin{array}{c}5.2 \\
(2.8-9.5)\end{array}$ & & & & $\begin{array}{c}3.7 \\
(2.7-5.3)\end{array}$ \\
\hline $\begin{array}{l}\text { Cerebral } \\
\text { palsy }\end{array}$ & $\begin{array}{c}2.0 \\
(1.0-3.9)\end{array}$ & & & & & & $\begin{array}{c}2.1 \\
(1.1-4.1)\end{array}$ & $\begin{array}{c}8.3 \\
(4.5-15.5)\end{array}$ & $\begin{array}{c}0.1 \\
(0.0-0.1)\end{array}$ \\
\hline $\begin{array}{l}\text { Autism or } \\
\text { autistoform } \\
\text { disorder }\end{array}$ & & & $\begin{array}{c}0.3 \\
(0.1-0.6)\end{array}$ & $\begin{array}{c}0.2 \\
(0.1-0.5)\end{array}$ & & & $\begin{array}{c}4.2 \\
(1.7-10.8)\end{array}$ & $\begin{array}{c}6.1 \\
(2.4-15.2)\end{array}$ & $\begin{array}{c}0.2 \\
(0.110 .4)\end{array}$ \\
\hline $\begin{array}{l}\text { Affective } \\
\text { disorder }\end{array}$ & & & & & & & & & $\begin{array}{c}0.3 \\
(0.1-0.6)\end{array}$ \\
\hline $\begin{array}{l}\text { other } \\
\text { psychiatric } \\
\text { disorder }\end{array}$ & $\begin{array}{c}0.5 \\
(0.3-1.0)\end{array}$ & & & & & $\begin{array}{c}0.6 \\
(0.4-0.9)\end{array}$ & & & $\begin{array}{c}0.4 \\
(0.2-0.6)\end{array}$ \\
\hline
\end{tabular}

People with severe or profound ID were more likely to be affected by visual impaiments $(\mathrm{OR}=3.0$ and $\mathrm{OR}=5.3$ ), cerebral palsy $(\mathrm{OR}=2.1$ and $\mathrm{OR}=8.3$ ) and autistiform disorders $(\mathrm{OR}=4.2$ and $\mathrm{OR}=6.1)$ than people with mild ID. People with mild ID were more likely to be affected by psychiatric disorders, other than autistiform disorders or affective disorders (OR = $1.7(1: 0.6)$ than people with moderate ID. 
People with DS were more likely to have cardiac disorders ( $O R=5.5$ including congenital disorders and $O R=3.9$ excluding congenital disorders) and visual $(O R=2.8)$ and hearing $(O R=3.7)$ impairments than people with ID resulting from other causes. People with DS were less likely to have affective $(O R=0.3)$ or other psychiatric disorders $(O R=0.4)$.

Epilepsy was found to be less frequent in the older age groups than in the younger age groups. When adjusting for level of $I D$, dementia and aetiological diagnosis for people in the older age groups is $\mathrm{OR}<1$ (Table 4). Thus, older people were less likely to have this disorder. Also, the chance for people with DS to having epilepsy was less than for people with other causes of ID $(\mathrm{OR}=0.2$ after adjusting for level of $\mathrm{ID}$, age and dementia). The level of $\mathrm{ID}$ also was a significant factor ( $O R=2.4$ for severe versus mild ID). People with dementia were more likely to have epilepsy than people without this diagnosis $(\mathrm{OR}=8.8)$.

Table 4 OR and $90 \%$ confidence interval with respect to epilepsy according to age, level of ID, presence/absence of dementia and aetiological diagnosis.

Results of backward stepwise logistic regression analysis.

\begin{tabular}{llcc}
\hline & & OR & $90 \%$ C.I. \\
\hline Age (years) & $\begin{array}{l}50-59 \text { vs. 30-39 } \\
>60 \text { vs. 30-39 }\end{array}$ & 0.6 & $0.4-1.0$ \\
Level of mental handicap & $\begin{array}{l}\text { moderate/severe/profound } \\
\text { vs. mild/borderline }\end{array}$ & $0.2-0.5$ \\
Dementiat & present vs. absent & 2.4 & $1.7-3.3$ \\
Down's syndrome & DS+ vs. DS- & 8.8 & $4.8-16.2$ \\
\hline
\end{tabular}

\section{Incidence rates}

For 11 disorders, a sufficient number of new cases were reported to calculate incidence percentages. Criterion was a difference in percentages of more than $1 \%$ between at least two age groups. The 3 years incidence rates of these disorders are shown in Table 5. Increasing incidences were found in successive age groups from childhood on for visual and hearing impairment, as well as for gastric and oesophageal disorders. Although not age-related, the incidence of affective disorders was substantial in all age groups. The incidence of dementia continued to rise in the age groups of 40 years and older. The incidence rate was very low in the younger age groups and thus, the results on the 0-39-year-old age group were accumulated. Hypertension, other cardiovascular disorders, COPD, osteoarthritis, chronic urinary tract infections and diabetes showed substantial incidence rates above the age of 50 years. Here the results on the $0-49$ year-old age group were accumulated. 
Table 5 Three years incidence of health problems in relation to age in people with $I D(\%)$

\begin{tabular}{|c|c|c|c|c|c|c|c|c|}
\hline Age (years) & $0-19$ & $20-29$ & $30-39$ & $40-49$ & $50-59$ & $60 \div$ & total & pts \\
\hline$N=$ & 92 & 173 & 116 & 122 & 235 & 155 & 893 & \\
\hline Visual impaument & 8.5 & 3.7 & 6.8 & 7.3 & 15.3 & 118 & 9.5 & ** \\
\hline Hearing impaimment & 5.5 & 3.5 & 5.4 & 6.7 & 12.2 & 11.1 & 7.9 & *** \\
\hline Gastrointestinal disorders & 2.6 & 4.7 & 3.7 & 9.0 & 7.4 & 9.2 & 6.5 & 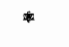 \\
\hline Affective disorder & 1.1 & 2.9 & 3.4 & 4.9 & 3.0 & 3.9 & 3.2 & n.s. \\
\hline Epilepsy & 8.6 & 0.7 & 2.0 & 1.9 & 1.8 & 2.0 & 2.3 & n.s. \\
\hline Dementia & & & $0.5^{\prime}$ & 5.6 & 2.9 & 5.7 & 2.7 & $* *$ \\
\hline Hypertenstion & & & & 0.8 & 3.0 & 2.9 & 1.7 & * \\
\hline Cardiovascullair disorders (other) & & & & 0.6 & 4.2 & 9.2 & 2.9 & $* *$ \\
\hline COPD & & & & $1.4^{2}$ & 3.6 & 5.6 & 2.7 & ** \\
\hline Ostheoarthitis & & & & $1.0^{2}$ & 5.0 & 4.5 & 2.6 & ** \\
\hline Cronic urinary tract infections & & & & $0.8^{2}$ & 2.8 & 4.4 & 1.9 & $* * *$ \\
\hline Diabetes & & & & $0.6^{2}$ & 1.6 & 3.8 & 1.4 & ** \\
\hline
\end{tabular}

Iage groups $0-39$ years are accumulated

agegroups $0-49$ years are accumulated

For some conditions (i.e.visual and hearing disorders, dementia and epilepsy), the incidences in people with DS were rather different than the incidences in people with $I D$ due to other causes. This is shown in Table 6 . The results in the data on epilepsy were most striking: whereas the incidence was diminishing in every older age group in people without DS, the incidence of epilepsy in people with DS was increasing.

Table 6 Three years incidence of som ehealth problems in people with Down's syndrome $(\mathrm{DS}+)(\mathrm{N}=214)$ and in people with ID due to other causes (DS-) $(\mathrm{N}=827)$ in relation to age $(\%)$

\begin{tabular}{lrrrrrrrr}
\hline Age (years) & $0-19$ & $20-29$ & $30-39$ & $40-49$ & $50-59$ & $>60$ & total & p\# \\
\hline Visual impairment & 9.1 & 11.8 & 22.9 & 23.1 & 42.9 & 0.0 & 20.4 & $* *$ \\
DS+ & 7.7 & 2.6 & 3.5 & 8.5 & 13.5 & 11.8 & 8.5 & $* *$ \\
DS* & 11.4 & 14.0 & 4.9 & 18.2 & 34.4 & 50.0 & 16.6 & $* *$ \\
Hearing impairment & 2.7 & 1.9 & 5.7 & 3.9 & 10.0 & 10.6 & 6.5 & $* *$ \\
DS+ & & & & & & & & \\
DS- & & & 1.5 & 4.3 & 15.4 & 44.4 & 6.3 & $* *$ \\
Epilepsy & & & 3.2 & 1.1 & 1.0 & 1.4 & 1.9 & $*$ \\
DS+ & & & & & & & & \\
DS* & & & 0.0 & 24.0 & 27.6 & 80.0 & 11.2 & $* *$ \\
Dementia & & & 0.6 & 0.0 & 1.5 & 5.1 & 1.6 & $* *$ \\
DS+ & & &
\end{tabular}

H $\mathrm{p}=$ test for linear trend $*=\mathrm{p}<0.05 \quad * *=\mathrm{p}<0.01 \quad$ n.s. $=$ not significant

age groups $0-39$ year are accunulated 


\section{DISCUSSION}

Older age clearly is not the only risk factor for contracting disease in people with ID. People with more serious levels of ID and people with DS are at a higher risk for some chronic conditions than those with a more mild level of ID and those with $\mathrm{ID}$ resulting from causes other than DS.

When looking at prevalence, significance of morbidity, possibility of early detection and treatability (Patterson \& Chambers 1995), some disorders have priority above others. According to these criteria, the following disorders should be considered when developing a screening instrument: visual and hearing problems, gastrointestinal disorders, dementia, depression and age-related disorders in general.

The results regarding incidence rates might be biased by the leaming effect of general practitioners completing the same questionnaires. Furthermore, since the incidence data are based on registered data and not on actual retesting, it is possible that even these high numbers might be an underestimation of the actual problem.

The reported incidence and prevalence rates of both visual and hearing disorders underline the need for an adequate screening policy and appropriate treatment. Attention should be focused on people with ID aged 50 years and over, and on people with DS in all age groups. Standarm dized screening procedures like the whisper test or pure tone audiometry for hearing capacities, or a Snellen type sight card are only applicable for people with mild or moderate ID.

There is an urgent need for appropriate screening methods for people with severe or profound ID, both for visual and hearing capacities (van Schrojenstein Lantman-de Valk et al. 1994; Evenhuis 1995a, 1995b). Estimating visual (Warburg 1994) or hearing capacities (Evenhuis 1990) by direct care staff is often inaccurate.

The relatively high incidence of gastrointestinal disorders, especially in the older age groups, should be of concern for at least two reasons. First, sudden deaths caused by gastrointestinal problems in people with cerebral palsy and/or epilepsy may occur (Cole et al. 1994). Further research on this issue is advised. Furthermore, some gastrointestinal disorders may have a serious impact on well-being and are difficult to diagnose in people with communication problems. For example, gastro-oesophageal reflux (i.e the return of gastric acid to the oesophagus) may cause ulceration. This condition is probably seen more often in persons, who are bedridden or persons with severe scoliosis. A study on the prevalence and incidence of gastro-oesophageal reflux and its therapy has recently begun in the Netherlands (Niezen-de Boer, 1992).

Incidence and prevalence of dementia have been reported in high percentages in people with DS aged 40 years and older, and in people with other aetiologies of ID from the age of 50 years on. In contrast, the results with regard to incidence of affective disorders in this study were low, varying between $1 \%$ in the youngest age group and up to $5 \%$ in the 40 -49-year-old age group. One may wonder if all people were diagnosed adequately. The symptoms of depression resemble those of a beginning dementia, especially in people with poor verbal capacities. Burt et al. (1992) reported on depression in people with DS, and this disorder may mimic or mask the signs of dementia. Diagnosing depression in people with poor verbal 
capacities is difficult, although not impossible (Tuinier \& Verhoeven 1992). Aylward et al. (1995) recently described a procedure for diagnosing dementia in people with ID.

Some of the age-related disorders in this study showed incidence and prevalence patterns that resemble those in the general population (Ruwaard \& Kramers 1993). From the age of 50 , COPD, cardiovascular disorders, osteoarthritis, chronic urinary tract infections and diabetes all show substantial incidences.

An exception is the low prevalence of hypertension reported in this study in people with DS. Several authors (Murdoch er al. 1977, Dömer et al. 1984, Ylä-Herttualläa et al. 1989) studied cholesterol and triglyceride metabolism in people with DS. None of these studies appeared conclusive. Does this mean that hypertension is less frequent in people with DS or that normal values of blood pressure in people with DS are lower than in people with aetiologies other than DS? This might be an issue for further research.

Ageing people with ID should be screened for the disorders mentioned above. Conditions such as hypertension, diabetes and chronic urinary tract infections may proceed symptom-free for a long period in people who have difficulty in verbalizing their health problems. Timely and adequate treatment may prevent secondary conditions. Whether a periodic health examination should consist of merely taking blood pressure, doing urinanalysis for cystitis and screening for diabetes (combined with the advised screening on hearing and visual capacities) or if a more extensive assessment is necessary and by whom this should be carried out, should be the subject of further study. This same problem was recently studied in another group of patients that need particular medical attention. Kendrick et al. (1995) assessed the impact of teaching general practitioners to carry out structured assessments of their long term mentally ill patients. These authors concluded that these assessments did not seem feasible in routine surgery appointments. Their conclusion might be applicable for people with ID. However some form of anticipation on probable health problems is necessary especially for those people with ID who experience communication problems in their contact with physicians.

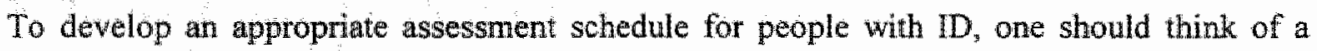
model in which at least part of the assessment can be carried out by especially trained community-nurses. The results of an implementation study might show us which assessment model would be the most effective, the least burdening and the most customer-friendly. 


\section{REFERENCES}

Aylward E.H., Burt D.B., Thorpe L.U., Lai F.L. \& Dalton A.J. (1995) Diagnosis of dememtic in individuals with intellectual disability. American Association on Mental Retardation, Washington.

Berkum H.W. van \& Haveman M.J. (1995) Zorg aan huis. Behoefle aan zorg, gebruik van zorg en discrepantie tussen vraag en aanbod onder ouders van verstandelijk gehandicapten in Zuid-Nederland. Department of Epidemiology, University of Limburg, Maastricht.

Badry D.E., Groeneweg G., Vrbanic M., McDonald L. \& Hurnick J. (1989) Service needs of community and institution-based older persons with a developmental handicap in Alberta, Canada. A wstralia and New Zealand Journal of Developmenal Disabilities 15, 257-66.

Burd D.B., Loveland K.A., \& Lewis K.R. (1992) Depression and the onset of dementia in adults with mental retardation. American Journat on Mental Retardation 96, 502-11.

Cole G., Neal W., Fraser W.1., \& Cowie V.A. (1994) Autopsy. findings in patients with mental handicap. Jowrnat of Intellectual Disability Research 38, 9-26.

Day K.A. (1987) The elderly mentally handicapped in hospital: a clinical study. Journol of Menial Deficiency Research 31, 131-46.

Day K.A. \& Jancar J. (1994) Mental and physical health and ageing in mental handicap: a review. Journal of Intellectwal Disability Research 38, 241-56.

Dixon W.J., Brown M.B., Engelman L. \& Jennrich R.I. (1990) BMDP statistical sofhware manual. Folume II. University of Callifornia Press. Berkeley/Los Angeles/Oxford.

Dorner K, Gaethke A.S., Tolksdorf M., Schumann K.P. \& Gustmann H. (1984) Cholesterol fractions and triglycerides in children and adults with Down's syndrome. Clinica Chimica Acta 142, 307-11.

Evenhuis H. M. Clinical studies of Alsheimer's dementia and hearing loss in Down's syndrome. PhD thesis, University of Amsterdam, 1990.

Evenhuis H.M. (1995a) Medical aspects of ageing in a population with intellectual disability: 1. Visual impairment. Journal of Intellectual Disability Research 39, 19-25.

Evenhuis H.M (1995b) Medical aspects of ageing in a population with intellectual disability: II. Hearing impairment. Journal of Intellectual Disability Research 39, 27-33.

Haveman M.J. \& Maaskant. M.A.(1989) Defining fragility of the elderly severely mentally handicapped according to mortality risk, morbidity, motor handicaps and social functioning. Journal of Mental Deficiency Research 33, 389-97.

Haweman M.J., Maaskant M.A. \& Sturnars F. (1989) Older Dutch residents with and without Down syndrome: Comparisons of mortality and morbibity trends and motor/social functioning. Austratia and New Zealand Journal of Development Disabilities 15, 241-55.

Hogg J., Moss S. \& Cooke D. (1988) Ageing and mental handicap. Croom Helm. London.

Janicki M.P. \& Jacobson J.W. (1986) Generational trends in sensory, physical and behavioral abilities among oider mentally retarded persons. American Journal of Mental Deficiency $5,490-500$.

Kendrick T., Burns T. \& Freeling P. (1995) Randomised controlled trial of teaching general practitioners to carry out structured assessments of their long term mentally ill patients. British Medical Joumal 311, 93-8.

Lai F. \& Williams R.S. (1989) A prospective study of Alzheimer disease in Down syndrome. Archives of Newrology 46, 849-53.

Maaskant M.A. \& Haveman M.J. (1988) Lang leven in de zwakzinigigenzorg; een onderzoek naar de consequenties van de veroudering wan bewoners wan algemene zwakzinnigenimichingen en gezinswervangende vehwizen. RU Limburg. Maastricht. 
Maaskant M.A., Haveman M.J., Schrojenstein Lantman-de Valk H.M.J. van, Urlings H.F.J., Akker M. van den \& Kessels A.G.H. (1995) Veroudering bif mensen met een verstandelijke handicap. Department of Epidemiology, University of Limburg, Maastrichit - Peptijn Centre, Echt.

McVicker R.W., Shanks O.E.P. \& McLelland R.J. (1994) Prewalence and associated features of epilepsy in adults with Down's syndrome. British Journal of Psychiony 164, 528-32.

Moss S., Goldberg D., Patel P. \& Wilkin D. (1994) Physical morbidity in older people with moderate, severe and profound mental handicap and its relation to psychiatric morbidity. Social Psychiatry and Psychiatric Epidiemiology 28, 32-9.

Murdoch J.C., Rodger J.C., Rao S.S., Fletcher C.D. \& Dunnigan M.G. (1977) Down's syndrome: an atheromafree model? British Medical Journal 2, 226-8.

Niezen-de Boer M.C. (1992) Acute and long term treatment of gastro-oesophageal reflux disease in the severely mentally handicapped. In: J. Roosendaal (ed) Mental Retardation and Medical Care. Proceedings of the first european congress on mental retardation and medical care, Kerckebosch, Zeist, 339-44.

Patterson C. \& Chambers L.W. (1995) Preventive health care. Lancet 345, 1611-5.

Ruwaard D. \& Kramers P.G.N. (1993). Volksgezondheid Toekomst Verkenning. De gezondheidstoestand van de Nederlandse bevolking in de periode 1950-2010. RIVM, Sdu., "s-Gravenhage.

Schrojenstein Lantman-de Valk H.M.J. van, Haveman M.J., Maaskant M.A., Kessels A.G.H., Urlings H.F.J. \& Sturmans F. (1994) The need for assessment of sensory functioning in ageing people with mental handicap. Journal of Intellectwal Disability Research 38, $289-98$.

Stafstrom C.E. (1993) Epilepsy in Down Syndrome: Clinical aspects and possible mechanisms. American Jownal on Mental Revardation 98 (Suppl.), 12-26.

Tuinier S. \& Verhoeven W.M.A. (1992) Psychopathology in mental retardation: a multidisciplinary approach. Integrative Psychiatry 8, 252-63.

Warburg M. (1994) Visual impairment among people with developmental delay. Journal of Intellectwal Disability Research 38, 423-32.

Welsh Health Planning Forum (1992) Protocol for Imestment in Health Gain. Mental handicap (Learning disabilities) University of Wales, Cardiff.

Ylä- Hertualâa S., Luoma J., Nikkari T., \& Kivimaki "T. (1989) Down's syndrome and atherosclerosis. Atherosclerosis $76,269-72$. 


\section{THE NEED FOR ASSESSMENT OF SENSORY FUNCTIONING IN AGEING PERSONS WITH MENTAL HANDICAP}

\section{Summary}

Within the framework of a study on the ageing process of people with mental handicap in the Netherlands, information about visual and hearing impairments in 1583 people with mental handicap living in group homes or institutions was obtained from their physicians by means of a written questionnaire.

Of the people with Down's syndrome (DS) who were older than 50 years of age, $46 \%$ had a visual impairment, whereas approximately $13 \%$ of subjects with other causes of mental handicap at the same age experienced similar visual impairment. Hearing loss in this age group was reported in $28 \%$ of people with DS, but only in $8 \%$ of subjects with other causes of mental handicap. The most common eye condition was cataracts, and the most frequent cause of hearing impairment was infection.

In persons with severe and profound mental handicap of all ages, sensory impairments were more frequent than in persons with mild or moderate mental handicap. Glasses or hearing aids were rarely used by people with severe or profound mental handicap.

Assessment of visual and hearing impairments in people with mental handicap seemed clearly indicated, especially in those aged 50 years and older, in those with DS and in those with severe or profound mental handicap.

Published as: Schrojenstein Lantman-de Valk, H.M.J van, Haveman H.J., Maaskant M.A., Kessels A. G.H., Urlings H.F.J. \& Sturmans F. (1994) The need for assessment of sensory functioning in ageing people with mental handicap Joumal of Intellectual Disability Research 38, 289-98. 


\section{INTRODUCTION}

Sensory impairments increase with age. Persons with mental handicap rarely complain sufficiently about visual or auditory problems. Special approaches are needed to establish the prevalence of sensory impairments in elderly persons with mental handicap to allow for a diagnosis, and, whenever feasible, an intervention. The age-related prevalence of hearing and vision disorders in persons with mental handicap has been reported by several authors (Janicki \& Jacobson 1986, Day 1987, Hogg et al. 1988, Maaskant \& Haveman 1988). All these crosssectional studies showed higher prevalence rates of visual and hearing impairment in the older age groups.

Detailed information about the prevalence and nature of visual or hearing impairment was provided by other authors, without indicating the age relationship. Warburg \& Rattleff (1991) found $10 \%$ of the people to be visually impaired when screening 778 adults with mental handicap in sheltered workshops.

Jacobson (1987) found ophthalmologic problems in $25 \%$ of 228 people with mental handicap living in institutions and mentioned a higher frequency in age-related eye problems in persons with Down's syndrome (DS). Hestnes et al. (1991) found only one person with DS without ophthalmologic problems when examining the eyes of 30 people with DS and 30 without DS. Cooke (1989) reported hearing loss in $31.5 \%$ of 398 people with mental handicap who lived in institutions. In an extensive hearing examination Nolan et al. (1980) found that $52 \%$ out of 67 subjects had auditory problems. In a similar way, Evenhuis (1990) found that 20 out of 35 people with DS were severely handicapped in hearing.

The work presented here is part of a larger prospective cohort study on ageing and mental handicap currently carried out in the Netherlands. The aim of this part of the study was to get insight into the reported frequency of visual and auditory impairment in relation to age, to identify the causes of these impairments, and to learn about the differences between people with DS and those with other causes of mental handicap.

Other questions considered were whether or not these impairments were related to the level of mental handicap, and how many people were reported to benefit from spectacles or hearing aids.

\section{MATERIALS AND METHODS}

\section{Study Design}

In 1990, a 5-year prospective cohort study on mental handicap and ageing was started (Maaskant et al. 1992; Haveman et al. 1992). The key question of the study was: "What are the implications of the ageing population in institutions and group homes for people with mental handicap in terms of the need and provision of adequate care?"

In this study, 1583 persons with a mental handicap, living in two southern provinces of the Netherlands, were included by means of a stratified random sampling procedure. Subjects were selected from five age groups: 0-19 years, $20-29$ years, 30-49 years, $50-59$ years, and 60 years and older. Per age group, people persons living in institutions and those living in group 
homes are equally represented. Persons with DS are likely to have characteristic ageing problems (Maaskant \& Haveman 1988). Thus, in each age group, 30\% of the group had DS.

Data were collected by means of two questionnaires. The medical questionnaire, completed by the subject's physician', contained questions about aetiology of mental handicap, chronic diseases, sensory functioning, medication and referrals to medical specialists, general hospitals, and nursing homes. The gerontological list, completed by the direct staff contained questions about level of mental handicap, ADL, challenging behaviour, dependence on care, internal and external social integration, day programmes and allocation of staff. As no assessment facilities were available, persons were not assessed personally by the authors.

The level of mental handicap was assessed by means of each persons score on the Scale for Social Functioning (S.R.Z.). These data were included in the gerontological list. Krayer and Kema (1985) tested the reliability and validity of this scale. They also developed a method to classify the results into the internationally accepted categories of profound, severe, moderate, mild and borderline.

The response rate for the questionnaires was $96 \%$ for group homes and $92 \%$ for institutions. The data of 307 persons with DS and of 1276 persons with other causes of mental handicap were obtained. In $3.5 \%$ of cases, gerontological data were missing, in $9.6 \%$ medical data were incomplete. Therefore data of 1309 (visual function) and 1312 people (hearing function) were available to establish relationships. This paper deals with results from the baseline data collection.

\section{Data on visual and hearing capabilities}

Visual and auditory functioning were assessed in the questionnaire completed by the physician.

Visual capabilities were assessed by questioning whether visual capability was considered to be normal with or without glasses, or whether the visual disability was considered to be moderate or severe and if it was considered to be stable or progressive. The instruction in the questionnaire was to give an opinion based on clinical observation and data from the patient's files. Moderate was defined as "functioning with apparent visual problems". Severe was defined as 'functioning as a visual impaired person'. If the vision was impaired, questions followed about possible categories of causes such as cataracts, keratoconus, high myopia, hypermetropia, nystagmus, squinting, retinal diseases, cerebral blindness, or others. Hearing was assessed by asking whether hearing was estimated to be good, with or without hearing aid or whether the auditory disability was considered to be moderate, severe or indeterminable. Similar to the instructions regarding the above questions, moderate was defined as 'having apparent auditory problems' and severe as 'functioning as a deaf person'. Possible categories of causes of anomalies were congenital anomalies, frequent otitis, presbyacusis, or others.

\footnotetext{
'In The Nederlands, medical care for persons with mental handicap is provided by registered gemeral practitioners. A majority of these physiciars completed a postgraduate course on mental handicap.
} 


\section{RESULTS}

\section{Visual capabilities}

The prevalence of visual impairment was higher in the older age groups, especially in persons with DS (Table 1). In people with DS, $46 \%$ of the persons aged $50-59$ years had visual impaiment. In persons with other causes of mental handicap in the same age group, this was 1,3\%. At 60 years of age and onward, $85 \%$ of persons with the DS and $20 \%$ of the other subjects had visual impairment. Among both people with DS and those whose mental handicap was due to other causes, the association between age and visual impairment was statistically significant (Kendalls" tau; $\mathrm{p}<0.01$ ).

Table 1 Visual capabilities in people with Down's syndrome $(\mathrm{DS}+)(\mathrm{N}=307)$ and people with ID due to other aetiologies (DS-) $(N=1117)$ in relation to age

\begin{tabular}{|c|c|c|c|c|c|c|c|c|}
\hline \multicolumn{9}{|c|}{ Visual capabilities (\%) } \\
\hline & age (yr) & normal & $\begin{array}{l}\text { normal with } \\
\text { glasses }\end{array}$ & moderate & blind & degenerative & $\%$ & abs. N \\
\hline \multirow[t]{6}{*}{$\overline{\mathrm{DS}+}$} & $0-19$ & 55.6 & 33.3 & 11.1 & - & - & 100 & 45 \\
\hline & $20-39$ & 43.1 & 32.1 & 20.2 & 1.8 & 2.8 & 100 & 109 \\
\hline & 4049 & 44.4 & 28.6 & 23.8 & 1.6 & 1.6 & 100 & 63 \\
\hline & $50-59$ & 36.5 & 17.5 & 38.1 & 6.3 & 1.6 & 100 & 63 \\
\hline & $60+$ & 11.1 & 3.7 & 51.9 & 22.2 & 11.1 & 100 & 27 \\
\hline & Total & 41.0 & 26.1 & 26.1 & 4.2 & 2.6 & 100 & 307 \\
\hline \multirow[t]{6}{*}{ DS- } & $0-19$ & 76.0 & 8.3 & 5.2 & 8.3 & 2.1 & 100 & 96 \\
\hline & $20-39$ & 64.3 & 27.1 & 4.5 & 3.9 & 0.3 & 100 & 336 \\
\hline & $40-49$ & 50.0 & 37.7 & 9.2 & 2.3 & 0.8 & 100 & 130 \\
\hline & $50-59$ & 49.8 & 37.0 & 10.8 & 1.3 & 1.0 & 100 & 305 \\
\hline & $60+$ & 40.0 & 40.8 & 14.0 & 3.6 & 1.6 & 100 & 250 \\
\hline & Total & 54.3 & 32.5 & 9.00 & 3.3 & 1.0 & 100 & 1117 \\
\hline
\end{tabular}

DS+: Kendall's tau* $=0.256 ;$ s.e $=0.47 ; P<0.01$

DS-: Kendall"s tau ${ }^{*}=0.117$; s.e. $=0.026: P<0.01$

*Test for the association between age and visual capabilities. 
Table 2 Causes of visual impaiment $(\%)$ in residents with Down's syndrome (DS-; $N=307$ ) and residents with ID due to other aetiologies (DS-; $N=1110)$

\begin{tabular}{lccc}
\hline Cause & DS + & DS- & two-tailed P-value* \\
\hline Cataracts & 14.3 & 3.9 & $<0.01$ \\
Severe refractive error & 11.7 & 2.8 & $<0.01$ \\
Keratoconus & 6.5 & 0.1 & $<0.01$ \\
Strabismus & 3.9 & 0.5 & $<0.01$ \\
Nystagmus & 1.0 & 0.3 & 0.12 \\
Cerebral blindness & 0.7 & 1.9 & 0.20 \\
Retinal diseases & 0.7 & 1.4 & 0.55 \\
Postoperative conditions & 0.3 & 0.6 & 1.00 \\
Miscellaneous & 3.9 & 1.4 & 0.02 \\
\hline
\end{tabular}

* Cause of visual impairment \#Test for the difference in proportions, tested with Fisher"s exact test.

Cataracts and severe refractive errors (high myopia and hypermetropia, insufficiently correctable by means of glasses) were reported as the most frequent causes of visual impairment (Table 2). In people with DS, $14 \%$ were reported as having cataracts and $12 \%$ were reported as having severe refractive errors, whereas in the persons with other aetiologies the figures were $4 \%$ and $3 \%$ respectively. Keratoconus had a frequency of $6.5 \%$ in patients with DS. Strabismus was reported in $3.9 \%$ of people with DS. Two tailed p-values showed significant differences between people with DS and subjects with other aetiologies for the above conditions. All other eye conditions were reported in small numbers for both groups. There was a remarkably high prevalence of cataracts in elderly people with DS: $16 \%$ (10 out of 63 cases) in the group aged 50-59, and 63\% (17 out of 27 cases) in those aged 60 and older (Table 3). The differences in proportions were statistically significant.

Table 3 Age-related prevalence of cataracts (\%) in relation to age in people with Down's syndrome (DS+; $\mathrm{N}=307$ ) and in people with ID due to other aetiologies (DS-; $\mathrm{N}=1110$ )

\begin{tabular}{lccc}
\hline $\begin{array}{l}\text { Cataracts } \\
\text { age (years) }\end{array}$ & DS & DS & two-tailed P-value \\
\hline $0-19$ & - & - & 1.00 \\
$20-39$ & 8.3 & 2.7 & 0.02 \\
$40-49$ & 12.7 & 2.3 & $<0.01$ \\
$50-59$ & 15.9 & 2.3 & $<0.01$ \\
$60-4$ & 63.0 & 9.6 & $<0.01$ \\
& & & \\
Total & 14.3 & 3.9 & \\
\hline
\end{tabular}

Test tor the difference in proportions, tested with F isher"s exact test.

Severe visual impairment was much more frequent in people with profound mental handicap $(25 \%)$ than in people with mild or borderline mental handicap (less than $1 \%$; (Table 4). Kendall's tau showed no significant association between cognitive level and visual functioning. The possibility of obtaining normal vision by means of spectacles appeared to be strongly related to the level of mental impairment: among the people with profound handicap 
only $3 \%$ (three out of 96 cases) obtained normal vision with spectacles. This percentage was higher in the persons with mild mental handicap ( $45 \%$ ).

Table 4 Visual functioning in relation to the level of ID in 1309 people with ID

\begin{tabular}{|c|c|c|c|c|c|c|c|}
\hline \multicolumn{8}{|c|}{ Visual function ( $\%)$} \\
\hline Level of ID & normal & $\begin{array}{c}\text { normal with } \\
\text { glasses }\end{array}$ & moderate & blind & degenerative & total & abs. $N$ \\
\hline Profound & 61.5 & 3.1 & 7.3 & 25.0 & 3.1 & 100 & 96 \\
\hline Severe & 62.0 & 12.8 & 15.7 & 5.5 & 4.0 & 100 & 274 \\
\hline Moderate & 49.7 & 32.1 & 17.0 & 0.3 & 0.8 & 100 & 358 \\
\hline Milld & 43.3 & 44.5 & 11.0 & 0.6 & 0.6 & 100 & 353 \\
\hline Borderline & 50.0 & 44.3 & 5.3 & 0.4 & - & 100 & 228 \\
\hline Total & 51.5 & 31.4 & 12.4 & 3.3 & 1.5 & 100 & 1309 \\
\hline
\end{tabular}

Test for the association between level of $1 \mathrm{D}$ and visual functioning

Kendall's tau $=0.01$; s.e. $=0.025 ; \mathrm{P}=$ n.s.

\section{Auditory impairment}

A higher percentage of auditory impairment was found in residents with DS than in other adults (Table 5).

Table 5 Auditory capabilities and severity in people with Down"s syndrome (DS+) (N=307) and in people with ID from other aetiologies (DS-) $(\mathrm{N}=1121)$ in relation to age.

\begin{tabular}{|c|c|c|c|c|c|c|c|c|}
\hline \multicolumn{9}{|c|}{ Auditory capabilities (\%) } \\
\hline & age $(y r)$ & normal & $\begin{array}{l}\text { normal with } \\
\quad \text { aid }\end{array}$ & moderate & deaf & not testable & total\% & abs. $N$ \\
\hline \multirow[t]{6}{*}{ DS+ } & $0-19$ & 84.4 & 6.7 & 8.9 & - & - & 100 & 45 \\
\hline & $20-39$ & 90.8 & 1.8 & 4.6 & 0.9 & 1.8 & 100 & 109 \\
\hline & $40-49$ & 79.4 & 3.2 & 11.1 & 4.8 & 1.6 & 100 & 63 \\
\hline & $50-59$ & 66.7 & 4.8 & 14.3 & 9.5 & 4.8 & 100 & 63 \\
\hline & $60+$ & 51.9 & 3.7 & 22.2 & 22.2 & - & 100 & 27 \\
\hline & Total & 79.2 & 3.6 & 10.1 & 5.2 & 2.0 & 100 & 307 \\
\hline \multirow[t]{6}{*}{ DS- } & $0-19$ & 93.8 & - & $=$ & - & 6.3 & 100 & 96 \\
\hline & $20-39$ & 91.4 & 1.8 & 3.0 & 3.0 & 0.9 & 100 & 338 \\
\hline & $40-49$ & 92.3 & 1.5 & 3.1 & 23 & 0.8 & 100 & 130 \\
\hline & $50-59$ & 49.8 & 37.0 & 10.8 & 1.3 & 1.0 & 100 & 306 \\
\hline & $60+$ & 79.3 & 4.8 & 11.2 & 3.2 & 1.6 & 100 & 251 \\
\hline & Total & 88.5 & 2.5 & 5.1 & 2.4 & 1.5 & 100 & 1121 \\
\hline
\end{tabular}

DS+: Kendall's tau $=0.237 ;$ s.e. $\approx 0.49 ; P<0.01$

DS-: Kendall's tau $=0.116 ;$ s.e. $=0.027: P<0.01$ 
In people with DS, there was a higher prevalence of hearing impaiment in the older age groups. Over the age of 60 years, $45 \%$ had impaired hearing whereas this was only $16 \%$ in subjects with other aetiological diagnoses. Both in people with DS and those with other aetiologies, the association between the age and auditory impaiment was statistically significant.

The most notable causes of impaired hearing in people with DS were infections (36\%) and presbyacusis (37\%). In persons with other causes of mental handicap, these figures were $21 \%$ and $34 \%$ respectivelly.

Deafness was reported more frequently in persons with profound mental handicap $(8 \%)$; in persons with moderate or mild mental handicap the frequency was only $2-3 \%$. Among people whose hearing capabilities could not be determined, $12 \%$ were people with a profound mental handicap and 1-2\% were people who were less impaired (Table 6). The association between cognitive level and auditory impaiment was statistically significant.

Table 6 Auditory impairment in rellation to the level of ID in 1321 people with ID

\begin{tabular}{lccccccc}
\hline $\begin{array}{l}\text { Auditory impaiment (\%) } \\
\text { level of ID }\end{array}$ & normal & $\begin{array}{c}\text { normal with } \\
\text { aid }\end{array}$ & moderate & deaf & not testable & total\% & abs.N \\
\hline Profound & 79.2 & - & 1.0 & 8.3 & 11.5 & 100 & 96 \\
Severe & 83.2 & 1.8 & 8.8 & 4.0 & 2.2 & 100 & 274 \\
Modlerate & 85.8 & 3.3 & 8.6 & 1.7 & 0.6 & 100 & 359 \\
Mild & 90.1 & 3.1 & 4.0 & 2.0 & 0.8 & 100 & 353 \\
Borderline & 89.6 & 3.5 & 4.3 & 2.6 & - & 100 & 230 \\
& & & & & & & 100 \\
Total & 86.6 & 2.7 & 6.1 & 2.9 & 1.7 & 1312 \\
\hline
\end{tabular}

Kendall"s tau $=0.092 ;$ s.e. $=0.025 ; \mathrm{P}<0.01$

At all levels of mental handicap, the small number of persons who regained normal hearing with the help of a hearing aid was striking. Of the people with a profound level of mental handicap ( 96 cases), no one obtained normal hearing with the help of a hearing aid. In the people with severe mental handicap, $2 \%$ (five out of 274 cases) used a hearing aid (Table 6) and heard well. In people with moderate, mild and borderline handicap, 3-4\% heard well with a hearing aid.

\section{DISCUSSION}

This study drew data from a questionnaire completed by physicians, from patient's filles, and from a questionnaire completed by the subject's direct care staff.

The results showed that $13 \%$ of the people aged $50-59$ years had visual impairments and $20 \%$ of the people who were at least 60 years of age showed visual impairments. Auditory impairments were reported in $8 \%$ of the people aged $50-59$ years and in $16 \%$ of the people who were 60 years of age or older. 
The prevalence of both visual and auditory impairments appeared to be three to four times higher in elderly people with DS.

It was regrettable that comparing data from this study to the results from other age-related studies was difficult for various reasons including the combination of subjects with visual and auditory impairments into one category (Janicki \& Jacobson 1986), the sample of persons aged 65 years and over (Day 1987).

The following studies used different - perhaps more exact - means of data collection: the report on visual impairment by Warburg \& Rattleff (1992) and Jacobson (1987) was based on the screening of all patients; this was also true for the data of Nolan et al. (1980) and Evenhuis (1990) on hearing impairment. Cooke (1989) collected data on hearing impairment by sending a questionnaire to nursing staff.

However, the above authors gave neither age-related data, nor did they separate the results of people with DS from those with other causes of mental handicap.

In elderly persons without mental handicap in the Netherlands (C.B.S. 1980), visual impairment in persons over the age of 55 was present in $7 \%-14 \%$ and auditory impairment in $13-20 \%$ of those living in homes for the elderly. For those living at home, the figures were $3 \%$ for visual problems and $4 \%$ for auditory problems in the same age group. These data were based on self-reports.

The results of the present study suggested a prevalence of visual and hearing impairment in persons with mental handicap which was higher than the prevalence in elderly people without mental handicap who were living at home, but comparable to persons without mental handicap living in homes for the elderly. Elderly persons with DS in this study showed six to seven times higher prevalence of visual impairment and a three to four times higher prevalence of auditory impairment than elderly persons without mental handicap in residential settings.

No data were found concerning the relationship between the level of mental handicap and visual or auditory impairment in the literature. It was clear that a more severe brain damage may have had the same consequences for intellectual as well as for sensory functioning. The results of the present study showed that $25 \%$ of the people with profound mental handicap were blind and $8 \%$ were deaf. Twelve percent were untestable in terms of hearing. It is not known whether or not these percentages could be decreased by using special assessment procedures.

The frequency of reported cataracts in persons with DS, and the age-related prevalence (up to $63 \%$ in those aged 60 years and older) underlined the need for repeated assessment. In principle, cataracts are a treatable eye condition. The same is true for infection as a cause of hearing loss.

Could this percentage have been lower if all people with DS had been regularly examined for ear problems from an early age (Turner \& Sloper 1990)?

There is enough evidence of the inappropriate use of spectacles or hearing aids for persons with mental handicap (Cooke 1989; Wilson \& Haire 1990; Warburg \& Rattleff 1992) and 
there is probably a need for objective assessment in order to establish vision and hearing, as well as educational methods to utilize spectacles and/or hearing aids with these persons. In itself, this goal seems to be a major undertaking in the care for people with mental handicap. Regular and systematic assessment of both visual and hearing assessment is necessary, with special attention being paid to elderly people with mental handicap, persons with DS, and persons with a severe or profound mental handicap.

Further study is needed to determine the most effective method of screening, and necessary frequency of these screens, as well as an evaluation as to how much more people would improve if adequately supported with the use of corrective devices. 


\section{REFERENCES}

C.B.S. (Central Bureau of Statistics) (1980) Compendium Health Stotistics of the Netherlands 1979, Sdu., The Hague.

Cooke L.B. (1989) Hearing loss in aging mentally handicapped persons. A ustralian and New Zealand Joumal of Development Disabilities 12,321-27.

Day K. (1987) The elderly mentally handicapped in hospital: a clinical study. Jourral of Mental Deficiency Research 31, $131-46$.

Evenhuis H.M. (1990) Clinical studies of Alzheimer's dementia and hearing loss in Down's syndrome. Thesis, University of Amsterdam, The Netherlands

Haveman M.J., Schrojenstein Lantman-de Valk H.M.J.van, Maaskant M.A., Kessels A.G.H., Urlings H.F.J. \& Claessens M.J.J.T. (1992) Prevalence of diseases and medical support: a planning option for better services to the mentally handicapped. In: J. Roosendaal (ed), Mental retardation and medical care. Proceedings of the first European congress on mental retardation and medical care, Kerckebosch, Zeist, 68-83.

Hestnes A., Sand T. \& Fostad K. (1991) Ocular findings in Down's syndrome. Jourmal of Mertal Deficiency Research 35, 194-203.

Hogg J., Moss S. \& Cooke D. (1988) Ageing and mental handicap. Croon Helm L.td., London.

Jacobson L. (1987) Ophthalmology in mentally retarded adults. A clinical survey. Acta Ophthalmologica 66, $457-62$.

Janicki M.P. \& Jacobson J.W. (1986) Generational trends in sensory, physical and behavioural abilities among older mentally retarded people. American Journal of Mental Deficiency Research 90, $490-500$.

Krayer D.W. \& Kema G.N. (1985) Saciale Redzaamheidsschad voor Zwakzimingen (S.R.Z.), Swets and Zeitlinger, Lisse, The Netherlands

Maaskant M.A. \& Haveman M.J. (1988) Lang leven in de zwakzinnigenzorg; een onderzoek naar de consequenties van de veroudering van bewomers van algemene zwakinmigeninrichtingen en gezinsvervangende tehwizen. Rijksuniversiteit Limburg, Maastricht

Maaskant M.A., Haveman M.J., Schrojenstein Lantman-de Valk H.M.J. van, Urlings H.F.J., Claessens M.J.J.T. \& Kessels A.G.H. (1992) Ageing and Mental Handicap. A prospectiwe cohort study in the Netherlands. In: J. Roosendaal (ed), Mental retardation and medical care. Proceedings of the first European congress on wental retardation and medical care. Kerckebosch, Zeist, 424-33.

Nolan M., McCartney E., McArthur K. \& Rowson V.J. (1980) A study of the hearing and receptive vocabulary of the trainees of an adult training centre. Journal of Mental Defictency Research 24, 271-86.

Turner S. \& Sloper P. (1990). Health problems in children with Down's syndrome. Child: Care. Health and Development 16,83-97.

Warburg M. \& Rattleff J. (1992) Treatable wisual impairment. A study of 778 consecutive patients with mental handicap pllaced in sheltered workshops.In: J. Roosendaal (ed), Mental retardation and medical care. Proceedings of the first European congress an mental retardation and medical care. Kerckebosch, Zeist, 350-6.

Wilson D.N. \& Haire A. (1990) Health care screening for people with mental handicap living in the community, British Medical Journal 30, $1379-81$. 


\section{USE OF MEDICATION BY PEOPLE WITH INTELLECTUAL DISABILITY IN RESIDENTIAL FACILITIES}

\section{Summary}

Objective. Description of use of medication by people with intellectual disability (ID) in relation to age, level of mental handicap and living facility.

Desïgn. Cross-sectional study.

Setting. Institutions and group homes for people with ID in North Brabant and Limburg, The Netherlands.

Methods. Of a patient sample $(\mathrm{N}=1265$ ), stratified according to age and living facility (i.e. institution or group home) data were collected by means of questionnaires to be completed by the general practitioners. For 101 persons data about level of ID were lacking.

Results. $57 \%$ of the patients used one or more drugs. The number of drugs used were significantly related to (increased) age and level of ID. Older patients more often used antipsychotics, laxatives and cardiovascular medication, younger ones more often used anticonvulsants. Persons with more severe ID used antipsychotics, anticonvulsants, laxatives, antacids, psychoactive medication and gastrointestinal medication more often. There was no relationship between amount of medication and living facility.

Conclusion. Many persons with ID use medication. Since epilepsy, psychiatric and behavioural diseases and gastrointestinal problems are frequent, and because the patients offer little spontaneous information, alertness with respect to drug interaction and side effects is indicated.

Published as: Schrojenstein Lantman-de Valk H.M.J. van, Kessels A.G.H., Haveman M.J., Maaskant M.A., Urlings H.F.J., Akker M. van den (1995)

Medicijngebruik door verstandelijk gehandicapten in instituten en gezinsvervangende tehuizen. Nederlands Tijdschrift voor Geneeskunde 139, 1083-8 


\section{INTRODUCTION}

As a result of the increased social integration of people with intellectual disability (ID), many of them do not only live in small-scale accommodation facilities but also make use of regular medical care facilities more often. By no means all physicians are familiar with this type of patient. A qualitative problem here is the fact that many of the persons with ID cannot express their complaints adequately (Smink 1992).

In order to arrive at a thorough medication policy for such patients, we need recent data on their present use of medication. The purpose of this paper is to provide a contribution in this area.

In $1982,60 \%$ of al] people with ID patients in Dutch institutions took some kind of medication; $32 \%$ of all prescriptions concerned anticonvulsants, $22 \%$ antipsychotics, and $46 \%$ related to different medication (Van Essen \& Romein 1985). Both American (Aman 1990, Intagliata \& Rinck 1985) and British (Walters 1988, Searle et al. 1989) publications also showed that psychoactive drugs (anticonvulsants, neuroleptics, tranquillisers, etc.) were by far the most frequently used drugs. Psychoactive drugs are taken by $32 \%$ (Walters 1988 ) to $76 \%$ (Intagliata \& Rinck 1985) of all people with ID in the research populations described. Of the non-psychoactive drugs, the most frequently used are gastrointestinal drugs, vitamin preparations, dermatological preparations, and cardiac drugs (Searle et al. 1989). The organisation of medical care for the persons with ID in these countries, however, differs from the one in the Netherlands.

The question is how many and which drugs the persons with ID in the Netherlands take. There are at this moment approximately 120,000 disabled patients in the Netherlands, ranging from slightly to profoundly disabled. About 30,000 of them live in institutions, while circa 15,000 live in group homes. The remaining 75,000 either live with their families or independently (Maaskant et al. 1993).

This paper will address the following questions: how many and which drugs do people with ID in institutions and group homes take? Is there a relationship between the use of these drugs and age, or between the use of drugs, the functional level and the residential situation?

\section{RESEARCH METHOD}

\section{The research on ageing}

Within the framework of a study of the effects of ageing among people with ID in 1990, data were collected on 1583 patients. $92 \%$ of the institutions and $96 \%$ of the group homes in the provinces of Northern Brabant and Limburg and one institute in the province of Gelderland took part in the study.

The research population constituted a sample stratified as to age and residential facilities, with 30 residents being selected for each institutions and 10 residents for each group home. The residents were taken nonselectively from the strata by means of anonymised lists of residents. 
Within the age strata, the sample is regarded as representative for the persons with $\mathrm{D}$ in residential facilities, i.e. those living in institutions and group homes in the Netherlands.

The data were collected by means of questionnaires. The case history checklist (CHC) included questions on the use of medication. This list was completed by each resident's general practitioner. The reference date for the use of medication was the date when the questionnaire was completed.

The functional level was determined on the basis of the score on the Social Capability Scale for the Mentally Disabled and classified as either profoundly, severely, moderately and lightly intellectually disabled (Kraijer \& Kema 1985). People with profound ID function at the level of a child of no more than one-and-a-half to two years old; people with severe ID function up to the level of a four-year old. A person with moderate ID may have the level of a child between four and seven years old, while a person with mild ID may have the level of a child between seven and eleven years old.

This method of determining the level was chosen because it is the most frequently used in the Dutch care system for the persons with $\mathrm{ID}$. The validity and reliability of this scale has been sufficiently proven (Kraijer \& Kema 1985). In addition, Kraijer and Kema developed a method of converting the results to the internationally accepted equivalents for people with deeply, severely, moderately and lightly ID.

\section{Data on the use of drugs}

With regard to the classification and nomenclature of medication, use was made of the Anatomic Therapeutic Chemical coding system (ATC code) (de Smet \& Leufkens 1987, ATC-index 1991). This internationally applied system distinguishes twenty main groups of drugs as to the anatomic system, such as agents affecting the central nervous system, the socalled psychoactive agents. Each of these has a number of subgroups classified as to their therapeutic mechanism of action. In the case of psychoactive agents, these include anticonvulsants, psycholeptics, and anti-Parkinson agents. The subgroups have been classified as to chemical relationships. The group of psycholeptics includes antipsychotic agents, anxiolytic agents, hypnotics and sedatives.

\section{Statistic calculations}

The relationship between the number of drugs per resident and their age or the level of mental disability, was tested using Kendall's tau. The linear trend test was used for the use (or non-use) of certain types of drugs in relation to age or level of mental disability. In the statistic test of the use of drugs in relation to age, the group of patients between 0 - 18 years old was exclluded. As a result of restrictions of the accommodation capacities, changes in intake policies, and an extension of day-care facilities, the group of patients between $0-18$ years old in residential facilities is relatively more severely disabled than the older patients (Maaskant 1993a).

Lastly, four backward stepwise logistic regression analyses were carried out to determine the relationship between the use of drugs and the residential situation, corrected for other interfering variables. The dependent variable is the use (or non-use) of anticonvulsants, 
antipsychotic agents, anxiolytic agents or antidepressants. In addition to the residential situation (institution or group home) the following independent variables were used: the diagnosis of epilepsy, affective disorder, other psychiatric diagnosis, Down's syndrome, spasticity, demographic data such as age, gender, duration of residence, group size, disability level, and the other personal characteristics of care dependence, language understanding, active use of language, expression of physical complaints, self-mutilating behaviour, and hurting others. A $15 \%$ significance level was used as threshold level. The Bio Medical Data Processing (BMDP) program temoves from the model all variables which fail to meet this level.

Complete medical data were available for 1265 persons. For 101 persons, there were no data on their functional level. The data on the use of drugs in relation to the functional level therefore relate to 1164 persons.

\section{RESULTS}

\section{Use of drugs in relation to age}

Table 1 shows that the percentage of individuals not receiving any medication is the lowest in the group of 60 years and older $(36 \%)$. The percentage of people receiving three or more different drugs is the highest in the groups of 50 years and older. The relationship between age and number of drugs used is statistically significant.

Table 1 Number of drugs according to age, used by 1265 people with ID living in institutes or group homes (in \% between parentheses)

\begin{tabular}{|c|c|c|c|c|c|c|c|}
\hline \multicolumn{8}{|c|}{ Age/years } \\
\hline Number of drugs & $0-18$ & $19-29$ & $30-39$ & $40-49$ & $50-59$ & $60+$ & total \\
\hline $\mathrm{N}$ & 95 & 264 & 146 & 158 & 340 & 262 & 1265 \\
\hline 0 & $51(53.7)$ & $131(49.6)$ & $78(53.4)$ & $64(40.5)$ & $125(36.8)$ & $94(35.9)$ & $533(42.9)$ \\
\hline 1 & $18(18.9)$ & $63(23.9)$ & $26(17.8)$ & $37(23.4)$ & $78(22.9)$ & $76(29.0)$ & $298(23.6)$ \\
\hline 2 & 11. (11.6) & $27(10.2)$ & $12(8.2)$ & $25(15.8)$ & $56(16.5)$ & $32(12.2)$ & $163(12.9)$ \\
\hline 3 or more & $15(15.8)$ & $43(16.3)$ & $30(20.5)$ & $32(20.3)$ & $81(23.8)$ & $60(22.9)$ & $26](20.6)$ \\
\hline
\end{tabular}

Kendallt's tau: $\mathrm{p}<0.01$

The age group 0-18 was excluded from this test 
Only $10 \%$ of all patients receive 4,5 or more different drugs. These groups have therefore been combined with the group taking three or more different types of drugs. The highest number of different drugs is 12 ( 1 person).

The three main groups of most frequently used drugs are psychoactive agents $(37 \%)$, followed by cardiovascular drugs $(10 \%)$, and drugs affecting the gastrointestinal tract and the metabolism ( $9 \%$ ).

Further analysis (Table 2) showed that of all psychoactive agents, the most frequently used are anticonvulsants, antipsychotic agents, anxiolytic agents, and psycho-analeptics - in particular antidepressants. These four main groups have been listed separately in Table 2.

The most frequently used anticonvulsant is Carbamazepine; Haloperidol is the most frequently preseribed antipsychotic agent. Of all anxiolytic agents, Oxazepam is the most frequently used.

Table 2 The most frequently used groups of drugs according to age in 1265 people with ID living in institutes or group homes (in \% between parentheses)

\begin{tabular}{|c|c|c|c|c|c|c|c|c|}
\hline \multirow{3}{*}{$\begin{array}{l}\text { medication } \\
\qquad \mathbb{N}\end{array}$} & \multicolumn{3}{|c|}{ Age/years } & \multirow{3}{*}{$\begin{array}{c}40-49 \\
158\end{array}$} & \multirow{3}{*}{$\begin{array}{c}50-59 \\
340\end{array}$} & \multirow{3}{*}{$\begin{array}{l}60+ \\
262\end{array}$} & \multirow{3}{*}{$\begin{array}{l}\text { total } \\
1265\end{array}$} & \multirow{3}{*}{$p^{*}$} \\
\hline & $0-18$ & $19-29$ & $30-39$ & & & & & \\
\hline & 95 & 264 & 146 & & & & & \\
\hline $\begin{array}{l}\text { all psycho- } \\
\text { active drugs }\end{array}$ & $30(31.6)$ & $87(33.0)$ & $50(34.2)$ & $66(41.8)$ & $139(40.9)$ & $93(35.5)$ & $465(36.8)$ & 0.21 \\
\hline antipsychotics & $7(7.4)$ & $33(1.2 .5)$ & $24(16.4)$ & $37(23.4)$ & $77(22.6)$ & $43(16.4)$ & $221(17.5)$ & 0.05 \\
\hline anxiolytics & $3(3.2)$ & $19(7.2)$ & $11(7.5)$ & $7(4.4)$ & $34(10.0)$ & $12(4.6)$ & $86(6.8)$ & 0.73 \\
\hline $\begin{array}{l}\text { psycho- } \\
\text { analeptics }\end{array}$ & $1(1.1)$ & $7(2.7)$ & $4(2.7)$ & $9(5.7)$ & $14(4.1)$ & $11(4.2)$ & $46(3.6)$ & 0.27 \\
\hline anticonvulsants & $26(27.4)$ & $63(23.9)$ & $29(19.9)$ & $26(16.5)$ & $55(16.2)$ & $34(13.0)$ & $233(18.4)$ & $<0.01$ \\
\hline $\begin{array}{l}\text { all gastro- } \\
\text { intestinals }\end{array}$ & $13(13.7)$ & $20(7.6)$ & $10(6.8)$ & $8(5.1)$ & $35(10.3)$ & $29(11 . \mathrm{I})$ & $115(9.1)$ & 0.06 \\
\hline dyspepsia drugs & $3(3.2)$ & $7(2.7)$ & $2(1.4)$ & $2(1.3)$ & $13(3.8)$ & $10(3.8)$ & $37(2.9)$ & 0.18 \\
\hline laxatives & $9(9.5)$ & $7(2.7)$ & $3(2.1)$ & $5(3.2)$ & $12(3.5)$ & $15(5.7)$ & $51(4.0)$ & 0.05 \\
\hline $\begin{array}{l}\text { all cardio- } \\
\text { vaseular drugs }\end{array}$ & $1(1.1)$ & $3(1.1)$ & $4(2.7)$ & $12(6.7)$ & $41(12.1)$ & $61(23.3)$ & $122(9.6)$ & $<0.01$ \\
\hline
\end{tabular}

Patients could use more then one drug.

* Test for linear trend.

The age group 0-18 was excluded from this test. 
Of all drugs affecting the gastrointestinal tract and the metabolism, laxatives and antidyspepsia drugs are the most frequently used; laxatives most often by the youngest age group, antidyspepsia drugs most often by patients over 50 years old. Because of their numbers, the cardiovascular drugs have not been subclassified.

The linear trend test showed that in the case of anticonvulsants, antipsychotic drugs, laxatives, and cardiovascular drugs, there was no statistically significant relationship between the use of these drugs and age. For reasons mentioned above, the group of people between 0-18 years old was not included here. For anticonvulsants, the percentage of individuals taking these drugs decreases for each consecutive age group. For all other drugs mentioned, the percentage of individuals taking them increases for each consecutive age group.

\section{Use of drugs in relation to functional level}

Of the people with very severely ID, $74 \%$ takes one or more different drugs; of the persons with mild ID, $51 \%$ takes some kind of drugs (Table 3 ). The percentage of individuals taking three or more different drugs is highest in individuals at the lowest functional level. Thirty four per cent of people with very severe ID take three or more drugs, against $16 \%$ of the persons with mild ID. This relationship appears statistically significant.

Table 3 Number of drugs per resident according to functional level in 1164 people with ID living in institutes or group homes (in \% between parentheses)

\begin{tabular}{lccccc}
\hline & profound & severe & $\begin{array}{c}\text { Disability level } \\
\text { moderate }\end{array}$ & mild & total \\
$\begin{array}{l}\text { Number } \\
\mathrm{N}\end{array}$ & 86 & 228 & 302 & 548 & 1164 \\
\hline 0 & $22(25.6)$ & $79(34.6)$ & $133(44.0)$ & $268(48.9)$ & $502(43.1)$ \\
1 & $17(19.8)$ & $57(25.0)$ & $75(24.8)$ & $131(23.9)$ & $280(24.1)$ \\
2 & $18(20.9)$ & $34(14.9)$ & $37(12.3)$ & $60(10.9)$ & $149(12.8)$ \\
3 or more & $29(33.7)$ & $58(25.4)$ & $57(18.9)$ & $89(16.2)$ & $233(20.0)$ \\
\hline
\end{tabular}

Kendall's tau: $p<0.01$

More than half of the individuals with a profound ID take psychoactive drugs (Table 4), in particular anticonvulsants. Another striking fact is the frequent use of drugs affecting the gastrointestinal tract, in particular laxatives. Almost all drugs listed here are taken more often by individuals with a very severe ID than by individuals with a higher functional level. Only in the case of cardiovascular drugs, the opposite is found: a small percentage of users ( $2 \%$ ) in the people with profound ID and an almost five times higher percentage in all other level groups. 
Table 4 The most frequently used groups of drugs per resident according to level of disability in 1164 people with ID living in institutes or group homes (in \% between parentheses)

\begin{tabular}{lcccccc}
\hline & \multicolumn{7}{c}{ Disability level } & & & \\
medication & profound & severe & moderate & mild & total & $p^{*}$ \\
N & 86 & 228 & 302 & 548 & 1164 & \\
\hline all psychoactive druggs & $48(55.8)$ & $108(47.4)$ & $105(35.1)$ & $155(28.3)$ & $417(35.8)$ & $<0.01$ \\
antipsychotics & $10(11.6)$ & $61(26.8)$ & $63(20.9)$ & $63(11.5)$ & $197(16.9)$ & $<0.01$ \\
anxiolytics & $6(7.0)$ & $14(6.1)$ & $20(6.6)$ & $35(6.4)$ & $75(6.4)$ & 0.95 \\
psychoanaleptics & $3(3.5)$ & $7(3.1)$ & $11(3.6)$ & $22(4.0)$ & $43(3.7)$ & 0.57 \\
anticonvulsants & $38(44.2)$ & $53(23.2)$ & $42(13.9)$ & $74(13.5)$ & $207(17.8)$ & $<0.01$ \\
all ggastrointestinals & $26(30.2)$ & $31(13.6)$ & $25(8.3)$ & $22(4.0)$ & $104(8.9)$ & $<0.01$ \\
dispepsia drugs & $8(9.3)$ & $12(5.3)$ & $8(2.6)$ & $7(1.3)$ & $35(3.0)$ & $<0.01$ \\
laxatives & $14(16.3)$ & $17(7.5)$ & $6(2.0)$ & $4(0.7)$ & $41(3.5)$ & $<0.01$ \\
all cardiovascullar drugs & $2(2.3)$ & $21(9.2)$ & $36(11.9)$ & $55(10.0)$ & $11.4(9.8)$ & 0.11 \\
\hline
\end{tabular}

* Test for linear trend.

In the linear trend test, a relationship was found between the functional level and the use of antipsychotic drugs, anticonvulsants, antacids and related drugs, laxatives, all psychoactive drugs together, and all gastrointestinal drugs. The highest percentages of drug-taking patients are always found in the groups suffering from a severe ID.

\section{Use of drugs in rellation to residential situation}

Of all residents of institutions, $60 \%$ take medication, against $45 \%$ of residents of group homes. For psychoactive drugs, the figures are $41 \%$ (residents of institutions), and $29 \%$ (group home residents) respectively. This difference is significant $(p<0.01$.)

The logistic regression analysis (Table 5) shows that the relationship between the residential situation and the use of drugs is only significant for antidepressants. To enhance readability, this table only lists the significant results. Epilepsy, affective disorders and other psychiatric diagnoses constitute the variables with greatest associations. Striking results are the negative relationship between de diagnoses of Down's syndrome and spasticity and the use of various psychoactive drugs, and the positive relationship between weekly hurting others and the use of antidepressants. 
Table 5 Variables affecting the use of psychoactive drugs by people with ID (OR based on backward stepwise logistic regression analysis)

\begin{tabular}{lccc}
\hline variable & OR & & \\
& anticonvulsants & antipsychotics $\quad$ anxiolytics & antidepressants \\
\hline
\end{tabular}

Epilepsy
monthly ws rarely
weekly vs rarely

Affective disorder

Other psychiatric diagnosis $66.66^{\text {***** }}$

$5.35^{* * *}$

$4.74^{\text {* * * }}$

$\begin{array}{lll}16.66^{* *} & 3.03^{* * *} & 40.0^{* * *} \\ 11.11^{* *} & 3.25^{* * *} & 3.44^{* *}\end{array}$

Age

$19-29 \mathrm{yr}$ ws $<18 \mathrm{yr}$

$2.71^{*}$

$6.71 * *$

$5.81 * *$

$>50 \mathrm{yr}$ vs $<18 \mathrm{yr}$

Level of disability

moderate vs mild

1.37

severe vs mild

$2.68 * *$

1.31

$2.00^{*}$

Down's syndrome

$0.27^{* *}$

$0.39^{* *}$

$0.21^{* *}$

Cerebral palsy

$0.17^{* * *}$

Hurting others

monthly vs rarely

$1.87^{*}$

$2.17^{*}$

1.14

are dependence

superv ${ }^{l}$ vs. independlent

depend. ${ }^{2}$ vs independent

$2.06^{*}$

Duration of residence

$10-20 \mathrm{yr}$ ws $>20 \mathrm{yr}$

$<10 \mathrm{yr}$ vs $>20 \mathrm{yr}$

0.68

$0.53^{*}$
0.76

$0.25 * *$

0.76

$4.08 * *$

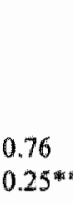

Group size

$9-15$ vs $<8$ persons

0.89

$>16$ vs $<8$ persons

$0.49 *$

Understanding language

Physical complaints

monthly ws rarely

weekly vs rarely

Residential setting institute vs group home

Legenid

* $p<0.05$

*** $p<0.01$

"needs supervision

${ }^{2}$ dependent on care from other people 


\section{DISCUSSION}

Of all the people with ID who took part in this study, 57\% took one or more drugs. Considering the extent of the sample, it is likely that this percentage is representative (at least within the age groups) for the people with ID in the Netherlands who live in institutions or group homes. The people with ID who live with their families were not included in this study. The use of drugs by people with ID appears to have changed hardly at all compared to 1982 . Van Essen and Romein (1985) found a similar percentage of drug usage in residents of institutions. In 1990, the percentage of anticonvulsants and neuroleptics was smaller, while the percentage of anxiolytic agents and antidepressants had increased.

Older people with $\mathbb{I D}$ in this study showed a relatively higher level of medication than younger ones. The same applies to general practices (Haaijer-Ruskamp \& Dingemans 1989).

In particular, older people take more antipsychotics than younger ones. The question is whether psychiatric disorders are more frequent at higher ages (Day \& Jancar 1994) or that it is difficult to stop prolonged use of antipsychotic drugs (Luchins et al. 1993). It is also possible that the institutional setting promotes the continuation of problematic behaviour.

People with very profound ID appear to receive more medication than people with mild ID. Probably, their cerebral dysfunction is more severe. This leads to a higher incidence of epilepsy (Luchins et al. 1993, Lund 1985, Lund 1985a) and organic psychiatric problems. The relationship between a more severe ID and a higher incidence of physical disorders has been described by Moss et al. (1993).

Of the characteristic problems in the category of the people with most severe ID, we only need to mention the following: the higher incidence of gastrointestinal reflux in bedridden patients or patients with a serious postural deviation (Niezen-de Boer 1992) and the relationship between immobility and obstipation. This matched the more frequent use of dyspepsia drugs or laxatives in the group of people with profound $\mathrm{ID}$ in our study.

The use of drugs in residents of institutions and of group homes is not related to their housing conditions, but can be explained largely by the diagnoses of epilepsy, affective disorders and other psychiatric diagnoses. In this model, the residential situation only plays a role with respect to the use of antidepressants. In itself, the medication policies in institutions are no different from those in group homes. As can be expected, institutions have a higher number of individuals whose diagnoses indicates psychoactive drugs. It is unclear why people who hurt others are prescribed antidepressants more often, in particular because Tuinier and Verhoeven (1994) have found that depressions were greatly underdiagnosed. The question whether or not people with ID receive too much medication, in particular too many psychoactive drugs, cannot be answered. Research of the applicable psychiatric diagnostic methods and possible deviating dosage-effect relationships has only just started (Tuinier \& Verhoeven 1994). 


\section{RECOMMENDATIONS}

Long-term use of drugs must be evaluated regularly, for example once every three months. Attention must be paid to interactions but also to the fact that people with ID will rarely report side-effects spontaneously. The use of psychoactive drugs must be part of a multidisciplinary treatment scheme, which is evaluated regularly (Sovner 1990). The development of protocols in this area is desirable.

In the curriculums of education programmes for physicians and general practitioners and additional training and refresher courses, more time will have to be devoted to the medical problems of people with ID. In doing so, attention should be paid to widespread disorders such as epilepsy, psychiatric and behavioural disorders, and gastrointestinal problems. Such courses should explicitly include prescription policies and the fact that any side-effects and interaction may avoid being noticed because existing drug use will seldom be reported spontaneously.

It may be possible to develop a model, analogous to the situation in nursing homes, in which a physician working in residential facilities for people with $I D$ functions as a consultant for colleagues who face complex problems. It is also advisable to investigate whether, and if so to what extent, the drug use of people with ID living with their families or on their own differs from the drug use of those who live in institutions or group homes. 


\section{REFERENCES}

Aman M.G.(1990) Considerations in the use of psychotropic drugs in elderly mental retarded persons. Journal of Mental Deficiency Research 34, 1-10.

A.TC. Index, uncluding DDD's for plain substances (1991) WHO Collaborating Centre for Drug Statistics Methodology. Oslo

Essen Ch. van \& Romein Th. (1985) Geneesmiddelen in de zwakzinnigenzorg. Medisch Contact 1, 17-20.

Day K. \& Jancar J. (1994) Mental and physical health and ageing in mental handicap: a review. Journal of Intellectual Disability Research 38, 241-56.

Haaijer-Ruskamp F.M. \& Dingemans C.A.J. (juli 1989) Wat krijgen ouderen aan geneesmiddelen thuis en in het werzorgingstehuis? Geriatrie-Informatorium, E 3020, 1-13.

Haveman M.J., Maaskant M.A. Schrojenstein Lantman-de Valk, H.M.J. van, Urlings H.F.J., \& Kessels A.G.H. (1994) Mental health problems in elderly people with and without Down's syndrome. Journal of Intellectual Disability Research 38, 341-55.

Intagliata J, \& Rinck C. (1985) Psychoactive drug use in public and community residential facilities for mentally retarded persons. Psychopharmacology Bulletin. 38, 317-9.

Kraijer D.W \& Kema G.N. (1985) S.R.Z Sociale Redzaamheidsschaal voor Zwakzimigen. Swets en Zeitlinger, Lisse.

Luchins D.J, Dojka D.M. \& Hanrahan P. (1993) Factors associated with reduction in antipsychotic medication dosage in adults with mental retardation. American Journal on Mental Retardation 98, 165-72.

Lund J. (1985) Epilepsy and psychiatric disorder in the mentally retarded adults. Acta psychiatrica scandinavica $72,557-62$.

Lund J. (1985ia) The prevalence of psychiatric morbidity in mentally retarded adults. Acta psychiatrica scandinavica 72, 563-70

Maaskant, M.A. (1993a) Mental Handicap and Ageing. Thesis, Rijksuniversiteit Limburg, Kavanah, Dwingeloo.

Maaskant M.A., Haveman M.J., Urlings H.F.J., Schrojenstein Lantman-de Valk H.M.J. van, Claessens M.J.J.T. \& Kessels A.G.H. (1993b) The internal and external integration of group home residents in the Netherlands. The Irish Joumal of Psychiany 14, 64-78.

Moss S., Goldberg D., Patel P. \& Wilkin D. (1993) Physical morbidity in older people with moderate, severe and profound mental handicap, and its relation to psychilatric morbidity. Social Psychiatry and Psychiatric Epidewiology 28, 32-9.

Niezen-de Boer M.C. (1992) Acute and long term treatment of gastro-oesophageal reflux disease in the severely mentally handicapped. In: Roosendaal J.J. Mental retardation and medical care. Proceedings of the first European congress on mental retardation and medical care. Kerckebosch, Zeist, 339-44.

Searle G.F., Berelowitz, G.J. \& Wright E.C. (1989) The use of drugs for physical conditions in adults with mental retardation. Journal of Mental Deficiency Research, 33, 69-79.

Smet P.A.G.M. de, Leufkens, H.G.M. (1987) ATC-classificaties en DDD-waarden. In: Smet P.A.G.M.de, Loenen A.C, van \& Does E. van der, Informatorium Medicamentorum dl.IIl A.lphen a.d. Rijn, 300-32.

Smink M., Eerdmans-Dubbelt S.L.C. \& Van der Wouden J.C. (1992) Medische problemen van werstandelijk gehandicapten in een gezinsvervangend tehuis. Huisaris en Wetenschap 35, 461-4.

Sovner R. (1990), Psychotropic drug therapy prescribing principles for mentally retarded persons. In: Došen A., Van Gennep A. \& Zwanikken G.J. (eds), Treatment of mental illness and behavioral disorder in the mentally retarded. Proceedings of the international congress. Logon Publications, Leiden, 91-101.

Tuinier S. \& Verhoeven W.M.A. (1992) Psychopathology in mental retardation: a multidisciplinary approach. inregrative Psychiaty 8, 252-63. 
Tuinier S. Verhoeven W.M.A. (1994) Pharmacological advances in mental retardation; a need for reconceptualization. Current Opinions in Psychiatry, 380-6.

Walters R.M.(1988) Prescribing requirements of the elderly mentally handicapped: future demands on primary health care teams. Joumal of the Royal College of General Practitioners 38, $317-9$. 


\section{CHAPTER 5}

\section{COMORBIDITY' IN PEOPLE WITH DOWN'S SYNDROME: A CRITERIA-BASED ANALYSIS}

\section{Summary}

The aims of this study were to review what is currently known about comorbidity in people with Down's syndrome and to detemine, if their risk for certain disorders was increased. Analysis was carried out on the published literature from 1982 through 1994.

In order to be included in this study, articles had to meet predetermined criteria. The strenghts and weaknesses of the selected articles were considered in this review. The estimation of risks was done by calculating the odds ratio (OR) or relative risk (RR).

$O R$ and $R R>2$ or $<0.5$ were found in more than one article for congenital heart defects, hypothyroidism, hearing impairment and hepatitis B. Only one article indicated an OR within this range for all of the following disorders: obesity, epilepsy, degenerative spine disorders and a wide atlanto-axial distance. The results were unclear in the areas of hyperthyroidism, visual disorders, dementia and psychiatric disorders.

The concept of comorbidity i.e. establishing the relationships between the various conditions in one person and understanding the implications for medical care, seems promising, especially for people with intellectual disability. Further work in this area may well improve the quality of care offered to these persons.

This chapter is a modified version of: Schrojenstein Lantman-de Valk H.M.J. van, Haveman M.J., Crebolder H.F.J.M. (1996) Comorbidity in people with Down's syndrome: a criteriabased analysis. Journal of Intellectual Disability Research 40, 385-99. 


\section{INTRODUCTION}

The phenomenon of comorbidity occurs when a person has more than one disease or medical condition at the same time. Little is known about comorbidity in people with intellectual disability. Congenital conditions are rarely found as a single condition. Most often, congenital problems are expressed in several organic systems in the same person. As people age, 'normal' ageing problems add to these congenital disorders.

This is also applicable to a great percentage of people with intellectual disability. It is to be expected that comorbidity occurs more frequently in this group. Until now, little was known about this phenomenon.

More knowledge regarding comorbidity would help to improve treatment for people with intellectual disability, who quite often have difficulties in verbalizing symptoms and signs (Day \& Jancar 1994) and to prevent secondary conditions whenever possible (Pope 1992),

There are several ways in which disorders might be related to each other. Schellevis (1993) discerned four types of comorbidity:

1. concurrence: a person has more than one disease; the diseases are not related to each other;

2. clustering: two diseases are found together more often than can be explained by their prevalence when found without each other; it is not clear how dependent one disease is upon the other;

3. complication: one disease is a direct complication of the other; for example, blindness in diabetics;

4. causal relation: both (or more) diseases have a common cause; e.g. both cardiovasculair diseases and chronic obstructive pulmonary disease (COPD) may be caused by smoking.

People with intellectual disability are not a homogeneous group, however, similar patterns of diseases are frequently observed in people with the same aetiological diagnoses (e.g. Down's syndrome, fragile X). People with Down's syndrome form the largest group of persons with intellectual disability. In the Netherlands $16 \%$ of the persons living in institutions for people with intellectual disability have Down's syndrome (LRZ, 1994). Most research has focused on persons with Down's syndrome for this reason.

The aim of the present article is to review what is known about comorbidity in people with Down's syndrome, as well as determining if their risk was increased for certain disorders as compared to other people.

\section{METHOD}

Analysis was done on the published literature from 1982 through 1994. This was done by a Medline search using the key words Down's syndrome and Alzheimer's dementia, psychiatric disorders, epilepsy, cardiovascular conditions, atherosclerosis, obesity, hypo- and hyperthyroidism, hearing disorders, eye conditions, dermatologic problems, oesophageal and intestinal 
problems, respiratory problems, hepatitis, leukemia, diabetes, dental problems or atlanto-axial dislocation.

Calculation of odds ratio's $(=\mathrm{OR})$ in case of prevalence rates and relative risks $(=R R)$ in case of incidence rates was deemed the most appropriate method to estimate risk factors in these studies. OR on the prevalence of disorders or RR on the incidence of disorders in people with and without Down"s syndrome were calculated, based on the information in each article.

It was decided to include only studies which had:

1. included at least 25 persons in both groups to have some solid basis for OR calculations: each article had to have included numbers of study subjects used to perform these calculations;

2. information on how the diagnosis Down's syndrome was made;

3. information about the gender and age range of the study sample, and type of living facilities (e.g. at home, residential care or both possibilities);

4. revealed whether or not data were collected by review of documents only or by actual examination of the persons;

5. specified whether it was a prospective, retrospective or cross-sectional study;

6. described the reference group, and whether this consisted of people with intellectual disability resulting from other causes or of people from the general population; and

7. specified the inclusion and exclusion criteria.

No references could be found that related $O R$ or $R R$ value to types of comorbidity.

The authors decided to label disorders as 'clustering' when $\mathrm{OR}$ or $\mathrm{RR}>2$ or $\mathrm{OR}<0.5$ and the confidence interval did not include 1 . When $O R$ or $R R<2$ and confidence interval did not include 1, the disorder was labeled as concurrent. This is in line with Schellevis' (1993) definition that disorders were 'clustering" when these met together more often than can be explained by their prevalences when met separately, and 'concurrent' when these were not related to each other.

Criteria like biological plausibility, cause-effect relationship and analogy (Fletcher et al. 1988) cannot be studied in this way. The method used in this study did not permit the authors to establish relationships of causality or complications.

\section{RESULTS}

The studies that fulfilled the criteria varied greatly in a number of ways. As a result, the findings were sorted under the following headings:

1. congenital malformations: congenital heart disease and other congenital malformations;

2. immunologic problems: leukemia, thyroid disorders and hepatitis;

3. sensory impairments: visual impairment, auditory impairment;

4. Alzheimer's disease; 
5. other psychiatric disorders; and

6. remaining issues: atlanto-axial dislocation, obesity, epilepsy, dental problems, and cardiovascular disorders.

No studies were found concerning diabetes or dermatological problems.

\section{Congenital malformations}

\subsection{Congenital heart disease}

Four studies were found in which the incidence/prevalence of congenital heart disease (CHD) in Down's syndrome children versus non-Down's syndrome children was studied (Table 1).

The combined impact of CHD and Down's syndrome on the workload of general practitioners treating patients who were living with their families was the focus of a study by Murdoch (1984). He concluded that special training for general practitioners was necessary as was the planning of special health care delivery for families with a Down's syndrome child. In a study of the causes of death of the younger residents of a large institution, Chaney et al. (1985) found that more persons with Down's syndrome died from CHD when compared with people with other kinds of ID. The OR was $10.2(5.5-18.9)$.

Table I Prevalence and incidence of congenital heart defect

\begin{tabular}{|c|c|c|c|c|c|c|}
\hline Reference & $N$ & age range & method & living facility & $\underset{*}{\text { diagnosis DS }}$ & OR or RR $95 \% \mathrm{Cl}$ \\
\hline $\begin{array}{l}\text { Murdoch } \\
1984\end{array}$ & $\begin{array}{l}134 \text { DSt } \\
134 \text { DS- }\end{array}$ & $0-10 \mathrm{yr}$ & questionmaire & 2 & $\mathrm{~K} / \mathrm{V}$ & $74.2^{\dagger}(10.7-231.8)$ \\
\hline $\begin{array}{l}\text { Chaney } \\
1985\end{array}$ & $\begin{array}{l}137 \text { DSt } \\
480 \text { DS- }\end{array}$ & $0 \rightarrow 30 \mathrm{yr}$ & $\begin{array}{l}\text { pastmortem } \\
\text { retrospective }\end{array}$ & - & - & $10.2^{\dagger}(5.5-18.9)$ \\
\hline $\begin{array}{l}\text { Schneider } \\
1989\end{array}$ & $\begin{array}{l}160 \text { DSt } \\
540 \text { DS- }\end{array}$ & $0-1 \mathrm{yr}$ & $\begin{array}{l}\text { cardiological } \\
\text { prospective }\end{array}$ & 2 & & $\begin{array}{l}27.7^{*}(14.7-52.2) \mathrm{q} \\
0.28^{*}(0.20 \mathrm{0} 0.40) \mathrm{r}\end{array}$ \\
\hline $\begin{array}{l}\text { Nuutinen } \\
1989\end{array}$ & $\begin{array}{c}39 \mathrm{DS}+ \\
12019 \mathrm{DS}-\end{array}$ & $0-14 \mathrm{yr}$ & $\begin{array}{l}\text { registration } \\
\text { retrospective }\end{array}$ & 3 & - & $41.6^{ \pm}(18.9-91.9)$ \\
\hline
\end{tabular}

Legend

* Living arrangement

$1=$ residential facility

$2=$ at home

$3=$ both

** Diagnosis DS: way in which diagnosis Down's syndrome was made:

K, by karyotyping

$\mathrm{V}$ : on visual appearance

$\mathrm{K} / \mathrm{V}$ : partly by one, partly by the other method

- not mentioned

$R$ : information from registry data

+ adds ratio

$q=$ central atriventriculair canal

* relative risk

$\mathbf{r}=$ ventricular septal canal 
Schneider et $a$ l. (1989) reported on the incidence of various forms of CHD and the response to treatment on all children with $\mathrm{CHD}$ in his outpatient clinic in Baltimore, Marylland. He reported that central atrioventricular canal was the most frequent form of CHD. His data yielded a relative risk of $25.5(13.9-46.9)$. Ventricular septal defect was seen less often in Down's syndrome children, yielding an relative risk of $0.27(0.20-0.37)$.

Nuutinen et al. (1989) studied a one-year birth cohort in Finland for the year 1966. Among the 12.058 live births there were 39 with Down's syndrome; 50 children had CHD, six Down's syndrome children, and 44 non-Down"s syndrome children. The RR for incidence was calculated to be 500 (140-1790). All children with Down"s syndrome and CHD died in the first month of life.

Unfortunately, reference groups varied from study to study, matched on age and gender (Murdoch, 1984) to all other people that died in the study period (Chaney et al. 1985), to all other people with a congenital heart defect (Schneider et al. 1989), and to all people born in the same year in the same country (Nuutinen et al, 1989). Prevalence and incidence refer primarily to childhood age. Only the post-mortem study of Chaney et al. (1985) contained data on people older than 14 years. Consequently, it was difficult to use the combined data to arrive at a sound estimate of prevalence and incidence.

\subsection{Other congenital disorders}

Congenital anomalies of the gastro-intestinal tract are common occurrences in people with Down's syndrome. Most frequent are oesophageal atresia, duodenal stenosis, imperforate anus. and Hirschprung's disease (Levy 1992). All these disorders need appropriate treatment, which. is generally surgical in nature and performed soon after birth. The outcome is not different from children without Down's syndrome. No studies were found that compared data on incidence or prevalence of these disorders in Down's syndrome and non-Down"s syndrome children.

\section{Immunologic problems}

People with Down's syndrome have a high mortality caused by infections and a high risk of developing malignancies, especially leukemia. A HBsAg-carrier state is quite common in Down's syndrome people. This prompted several authors to study immunology in Down's syndrome people.

Thymic morphological and functional abnormalities have been demonstrated. T-lymphocytes (Ugazio et al. 1990 ) appear to be less active. Phagocytes of subjects with Down's syndrome show low chemotactic abillity and a reduced production of oxygen radicals. Mehta et al. (1993) reported on elevated levels of the cytokine IL-6 among ageing persons with Down's syndrome who showed signs of dementia compared to those without signs.

The high frequency of thyroid auto-antibodies in people with Down's syndrome strengthens the hypothesis that auto-immunity plays a role in the prevalence of hypothyroidism in Down's syndrome people. Leukemia (2.1), hepatitis (2.2) and hypothyroidism (2.3) will be discussed more extensively in this section. 


\subsection{Leukemia}

The incidence of leukemia in Down's syndrome people is 10-to 20 -fold higher than in the general population (Fong \& Brodeur 1987). There are two peaks in the age of onset, the first during the newborm period, the second between 3 and 6 years of age.

Survival rates have rapidly improved recently. While the overall survival rate for acute nonlymphatic leukemia was less than $5 \%$ in the early $1970 \mathrm{~s}$, it was more than $25 \%$ by the mid. 1980 s (Stiller \& Eatock 1994). These authors found a survival rate for treated children with Down's syndrome similar to that of non-Down's syndrome children receiving the same treatment. It appeared that an age of less than one year and/or CHD could be contraindications for starting treatment in children with Down's syndrome. Buckley et al. (1994) who performed a regression analysis on 1282 cases of children with acute lymphocytic leukemia (ALL), 2002 other cancer cases and 679 community controls, found an OR of 3.1 for Down's syndrome and ALL.

No studies were found that compared prevalence and/or incidence of leukemia.

\subsection{Hepatitis}

The introduction of the hepatitis B vaccine in the early 1980 s meant a turning point in the care for people with intellectual disability, especially those living in institutions. The opportunity to stop the further spread of this endemic disease has stimulated much research. Risk factors for hepatitis B infection which have been identified include male gender, diagnosis of Down's syndrome and living in an institution.

We report on six studies of institution-based samples. Three others studies involved persons living in the community. The results are presented in Table 2.

In institutionalized subjects, the odds ratio for people with Down's syndrome compared to people with other intellectual disability varied from 3.2 (Heytink et al. 1984) to 8.7 (Clarke ef al. 1984).

For non-institutionalized people, the OR varied from 0.9-5.0. Only Pueschel et al. (1991) gave results that indicate an $\mathrm{OR}<1$, but the $95 \%$ confidence interval is broad $(0.1-6.2)$. Most authors companed results from subjects with Down's syndrome to people with other forms of intellectual disability.

Renner et al. (1985) also compared subjects with Down's syndrome to other forms of healthy, non-mentally handicapped adolescents. One out of 114 of these adolescents had a positive hepatitis B virus carrier state. The odds radio for Down's syndrome persons (25 out of 200) compared to these heal thy controls (1 out of 113) is $28(3.97-112.71)$.

Hepatitis A, contracted by oral-fecal contact, appeared to be less prevalent in people with Down's syndrome than in people with other forms of intellectual disability.

Results on hepatitis A are mentioned bij Renner et al. (1985). Seven out of 125 Down's syndrome persons had hepatitis A antibodies, compared to 10 out of 106 non-Down"s syndrome persons and 19 out of 199 healthy adolescents. The OR for hepatitis $A$ in subjects with Down's syndrome versus people with other forms of intellectual disability is not significant: $0.57(0.2-1.7)$. Consequently, the OR for hepatitis A in people with Down's syndrome versus healthy adolescents is $0.30(0.1-0.8)$. 
Table 2 Hepatitis $B$

\begin{tabular}{|c|c|c|c|c|c|c|}
\hline Reference & $\mathrm{N}$ & age range & method & living facility & $\begin{array}{c}\text { diagniosis DS } \\
*\end{array}$ & $\mathrm{OR}+95 \% \mathrm{Cl}$ \\
\hline $\begin{array}{l}\text { Clarke } \\
1984\end{array}$ & $\begin{array}{l}227 \text { DS } \\
2012 \text { DS- }\end{array}$ & $<10->70$ & lab & 1 & - & $8.7(5.8-13.1)$ \\
\hline $\begin{array}{l}\text { Heytink } \\
1984\end{array}$ & $\begin{array}{l}87 \text { DS+ } \\
73 \text { DS- }\end{array}$ & $33-63$ & lab & 1 & - & $3.2(1.2-8.9)$ \\
\hline $\begin{array}{l}\text { Renner } \\
1985\end{array}$ & $\begin{array}{l}125 \text { DSt } \\
106 \text { DS- }\end{array}$ & $4-42$ & lab & 2 & - & $5.0(1.3-16.0)$ \\
\hline $\begin{array}{l}\text { Wagemans } \\
1985 \text { (1) }\end{array}$ & $\begin{array}{l}104 \mathrm{DS}+ \\
\$ 73 \mathrm{DS}-\end{array}$ & $2-88$ & lab & 1 & - & $4.4(2.1-9.0)$ \\
\hline $\begin{array}{l}\text { Dicks } \\
1987\end{array}$ & $\begin{array}{l}103 \mathrm{DS}+ \\
2033 \mathrm{DS}=\end{array}$ & - & register & 1 & - & $5.0(3.0-8.1)$ \\
\hline $\begin{array}{l}\text { Ditzhurysen } \\
1988(2)\end{array}$ & $\begin{array}{l}117 \text { DS } \\
117 \text { DS- }\end{array}$ & $0-35$ & lab & 1 & - & $3.4(1.4-8.4)$ \\
\hline $\begin{array}{l}\text { Scanlon } \\
1989(2)\end{array}$ & $\begin{array}{l}56 \mathrm{DS}+ \\
193 \mathrm{DS}\end{array}$ & $3-76$ & lab & 1 & - & $4.6(1.8-11.6)$ \\
\hline $\begin{array}{l}\text { Pueschel } \\
1991 \text { (3) }\end{array}$ & $\begin{array}{l}180 \text { DSt } \\
155 \text { DS- }\end{array}$ & $1-29$ & lab & 3 & - & $0.9(0.1-6.2)$ \\
\hline $\begin{array}{l}\text { Devlin } \\
1993(3)\end{array}$ & $\begin{array}{l}94 \mathrm{DS}+ \\
145 \mathrm{DS}-\end{array}$ & $13 \cdot 61$ & lab & 2 & - & $2.1(0.9-5.3)$ \\
\hline
\end{tabular}

* Legend: see also table 1

(1) only females in this study

(2) only males in this study

(3) results based on all hepatitis markers, i.e. antigen and antibody carriers; all other results are based on Hbs Agstatus

Therefore, the conclusion is that the prevalence of hepatitis B is higher in people with Down's syndrome than in people with other forms of intellectual disability in both residential settings and in family living circumstances. There are insufficient data to permit any conclusions to be made when comparing the people with Down's syndrome to nom-handicapped people. There is an indication that hepatitis $A$ is less prevalent in people with Down's syndrome than in other people, whether they are mentally handicapped or not.

None of the three articles that dealt with vaccination response met the criteria for this study, two because of the very small numbers of patients, one because it gave no data on which odds ratios could be c的culated. All authors (Troisi et al. 1985, Avanzini et al. 1988, Van Damme et al. 1990) concluded that Down's syndrome persons had a normal response to vaccination. 


\subsection{Hypo- and hyperthyroidism}

The three studies that met the criteria are shown in Table 3. The data of Kinell et at: (1987) are based on thyroid microsomal antibodies. Hughes et al. (1982) based their diagnosis on T3, T4, TSH and thyroid hormone uptake.

Table 3 Hypo- and hyperthyroidism

\begin{tabular}{lcccc}
\hline Reference & $\mathrm{N}$ age range method living facility diagnosis DS \\
$*$ & $0 \mathrm{R}+95 \% \mathrm{Cl}$ \\
\hline
\end{tabular}

\section{Hypothyroidism}

$\begin{array}{lllllll}\begin{array}{l}\text { Hughes } \\ 1982\end{array} & \begin{array}{l}38 \mathrm{DS}+ \\ 364 \mathrm{DS}-\end{array} & 0-60+ & \text { lab } & 1 & \mathbb{K} & 5.4(2.0-14.8) \\ \begin{array}{l}\text { Kinnell } \\ 1987\end{array} & \begin{array}{l}111 \mathrm{DS}+ \\ 74 \mathrm{DS}-\end{array} & 22-72 & \text { lab } & 1 & \mathbb{K} & 3.9(1.5-10.4) \\ & & & & & \\ \begin{array}{l}\text { Percy } \\ 1990\end{array} & 29 \mathrm{DS}+ & 31-70 & \text { lab } & 1 & \mathbb{K} & 1.6(0.2-1.0 .1)\end{array}$

Hyperthyroidism

$\begin{array}{lllllll}\text { Percy } & 29 \mathrm{DS}+ & 31-70 & \text { lab } & 1 & \mathrm{~K} & 2.1(0.2-23.6) \\ 1990 & 29 \mathrm{DS}- & & & & \end{array}$

* Legend: see also table 1

Odds ratios based on these data for hypothyroidism in people with Down's syndrome compared to people with other forms of intellectual disability vary from 3.9-5.4. All persons in both studies lived in institutions. All people with Down's syndrome had their diagnosis confirmed by karyotyping. Percy ef al. (1990) compared adults with Down's syndrome to a matched sample (age and gender) of healthy controls. Tests of thyroid functioning included those mentioned by Hughes et al. (1982) plus thyroid antithyroglobulin and antimicrosomal antibodies.

OR for clinical hypothyroidism calculated on the data of Hughes et al. was 1.6 (0.2-10.1). This report also mentioned cases of hyperthyroidism. For this disorder, an OR could be calculated of $2.1(0.2-23.6)$. Furthermore, their laboratory results, although based on a small sample, suggested that subclinical hypothyroidism is common in adults with Down's syndrome and more pronounced in people with Down's syndrome persons with manifestations of Alzheimer"s disease than in those without.

In the study of Cutler et al. (1986) 49 children with Down's syndrome and 49 matched controls were included, all under 3 years of age and with an intellectual disability. Four Down"s syndrome children and none of the controls showed hypothyroidism.

The results of Kinell et al. (1987) and Hughes et al. (1982) indicate a higher prevalence of hypothyroidism in people with Down's syndrome when compared to other people living in institutions. The results of Percy et al. (1990) permit no conclusions in the frame of the present study. 


\section{Sensory impairments}

\subsection{Visual impairment}

Ocular abnormalities are rather common in people with Down's syndrome. Some of these abnormalities are congenital while others occur at later ages. Three studies were found with a variety of ocular disorders, some frequent, some less frequent. All three dealt with keratoconus, cataract and functional blindness, defined as a visual capacity less than 0.1 .

A choice was made to compare the results of the studies with regard to these conditions (Table 4). The data of Walsh (1981) and Hestnes et al. (1991) were based on ophtalmologic examination by the researcher. The data of van Schrojenstein Lantman-de Valk et al. (1994) were collected by means of a questionnaire, to be completed by each person's physician.

Odds ratios for keratoconus varied from 3.9 - 30.8. For cataract, the odds ratios were between 2.3 and 8.0. For blindness, the data indicated a variation between 1.3 and 3.7. The wide confidence intervals in the results of Hestnes et al. (1991) are caused by his relatively small sample size.

When excluding these results, a conclusion from the other results is that the above visual problems are more frequent in people with Down's syndrome than in others. A further limitation of the studies described above was that these all dealt with persons with intellectual disability who lived in residential facilities ${ }^{2}$.

Table 4 Keratoconus, cataract and functional blindness

\begin{tabular}{|c|c|c|c|c|c|c|c|c|}
\hline Reference & $\mathrm{N}$ & age range & method & $\begin{array}{l}\text { living } \\
\text { facility } \\
*\end{array}$ & $\begin{array}{c}\text { diagn. } \\
\text { DS } \\
*\end{array}$ & Keratoconus & $\begin{array}{c}\mathrm{OR}+95 \% \mathrm{Cl} \\
\text { Cataract } \\
\end{array}$ & Blindness \\
\hline $\begin{array}{l}\text { Walsh } \\
1981\end{array}$ & $\begin{array}{l}88 \text { DS }+ \\
357 \text { DS- }\end{array}$ & $14-83$ & opthalm & 1 & - & $30.8(3.7-122.9)$ & $8.0(3.2-20.2)$ & $3.7(1.1-12.5)$ \\
\hline $\begin{array}{l}\text { Hestnes } \\
1991\end{array}$ & $\begin{array}{l}30 \mathrm{DS}+ \\
30 \mathrm{DS}-\end{array}$ & $21-72$ & opthalmn & 1 & $\mathrm{~K}$ & $3.9(0.8-20.8)$ & $2.3(0.7-7.3)$ & $3.1(0.5-18.8)$ \\
\hline $\begin{array}{l}\text { Schrojenstein } \\
\text { Lantruan -de } \\
\text { Valk } 1994\end{array}$ & $\begin{array}{l}307 \mathrm{DS}+ \\
1110 \mathrm{DS}\end{array}$ & $0-60+$ & registration & 1 & - & $4.2(2.6-6.6)$ & $2.5(1.3-4.5)$ & $1.3(0.6-2.5)$ \\
\hline
\end{tabular}

\footnotetext{
"After closing down this study, Woodhouse et al. (1996) published a study on visual acuity in young children with and without Down's syndrome. It appeared that accomodation was defective in $92 \%$ of the Down's syndrome children, but in none of the control group.
} 


\subsection{Auditory impaimment}

Five articles were found that met the criteria (Table 5). Assessment of auditory capacities may be difficult to determine in people that do not understand what is asked of them. For pure tone audiometry active cooperation is necessary, while on the other hand tympanometry is a 'passive' method. The same can be said about brainstem evoked response audiometry (BERA). Dahle \& Mc Collister (1986) did not mention these considerations. In comparison, Brown et al. (1989) did but they only mentioned that cooperation or performance testing techniques were used as appropriate.

Table 5 Hearing impairment

\begin{tabular}{|c|c|c|c|c|c|c|}
\hline Reference & $\mathbb{N}$ & age range & method & living facility & $\begin{array}{c}\text { diagnosis DS } \\
*\end{array}$ & $\mathrm{OR}+95 \% \mathrm{Cl}$ \\
\hline $\begin{array}{l}\text { Dahle } \\
1986\end{array}$ & $\begin{array}{l}30 \mathrm{DS}+ \\
30 \mathrm{DS}-\end{array}$ & $5-14$ & $\begin{array}{l}\text { audiometry; } \\
\text { tympanometry, } \\
\text { ENT examination }\end{array}$ & 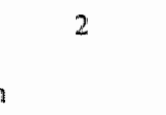 & $\mathbb{K}$ & $185(5.7-64.2)$ \\
\hline $\begin{array}{l}\text { Squires } \\
1986\end{array}$ & $\begin{array}{l}34 \mathrm{DS}+ \\
52 \mathrm{DS}-\end{array}$ & $31 \pm 9$ & audiometry & - & - & $9.7(3.2-30.2)$ \\
\hline $\begin{array}{l}\text { Brown } \\
1989\end{array}$ & $\begin{array}{l}28 \mathrm{DS}+ \\
33 \mathrm{DS}-\end{array}$ & $1.5-15$ & audiometry & 2 & - & $7.3(2.0-28.0)$ \\
\hline $\begin{array}{l}\text { Marcell } \\
1992\end{array}$ & $\begin{array}{l}26 \mathrm{DS}+ \\
26 \mathrm{DS}-\end{array}$ & $18 \pm 4$ & $\begin{array}{l}\text { audiometry, } \\
\text { psychological } \\
\text { examination }\end{array}$ & 3 & - & $3.5(1.4-9.0)$ \\
\hline $\begin{array}{l}\text { Schrojenstein } \\
\text { Lantmaan-de Valk } \\
1994\end{array}$ & $\begin{array}{l}307 \text { DS+ } \\
1110 \text { DS- }\end{array}$ & $0.60+$ & registration & 1 & - & $22(1.1-4.4)$ \\
\hline
\end{tabular}

Marcell \& Cohen (1992) extensively described using speech audiometry and cognitive testing when pure tone audiometry was impossible. Squires et al. (1986) described electrophysiological assessment methods. The study of van Schrojenstein Lantman et al (1994) was based on a questionnaire in which hearing capacity was asked. This questionnaire was to be completed by physicians. No specification about the assessment method used was asked for in this study.

Most authors compared people with Down's syndrome with people with other types of intellectual disability. Brown et al. (1989) compared children with Down's syndrome to children without intellectual disability. Squires et al. (1986) made two reference groups: one consisted of people with intellectual disability, attending the same daycare facilities as the people with Down's syndrome, the other consisted of the staff members of these facilities. Unfortunately only data concerning the hearing capacities of the people with intellectual disability and the Down's syndrome people were provided. The effect of ageing on auditory capacities was only dealt with in the study of van Schrojenstein Lantman et al. (1994).

The ORs for hearing impairment in people with Down's syndrome to non-Down's syndrome people in the selected studies varied from $2.2-18.5$. From these data it can be concluded that 
hearing impairment is more often seen in people with Down's syndrome than in other people with intellectual disability.

\section{Dementia}

Dementia of the Alzheimer's type (DAT) is quite common in older people with Down's syndrome. Post-mortem brain examinations in these persons, aged 35 years and older, showed neuropathological signs in high percentages (Wisniewski et al. 1985). The gene for beta amyloid protein precursor, which is responsible for amyloid plaques, amyloid deposits and probably neurofibrillary tangles as well, appears to be located on chromosome 21 (St. Clair 1987). This finding stimulated the research on Alzheimer's disease in people with Down"s syndrome as a model for studying Alzheimer's disease in general. Symptoms in living people with Down's syndrome are mainly seen in subjects with Down's syndrome aged 50 years and over (Zigman et al. 1987). However, these data are all retrospective and based exclusively on medical files.

Recent studies (Dalton 1992, Dalton et al. 1993) revealed that the clinical expression of Alzheimer's disease in Down's syndrome is substantially less frequent than would be expected from the results of postmortem examinations. Depression is one of the disorders that may mimic or mask the signs of dementia in individuals with Down's syndrome (Burt et al. 1992).

Schupf et al. (1989) found that adults with Down's syndrome over 50 years of age were three to four times more likely to regress than did either matched controls or younger adults with Down's syndrome, even when controlling for the elevated age-specific mortality in this group. Most studies that compared people with and without Down's syndrome consisted of very small groups, and most of these studies did not contain any data to calculate OR. From the hundreds of English and Dutch references on (Alzheimer's) dementia and Down's syndrome in the period 1982-1994, just two studies met the criteria for inclusion in this report (Table 6). Unfortunately, both Lund (1988) and Collacott et al. (1992) only mentioned 'dementia", but did not specify further diagnosis. An OR of $3.6(0.9-14.5)$ can be calculated from Lund's (1988) data. The OR calculated from the data of Collacott et al. (1992) is 16.7 (2.3-74.7). Both studies compared people with Down's syndrome to other people with intellectual disability.

Table 6 Dementia

\begin{tabular}{|c|c|c|c|c|c|c|}
\hline Reference & $\mathrm{N}$ & age range & method & living facility & diagnosis DS & $\mathrm{OR}+95 \% \mathrm{Cl}$ \\
\hline $\begin{array}{l}\text { Lund } \\
1988\end{array}$ & $\begin{array}{l}44 \mathrm{DS}+ \\
258 \mathrm{DS}-\end{array}$ & $>20$ & $\begin{array}{l}\text { psychiatric } \\
\text { examination }\end{array}$ & 3 & $\mathrm{~K} / \mathrm{V}$ & $3.6(0.9-14.5)$ \\
\hline $\begin{array}{l}\text { Collacont } \\
1992\end{array}$ & $\begin{array}{l}37 \| \mathrm{DS}^{-2} \\
371 \mathrm{DS}-\end{array}$ & $16-78$ & $\begin{array}{l}\text { registered } \\
\text { data }\end{array}$ & 3 & $R$ & $16.7(2.3-74.7)$ \\
\hline
\end{tabular}

* Legend: see also table 1 


\section{Psychiatric disorders}

The four articles that met the criteria are given in Table 7. Gath \& Gumley (1986) described only children, while Collacott et al. (1992) and Lund (1988) described adults. The sample of Haveman et al. (1994) consisted of all age groups. Lund (1988) examined his patients by himself, while Gath \& Gumley (1986) interviewed parents and teachers. Collacott et al. (1992) and Haveman et al. (1994) used registry data. All reference groups consisted of people with intellectual disability. Gath \& Gumley's (1986) sample was matched on age, sex and level of intellectual disability. The sample of Collacott et al. (1992) was matched on age, sex and type of residential facility. Haveman et al. 1994) matched on age, level of intellectual disability and type of residential facility.

Table 7 Psychiatric disorders

\begin{tabular}{|c|c|c|c|c|c|c|c|c|}
\hline Reference & $\mathrm{N}$ & age range & method & $\begin{array}{l}\text { living } \\
\text { facility } \\
*\end{array}$ & $\begin{array}{c}\text { diagn. } \\
\text { DS } \\
*\end{array}$ & infantile autism & $\begin{array}{l}\mathrm{OR}+95 \% \mathrm{Cl} \\
\text { belinaviour } \\
\text { disorder }\end{array}$ & $\begin{array}{l}\text { total of mental } \\
\text { disorders }\end{array}$ \\
\hline $\begin{array}{l}\text { Gath } \\
1996\end{array}$ & $\begin{array}{l}193 \text { DS+ } \\
154 \text { DS- }\end{array}$ & $6-17$ & $\begin{array}{l}\text { question- } \\
\text { naire and } \\
\text { interview }\end{array}$ & 3 & - & $0.5(0.1-3.9)$ & $0.6(0.2-1.7)$ & \\
\hline $\begin{array}{l}\text { Lund } \\
1988\end{array}$ & $\begin{array}{l}44 \mathrm{DS}+ \\
258 \mathrm{DS}-\end{array}$ & $>20$ & $\begin{array}{l}\text { psychiatric } \\
\text { examination }\end{array}$ & 3 & $\mathrm{~K} / \mathrm{V}$ & $1.8(0.6-14.5)$ & $0.2(0.03-1.3)$ & \\
\hline $\begin{array}{l}\text { Collacott } \\
1992\end{array}$ & $\begin{array}{l}371 \text { DSt } \\
371 \text { DS- }\end{array}$ & $16-78$ & $\begin{array}{l}\text { registered } \\
\text { data }\end{array}$ & 3 & $\mathbb{R}$ & $0.5(0.2-1.2)$ & $0.3(0.2-0.4)$ & \\
\hline $\begin{array}{l}\text { Haveman } \\
1994\end{array}$ & $\begin{array}{l}268 \text { DSt } \\
98.7 \text { DS- }\end{array}$ & $0-60 \div$ & $\begin{array}{l}\text { registered } \\
\text { data }\end{array}$ & 1 & $\mathbb{R}$ & & & $0.1(0.07-0.2)$ \\
\hline
\end{tabular}

* Legend: see also table 1

Since a great number of diagnoses were mentioned, we narrowed our review to infantile autism and behaviour disorder, which were described in three out of four studies. For behaviour disorders, ORs calculated from these reports varied between 0.2 and 0.6 . Only the data of Collacott et al. (1992) permitted a small $95 \%$ confidence interval $(95 \% \mathrm{Cl}): 0.3(0.2$ $0.4)$. For infantile autism ORs varied between 0.5 and 1.8 . The $95 \% \mathrm{Cls}$ in all three studies were wide and included 1 . Criteria for in - and exclusion in these reports may have varied from study to study.

Haveman et al. (1994) described other diagnoses. The total numer of persons with a psychiatric diagnosis, mentioned in this study was used for OR calculation: $0.1(0.07-0.21)$. An inverse relationship for psychiatric disorder, more specifically bipolar affective disorder and Down's syndrome, was also suspected by Craddock \& Owen (1994a, 1994b). These authors performed a literature search on the issue of bipolar/affective disorder and chromosomal abnormalities. They concluded that the numbers for chromosome 21 were too small to permit definite conclusions. Further studies on larger samples were recommended. The 
possible association of depression and dementia (Burt ef al. 1992) has already been mentioned (section 4, "dementia").

\section{Remaining issues}

On most issues only one study was found that met the criteria for this report. The results of this study are compiled in Table 8.

Table 8 Remaining issues: atlanto-axial dislocation, degenerative deformities of spine, obesity an d epilepsy

Reference Number age range method living faclity diagnosis $\mathrm{DS} \quad \mathrm{OR}-95 \% \mathrm{Cl}$
and issue

$A A D=3 \mathrm{~mm}$

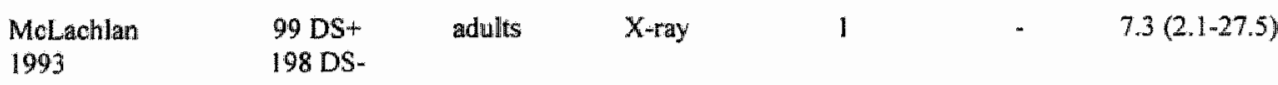

\section{Degenemative \\ disorder of spine}

$\begin{array}{lcccccc}\begin{array}{l}\text { McLachlan } \\ 1993\end{array} & \begin{array}{c}99 \mathrm{DS}+ \\ 198 \mathrm{DS}-\end{array} & \text { adults } & \text { X-ray } & 1 & & 3.7(2.1-6.6) \\ \text { Obesity } & & & & & & \\ \begin{array}{l}\text { Bell } \\ 1992\end{array} & \begin{array}{l}34 \mathrm{DS}+ \\ 71 \mathrm{DS}-\end{array} & \begin{array}{c}\text { male } \\ \text { adults }\end{array} & \begin{array}{c}\text { height and } \\ \text { weight }\end{array} & 2 & \mathrm{~V} & 2.5(1.0-6.5) \\ & 24 \mathrm{DS}+ & \begin{array}{c}\text { female } \\ \text { adults }\end{array} & \begin{array}{c}\text { height and } \\ \text { weight }\end{array} & 2 & \mathrm{~V} & 13.5(1.7-74.1) \\ & 54 \mathrm{DS}- & & & & \end{array}$

\section{Epilepsy}

\begin{tabular}{lllllll} 
Schrojenstein & 243 DS+ & $0-70+$ & registered data & 1 & $R$ & $0.6(0.4-0.9)$ \\
$\begin{array}{l}\text { Lantman } \\
1995\end{array}$ & 849 DS- & & & & & \\
& & & & & & \\
& 57 DS+ & $50-$ & registered data & 1 & $R$ & $2.8(1.3-5.8)$ \\
\hline
\end{tabular}

Legend: see also table I

\subsection{Atlanto-axial dislocation and degenerative disorders of the spine}

MacLachlan et al. (1993) compared radiographs of 99 adults people with Down's syndrome to 198 'normal' subjects, i.e. people that made an emergency room visit at the same hospital. The sample was matched on age and gender. Thirteen people with Down's syndrome and four controls showed an atlanto-occipital distance of $3.0 \mathrm{~mm}$ or more on X-rays. This is considered to be a risk factor for dislocation. An OR of $7.3(2.1-27.5)$ can be callculated from these data. Cremers (1993) found an atlanto-axial distance of $4.0 \mathrm{~mm}$ and more in 91 out of 282 children with Down's syndrome aged between 6 and 17 years. Risky sports did not cause additional damage in her sample. This study gave no data to calculate $\mathrm{OR}$. 
McLachlan et al. (1993) also studied X-rays of degenerative disorders of the spine, i.e. disc narrowing, osteophyle formation, deformity, subluxation and sclerosis. The OR for degenerative spine disorders for people with Down's syndrome compared to the reference group was $3.7(2.1-6.6)$.

These results suggest a higher prevalence of both a wider atlanto-axial distance and of degenerative spine disorders in people with Down's syndrome as compared to the general population.

\subsection{Overweight}

Bell \& Bhate (1992) measured and weighed adult participants of a local training centre, and calculated body mass index of each individual. Body mass index is weight in kilograms divided by height in square meters ( $\mathrm{kg} \mathrm{m}-2)$. A body mass index below 25 was considered as normal, and one of above 25 as overweight.

Femalles with Down's syndrome appeared to be overweight more often than males. Based on the data of Bell \& Bhate (1992), the OR for overweight in males with Down's syndrome was $2.5(1.0-6.5)$, and for females it was $13.5(1.7-74.1)$. The reference group consisted of people with intellectual disability due to other causes.

The question remains as to whether or not it is justifiable to consider the same criteria as normal for height and weight in people with Down's syndrome as in the general population, since people with Down's syndrome are generally shorter than people in the general population. Another issue is raised by Sharav \& Bowman (1992), who found comparable body mass indexes in both children with Down's syndrome and siblings from the same families. They postulated that both dietary practices and involvement in physical activities play a role in this issue.

\subsection{Cardiovascular disorders}

It has been repeatedly suggested that other than congenital heart defects, cardiovascular disorders are less frequent in people with Down's syndrome. No articles met our criteria, but a few gave indications of cholesterol or lipoprotein values in blood.

Murdoch et al. (1977) supplied data on abnormally high cholesterol concentrations in blood samples. This was found in 12 out of 70 people with Down's syndrome and in 14 out of 70 non-Down's syndrome subjects living in the same institution, yielding an OR of $0.8(0.3$ 2.1). Based on these data, it remains unclear if hypercholesterolaemia is less frequent in people with Down"s syndrome than in the other subjects studied. The studies of Dormer $e$ al. (1984), Ylä-Herttualäa et al. (1989) and Pueschel et al. (1992) all gave mean values of lipoprotein values in people with Down's syndrome compared to those of other people. 


\subsection{Epilepsy}

Quite a few articles on epilepsy in people with Down's syndrome are reviewed by Stafstrom (1993). None of the articles in his reference list nor those in Medline articles permitted OR calculation.

Two of the present authors (Haveman; Van Schrojenstein Lantman) were involved in a cohort study on agieing and intellectual disability. Data from this study ( Schrojenstein Lantman-de Valk ef al. 1995) on the prevalence of epilepsy in people with Down's syndrome and people with other kinds of intellectual disability are presented in Table 8. Based on registry data, the OR in this report for all ages groups of people with Down's syndrome was $0.6(0.4-0.9)$. An interesting shift was seen when only people above the age of 50 years were compared. Thus, the OR found was $2.8(1.3-5.8)$. Actually, this figure is the result of the high correlation between dementia and epilepsy in (ageingl persons with Down's syndrome.

The relationship between (Alzheimer's) dementia and epilepsy was described earlier by Lai \& Williams (1989), Collacott (1993), Stafstrom (1993) and McVicker et al. (1994).

\section{D. Dental problems}

Oral health problems specific to persons with Down's syndrome are caused by the congenital anomalies in the cranial morphology, particularly the jaws and dentition. Difficulties in controlling the tongue also play a rol with regard to proper dental treatment (Vigild 1992).

No studies could be found that permitted OR calculation on the prevalence/incidence of these problems in Down's syndrome persons and reference groups.

\section{DISCUSSION}

Based on an $\mathrm{OR}$ or $\mathrm{RR}>2$ or $<0.5$ and $\mathrm{a} 95 \% \mathrm{Cl}$ not including 1 , only a few of the disorders studied here could be labeled as 'clustering' with Down's syndrome:" CHD, hypothyroidism. hearing impaiment, visual disorders, especially cararact and keratoconus, and hepatitis B in people living in residential facilities. For these disorders, several studies confirm each other's results.

Only one study was available that fulfilled the above criteria for each of the following disorders: obesity, epilepsy, a wide atlanto-axial distance and degenerative spine disorders. These results need confirmation.

Although the results of some studies are highly suspective for a similar relation this could not be established for: hepatitis B in non-residential living persons, hyperthyroidism, dementia, psychiatric disorders. Here, some of the results show confidence intervals that include 1 , and thus, make the results unclear.

Although the method of the present study permits no conclusions about relations of causality or complications, the results of some studies give indications.

That epilepsy might be a complication of Alzheimer's dementia in persons with Down's syndrome is suggested by the results of Lai \& Williams (1989), Pueschel et al. (1991), Collacott (1993), McVicker et al. (1994) and Van Schrojenstein Lantman et al. (1995). 
Although a causal relationship between Down's syndrome and Alzheimer's disease is suspected (StClair 1987), most studies are not conclusive at this point (Dalton et al, 1993).

Theoretically, all congenital disorders and immunologic disorders in Down's syndrome should have a causal relation, all being determined by the same chromosomal disorder. These rellations are yet to be established.

Only one study dealt with more than one disorder in the same person (Tumer \& Sloper 1990). Unfortunately, their sample consisted of 120 school age children with Down's syndrome without a reference group. Combinations of disorders to be found in Down's syndrome persons should be documented more extensively.

The methods of the studies described in this article varied in several ways. As can be seen in the tables, karyotyping (examination of the chromosomes), which is considered as the gold standard in diagnosing, was not always met. Some authors mention verifying the diagnosis on physical appearance. No articles could be found that provided information on sensitivity and specificity of this method versus karyotyping. Experts (A.J. Dalton, W.B. Zigman, New York State Institute for Basic Research in Developmental Disabilities; personal communication) mention a true positive diagnosis on physical features of $95-99 \%$. These figures could be lower in less experienced persons. The fact that the diagnostic method was not mentioned in three out of four studies on $\mathrm{CHD}$, in four out of five studies on hearing impairment and in none of the studies on hepatitis $B$ respectively, limits the value of their conclusions. With regard to the other methadological criteria, most are presented in the tables. The gender of the studied persons was not always mentioned. Inclusion and exclusion criteria were so infrequently specified that we decided to not include these in the tables. In most studies reference groups consisted of other people with intellectual disability. The few exceptions are all specified in the "Results" section.

An advantage of comparing results of people with Down's syndrome to those of other people with intellectual disability is that bias caused by (lack of) verbalizing capabilities and level of intellectual disability is ruled out. However, a disadvantage is that all other people with intellectual disabilities may be highly susceptible to all kind of congenital or acquired disorders. Risk factors might be underestimated in this way.

The available studies on thyroid disorders, visual disorders, degenerative disorders of the spine and epilepsy all dealt only with people living in residential facilities. This also might be a source of bias, since these people generally have more severe handicaps than people living on their own or with families.

In conclusion: the 'strong' relations of clustering with Down's syndrome for CHD, hearing disorders and hepatitis B (residential people) might be biased because of incomplete descriptions of the sample. The results need confirmation for all disorders studied. Furthermore, it should be acknowledged that ORs only give an indication of relative risk. To calculate "true' relative risks, cohort studies are necessary in which both "exposed" (Down's syndrome) an 'non-exposed' (people without Down's syndrome) are followed over a length of time. 
Since in most countries there is a move from large-scale living facilities to community residential facilities, it is necessary to include people living with their natural families in the studies. Although expensive, establishing the diagnosis of Down's syndrome by karyotyping in all persons included in a study is a method to strengthen the conclusions that can be made. The concept of comorbidity, i.e. establishing the relationships between the various conditions in one person and to realize their implications for medical care might improve the quality of care to be offered to people with intellectual disability. This concept seems a promising avenue for further exploration. 


\section{REFERENCES}

Akker M. van den, Buntinx F. \& Knottnerus J.S. (1996) Comorbidity or multimorbidy: what's in a name? A review of literature. European jowmal of General Pracrice 2, 65-70.

Avanzini M.A., Söderström T., Wahl M., Plebani A., Burgio G.R. \& Hanson L.A. (1988) lgGi subclass deficiency in people with Down's syndrome and aberrant hepatitis B vaccine response. Scandimavian Jownd of Immunology 28, 465-70.

Bell A.J. \& Bhate M.S. (1992) Prevalence of overweight and obesity in Dowt's syndrome and other mentally handicapped adults living in the community. Joumal of Intellectual Disability Research 36, 359-64.

Brown P.M., Lewis G.T.R., Parker A.J. \& Maw A.R. (1989) The skuil base and nasopharymx in Down"s syndrome in relation to hearing impairment. Clinical Otolartyngology 14, $241-6$.

Buckley J.D., Buckley C.M., Ruccione K., Sather H.N., Waskerwitz M.J., Woods W.G. \& Robison L.L. for the Childrens Cancer Group (1994) Epidemiological characteristics of childhood acute lymphocytic leukemia. Analysis by immunophenotype. Leukemia 8, 856-64.

Burt D.B., Loveland K.A. \& Lewis K.R. (1992) Depression and the onset of dementia in adults with mental retardation. American Journal on Mental Retardanion 96, 502-11

Chaney R.H., Eyman R.K. \& Miller C.R. (1985) The relationship of congenital heart disease and respiratory infection mortality in patients with Down's syndrome. Journal of Mental Deficiency Research 29, $23-7$.

Clarke S.K.R., Caul E.O., Jancar J. \& Gordon-Russell J.B. (1984) Hepatitis B in seven hospitals for the mentally handicapped. Journal of Infection 8, 34-43.

Collacott R.A., Cooper S-A. \& McGrother C. (1992) Differential rates of psychiatric disorders in adults with Down"s syndrome compared with other mentally handicapped adults. British Journal of Psychiatry 161,671-4.

Collacott R.A. (1993) Epilepsy, dementia and adaptive behavior in Down's syndrome. Journal of Intellectual Disability Research 37, 153-60.

Craddock N. \& Owen M(1994a) Cromosomal aberrations and bipolar affective disorder. British Journal of Psychiaty 164, 507-12.

Craddock N. \& Owen M. (1994b) Is there an inverse relationship between Down's syndrome and bipolar affective disorder? Literature review and genetic implications. Journal of Imtellectual Disability Research 38, 613.20.

Cremers M.J.G. (1993) Down's syndrone and Sports. Ph.D. Thesis, University of Utrecht, Utteht.

Cutter A.T., Benezra-Obeiter R. \& Brink S.J. (1986) Thyroid function in young children with Down syndrome. American Journal of Diseases in Children 140,479-83.

Dahle A.J. \& McCollister F.P. (1986) Hearing and otollogic disorders in children with Down syndrome. American Journal of Mental Deficiency $90,636-42$.

Dalton A.J. (1992) Dementia in Down syndrome; methods of evaluation. In: Nadel L. \& Epstein C.J. (eds). Down syndrome and Alzheimer disease, Wiley Liss Inc., New York, 51-76.

Dalton A.J., Selzer G.B., Adlin M.S. \& Wisniewski H.M. (1993) Association between Alzheimer disease and Down syndrome: clinical observations. In: Berg J.M. Karlinsky H. \& Holland A.J.(eds). Alzheimer disease. Down syndrome and their relationship. Oxford University Press, Oxford, 53-69.

Day K.A. \& Jancar J. (1994) Mental and physical health and ageing in mental handicap: a review. Journal of Intellectwal Disability Research 38,241-56.

Devlin J.B., Mulcahy M., Corcoran R. Ramsay L., Tyndall P. \& Shattock A. (1993) Hepatitis B in the nonresidential mentally handicapped population. Journal of Intellectual Disability Research 37, 553-60.

Dicks J.L. \& Dennis E.S. (1987) Down's syndrome and hepatitis: an evaluation of carrier status. Journal of the American Dentists Assaciation 114, 637-9. 
Ditzhuyzen ThJ. wan, Witte-van der Schoot E.de, Low A.M. van, Rijntjes P.J.M. \& Yap S.H. (1988) Hepatitis $\mathrm{B}$ virus infection in an institution for the mentally retarded. American Journal of Epidemiology 128, 629-38.

Dömer K., Gaethke A-S., Tolksdorf M., Schumann K. \& Gustmann H. (1984) Cholesterol fractions and triglycerides in children and adults with Down's syndrome. Clinica Chimica Acta 142, 307-11.

Fletcher R.H., fletcher S.W. \& Wagner E.H. (1988) Clinical Epidemiology, the essentials. Williams \& Wilkins, Baltimore.

Fong C. \& Brodeur G.M. (1987) Down's syndrome and leukemia: epidemiology, genetics, cytogenetics and mechanisms of leukemogenesis. Cancer, Genetics and Cyrogenetics 28, 55-76.

Gath A. \& Gumley D. (1986) Behaviour problems in retarded children with special reference to Down's syndrome. British Jownal of Psychiary 149, 156-61.

Haveman M.J., Maakkant M.A., Schrojenstein Lantman-de Valk H.M.J. wan, Urlings H.F.J. \& Kessels A.G.H. (1994) Mental health problems in elderly people with and without Down's syndrome. Journal of Intellectual Disability Research 38, 341-55.

Hestnes A., Sand T. \& Fostad K. (1991) Ocular frndings in Down's syndrome. Journal of Mental Deficiency Research 35, 194-203.

Heytink R.A., Jong P. de, Schalm S.W. \& Masural N. (1984) Hepatitis B waccination in Down's syndrome and other mentally retarded patients. Heparology $4,6114$.

Hughes V.C., Cameron J. \& Goonetilleke A.S.R. (1982) The prevalence of thyroid dysfunction in mentally handicapped in-patients. Journal of Mental Deficiency Research 26, $115-20$.

Kinnell H.G., Gibbs N., Teale J.D. \& Smith J. (1987) Thyroid dysfunction in institutionalised Down's syndrome adults. Psychological Medicine 17, 387-92.

Lai F. \& Williarns R.S. (1989) A prospective study of Alzheimer disease in Down syndrome. Archives of Neurology 46, 849-53.

Levy J. (1992) Gastrointestinal concerns. In: Pueschel S.M \& Pueschel J.K. (eds), Biomedical concerns in people with Down syndrome. Paul H Brookes Publ.Co., Baitimore, 119-25.

LRZ (1994) Jaarboek Verstandelijk Gehandicaptenzorg 1992. Publ.nr.794.022. Nederlandse Vereniging voor Gehandicaptenzorg, Utrecht.

Lund J. (1988) Psychiatric aspects of Down"s syndrome. Acta Psychiarrica Scandinavia 78, 369-74.

Marcell M.M. Cohen S. (1992) Hearing abilities of Down syndrome and other mentally handicapped adolescents. Research in Developmental Disabilities 13,533-51.

Maclachlan R.A. Fidler K.E., Yeh H., Hodgetts P.G., Pharand G. \& Chau M. (1993) Cervical spine abnormalities in institutionalized adults with Down syndrome. Journal of Intellectual Disability Research 37 , 277.85 .

McVicker R.W, Shanks O.E.P.\& McLelland R.J. (1994) Prevalence and associated features of epilepsy in adults with Down's syndrome. British Journal of Psychiary 164, 528-32.

Mehta P.D., Dalton A.J., Mehta S.P., Percy M.E. \& Wisniewski H.M. (1993) Increased beta-2-microglobulin (B 2-M) and interleukin $6(1 \mathrm{~L}-6)$ in sera from older persons with Down syndrome. Advances in the Biosciences 87 , $95-6$.

Murdoch J.C., Rodger J.C., Rao S.S., Fletcher C.D. \& Dunnigan M.G. (1977) Down's syndrome: an atheromaw free model? British Medical Jourmal 2, 226-8.

Murdoch J.C. (1984) Comparison of the care of children with Down's syndrome with the care of matched controls. Journal of the Royal College of General Practitioners 34, $205-9$.

New York State Office of Mental Retardation and Developmental disabilities (1994) International colloquium on Alsheimer disease and mental retardation: preliminary bibliography and abstracts on Atzheimer disease and mental retardation. Albany, New York. 
Nuutimen M., Koiva M. \& Rantakallio P. (1989) Long-term outcome for children with congenital heart defects. A study from 1 year birth cohort bom in 1966 in Northern Finland. ftrot. Med Res. 48, 175-84.

Percy M.E., Dalton A.J., Markovic V.D.y Crapper McLachlan D.R.y Gera E., Hummel J.T. Rusk A.C.M., Sommerville M.J., Andrews D.F \& Walfish P.G. (1990) Autoimmune thyroiditis associated with mild "subclinical" hypothyroidism in adults with Down symdrome: a comparison of patients with and without manifestations of Alzheimer disease. American Journal of Medical Cenetics 36, 148-54.

Pope A.M. (1992) Preventing secondary conditions. Mental Retardation 30, 347-54.

Pueschel S.M., Bodenheimer H.C. jr., Giesswein P. \& Dean M.K. (1991) The prevalence of hepatitis B surface antigen and antibody in home-reared individuals with Down syndrome. Research in Developmental Disabihies 12, 243-9.

Pueschel S.M., Craig W.Y. \& Haddow J.E. (1992) Lipids and lipoproteins in persons with Down's syndrome. Joumal of Intellectual Disability Research 36, 365-9.

Renner F., Andrle M., Horak W. \& Rett A. (1985) Hepatitis A and B in non-institutionalized mentally retarded patients. Hepalo-gastroenterology 32, $175-7$.

Scanlon S. \& Khan S.A. (1989) Hepatitis B in a residential population with a mental handicap. Irish Medical Jownal 82, 80-2.

Schellevis F. (1993) Chronic diseases in general practice. Comorbidity and quality of care. Ph.D. Thesis, Katholieke Universiteit Nijmegen, Nijmegen.

Schneïder D.S., Zahka K.G., Clark E.B., Neill C.A. and the Baitimore-Washington Infant Study Group (1989) Patterns of cardiac care in infants with Down syndrome. American Journal of Diseases in Children 143,363-65.

Schrojenstein Lantman-de Valk H.M.J. van, Haveman M.J., Maaskant M.A., Kessels A.G.H., Urlings H.F.J. \& Sturnans F. (1994) The need for assessment of sensory functioning in ageing people with mental handicap. Journal of Intellectual Disability Research 38, 289-98.

Schrojenstein Lantman-de Valk H.M.J.van. Akker M. van den, Maaskant M.A. (1995) Chronische aandoeningen. In: Maaskant M.A., Haveman M.J., Schrojenstein Lantman-de Valk H.M.J. van., Urlings H.F.J. \& Kessels A.G.H.(eds), Veroudering bij mensen met een versiandelike handicap. University of Limburg Maastricht, Pepijn Centre Echt, 83-92.

Schupf N., Silverman W.P., Sterling R.C. \& Zigman W.B. (1989) Down syndrome, terminal illiness and risk for dementia of the Alzheimer type. Brain Dysfunction 2, $181-8$.

Sharav T. \&, Bowman T. (1992), Dietary practices, physical activity and body-mass-index in a selected population of Down syndrome children and their siblings. Clinical Pediatrics $1,341-4$.

Squires N., Ollo C. \& Jordan R. (1986) Auditory brain stem responses in the mentally retarded: audiometric correlates. Ear and Hearing 7, 83-92.

Stafstrom C.E. (1993) Epilepsy in Down syndrome: Clinical aspects and possible mechanisms. American Journal on Mental Retardation 98, Suppl. 12-26.

StClair D. (1987) Chromosome 21, Down's syndrome and Alzheimer's disease. Journal of Mental Deficiency Research 31, $213-4$.

Stiller C.A. \& Eatock E.M. (1994) Survival from acute non-lymphocytic leukemia 1971-88: a population based study. Archives of Disease in Childhood 70, 219-23.

Troisi C.L., Heiberg D.A. \& Hollinger F.B. (1985) Normal immune responst to hepatitis B vaccine in people with Down's syndrome. Journal of the American Medical Association 254, $3196-9$.

Turner S. \& Sloper P. (1990) Health problems in children with Down's syndrome. Child, Care, Health and Development 16, 83-97.

Ugazio A.G., Maccario R., Notarangelo L.D. \& Burgio G.R. (1990) Immunology of Down syndrome: a review. American Journal of Medical Genetics Suppl. 7, 204-12. 
Wan Damme P., Vrarickx R. \& Meheus A. (1990) Immunogenicity of a recombinant DNA hepatitis B vaccine in institutionalized patients with Down's syndrome. Paccine Supplement 8, 5 53-5.

Vigrild M.(1992) Oral health conditions. In: Pueschel S.M. \& Pueschel J.K. (eds). Biomedical concerns in persoms with Down syndrome. Paul H. Brookes Publ. Co., Balltimore, 81-9.

Wagemans A. \& Zielhuis G.A. (1985) Een gedifferentieerd hepatitis B-vaccinatiebeleid in een zwakzinnigeninstituut. Nederlands Tijdschriff woor Geneeskunde 129, 1325-8.

Walshil $\$ . Z$. (1981) Keratoconus and blindmess in 469 institutionalised subjects with Down syndrome and other causes of mental retardation. Journal of Mental Deficiency Research 25, 243-51.

Wisniewski K.E., Dalton A.J., Crapper McLachlan D.R., Wen G.Y. \& Wisniewski H.M. (1985) Alzheimer's disease in Down's syndrome: Clinicopathologic studies. Neurology 35, 957-61.

Woodhowse J.M., Pakeman V.H., Saunders K.J., Parker M., Fraser W.1, Lobo S. \& Sastry P. (1996) Visual acuity and accomodation in unfants and young children with Down's syndrome. Journal of Intellectual Disability Research 40,49-55.

Yla-Herttualäa S., Luoma J., Nikkari T. \& Kiwimaki T. (1989) Down's syndrome and atherosclerosis. Acheroscherosis 76, 269-72.

Zigman W.B., Schupf N., Lubin R.A. \& Silverman W.P. (1987) Premature regression of adults with Down syndrome. American Journal of Mental Deficiency, 92, 161-8. 


\section{PEOPLE WITH INTELLECTUAL DISABILITY IN GENERAL PRACTICE: CASE DEFINITION AND CASE FINDING}

\section{Summary}

In a general practice database containing data on 62,500 patients, those with intellectual disability (ID) were traced. Health problems in this database were recorded according to the International Classification of Primary Care (ICPC) code. By using selected codes, 318 people with ID $(0.65 \%$ of the study population) were found; the sample contained nearly as many false positives. Adding up the percentage of people with ID living in residential facilities, the total prevalence of people with ID was estimated on $0.82 \%$.

Documentation on the cause and level of ID was available in about half of the cases. The demographic characteristics of the people with ID were significantly different from the general population: there was a higher percentage of males, and a lower percentage of people over 50 years of age among those with $\mathrm{ID}$.

Information about the use of home care was virtually non-existent in the general practice data. The results are compared with those of other studies.

The discussion deals with reasons for complete documentation of cases with ID in general practice and the rol of the general practitioner in health care supply to people with ID.

Published as: Schrojenstein Lantman-de Valk H.M.J. van, Metsemakers J.F.M., SoomersTurlings J.M.S.J.G., Haveman M.J. \& Crebolder H.F.J.M. (1997) People with intellectual disability in general practice: case definition and case finding. Journal of Intellectual Disability Research 41, 373-9 


\section{INTRODUCTION}

Information regarding health problems of people with Intellectual Disability (ID) living with their families is rare. Until now, Kerr et al. (1996) were the only group who had studied information from general practitioners (GPs) on people with ID on their caseload. General practitioners see a variety of patients and have excellent opportunities to provide an overview of potential health problems.

In the UK, guidelines for primary health care for people with (ID) were formulated in the early 1990 s (Howells \& Barker 1990, Welsh Health Planning Forum 1992).

In the Netherlands, the organization of care supply is changing rapidly: There is a tendency towards community living and to separate living arrangements from care provision. Institutions are being divided into smaller facilities, which are quite often located in villages and suburbs. These residents belong to the list of GPs as much as any other patient in the community.

At the same time, there is an increased awareness and attention being given to chronic conditions. The focus is changing from cure to care. Home care, i.e. in-home services for both nursing care, and assistance in activities of daily living (ADL) and management of household activities are being developed as a means of offering people adequate care in their original living environments. This facility is available for all people with handicaps who live at home. Among parents of children with ID living at home, van Berkum \& Haveman (1995) found the need for advice, instruction and assistance in mursing and care was 30-50\% more than the actual use of these facilities.

Quite often, people with ID experience difficulties in verbalizing complaints or feelings of discomfort. By the nature of their handicap and the communication problems that exist between people with ID and their doctors, it is likely that the people will experience difficulty in cooperating with examination techniques which they don't understand (Day \& Jancar 1994). This is most striking when taking a blood sample or when taking cervical smears.

Intellectual Disability is not a disease. However, the cause of ID quite often predisposes a person to health problems. In this respect, the comorbidity of Down"s syndrome is most extensively studied (van Schrojenstein Lantman-de Valk et al. 1996), while the reference material on other circumscribed syndromes is growing fast (Carey 1992).

The International Classification of Primary Care (ICPC; Lamberts \& Wood 1987), was developed for GPs to provide insight into disease patterns, and to be able to compare their personal results with those available nationally and internationally.

To gain insight into the size and the characteristics of the population of people with ID living with their families, the Maastricht study on people with ID in general practice was initiated. The questions in this study were:

1. How many people with ID can be detected in a general practice database?

- Which people without $\mathrm{ID}$ are registered in the same manner?

- Is documentation available on the cause of the person's ID and/or on the level of ID?

2. Are there differences in age and gender stucture, and marital status between the people with ID and the other people in the general practice database? 
3. Under what codes are people with ID registered, and are these codes sufficientily defined?

4. How many persons with ID use home care facilities and which home care facilities are being used?

\section{METHOD}

The study was done with the help of the Registration Network Family Practices (RNH) within the University of Maastricht, The Netherlands.

This database is a cooperative effort of 15 practices ( $45 \mathrm{GPs}$ ) which record specified patient characteristics and all relevant health problems in a computerized health information system. (Metsemakers et al. 1992). This database contains information on 62,500 patients.

Health problems are registered according to the ICPC (Lamberts \& Wood,1987). This ICPC is based on the International Classification of Diseases (ICD) code system and is developed for use in general practice. The ICPC system has two axes. The first consist of chapters analogous to body systems (e.g. neurological, cardiac and ophthalmologic). These are coded alphabetically.

The second consists of several components (in two digits) referring to symptoms and signs (00-29), diagnostic and therapeutic interventions and referrals (30-69) and diagnoses (71-99).

The registration is limited to those health problems which affect the present functional status of the patients, or their future functioning. This means that only permanent problems (no recovery expected), chronic problems (duration longer than 6 months) or recurrent problems (at least three occurrences in last 6 months) are included.

The data on health problems and certain patient characteristics are registered in each physicians' record system. Anonymous data are transferred to the central data base every 3 monthis and may be used for research purposes. The ICPC system does not contain one exclusive code for ID.

Codes indicating possible intellectual disability were identified in a pilot study in one practice (3,000 patients). Selected codes were: N85, congenital disorders of the nervous system; P24, specific learning disorders; $\mathrm{P} 85$, mental retardation.

Using the opinion of a skilled physician as a 'Gold Standard', a sensitivity of $59 \%$ and a specificity of $99 \%$ were found in the pilot study by using these codes. It was decided to compose a sample of all people registered under these codes within the RNH and to check whether or not the selected people indeed had ID with the help of a questionnaire.

All 15 practices were invited to participate in this study by written request. Funding was available to pay for time investment by the general practitioners.

Eleven practices $(48,777$ patients) agreed to participate. Among the cooperating practices were five group practices, two single practitioners and four practices that were partnerships. The non-cooperating practices were two group practices and two single practitioners. The patients on the lists of included and non-included practices did not differ in age structure, gender structure or marital status. 
Questionnaires concerning each selected patient were sent out to their GP. The questionnaires were coded according to patient and practice number. This was anonymous to the researchers and could only be decoded in the administrative system of the patient's GP.

The questionnaire' deals with the following items:

1. the opinion of a GP as to whether or not this patient had ID, and if documentation was available to support or discard a diagnosis of ID;

2. a checklist to verify the diagnosis of ID;

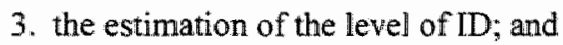

4. the use of home care by this patient.

The checklist was designed by the researchers and was discussed with several experts from general practice and/or from intellectual disability. It contained items which were found in the new AAMR definition (American Association on Mental Retardation 1992), such as whether or not the person had a subnormal intelligence and whether this had been clear before the age of 18 .

Further questions were whether or not the person experienced problems in comprehending active/passive language, whether or not she/he had problems in ADL and grooming, whether she/he he had a notion of time, and whether she/he could handle money and do shopping. All questionnaires were completed in the first half of 1996.

The first author of this article discussed unclear results by telephone with the GPs who completed the questionnaire. It was decided to use the opinion of each person's GP as the final criterion for diagnosis.

The results were coded in digits, and according to patient number and practice number, joined to the RNH database described above. Data analyses were performed with the BMDP program (Dixon et al. 1990).

\section{RESULTS}

\section{Response}

The response rate of the GPs after two reminders was $100 \%$. From the sample of 661 subjects with the selected codes, 16 persons $(2 \%)$ had either moved, died or were otherwise untwaceable.

\section{Number of people with intellectual disability}

Three hundred and eigtheen people, i.e $0.65 \%$ of the study population and $48 \%$ of the selected sample, appeared to have ID. Two hundred and ninety-four people, i.e. $45 \%$ of the sample, did not have ID. In 33 persons (5\%) the diagnosis was as yet incertain. Apart from two children with Down's syndrome, all children under 5 years of age were labeled as uncertain diagnoses.

\footnotetext{
1 See Appendix of this book
} 


\section{Documentation}

Documentation of the nature of the handicap, primarily originating from medical specialists, was present in $49 \%$ of the cases who had ID. Not surprisingly, documentation was more often avallable in younger people than in older subjects: in the group under the age of 15 years, $82 \%$ of the cases were documented, whereas in those above 50 years, documentation was available in only $32 \%$ of the cases. In the groups aged $16-30$ years and $31-50$ years, $57 \%$ and $35 \%$ of the cases were documented respectively.

Documentation most often originated from a pediatrician or a neurologist (Table 1). In 93 cases $(29 \%)$ documentation originated from one specialism. In 63 cases $(20 \%)$ documentation came from more than one discipline. In 16 cases $(5 \%)$ an early diagnosis team was involved in providing information; in one case the early diagnosis team was the only source of information.

Table 1 Origins of documentation on people with ID in general practice $(N=318)$ in $\%$ of total

\begin{tabular}{|c|c|c|c|c|}
\hline $\begin{array}{l}\text { Expert } \\
\text { abs N } \\
\end{array}$ & $\begin{array}{c}\text { No documentation } \\
162 \\
\end{array}$ & $\begin{array}{c}\text { one discipline } \\
93\end{array}$ & $\begin{array}{c}\text { Documentation preser } \\
\text { more disciplines } \\
63 \\
\end{array}$ & $\begin{array}{l}\text { total } \\
318 \\
\end{array}$ \\
\hline pediatrician & & 7 & 12 & 19 \\
\hline neurologist & & 5 & 11 & 16 \\
\hline psychiatrist & & 7 & 4 & 12 \\
\hline school physician & & 1 & 7 & 8 \\
\hline \multicolumn{2}{|c|}{ Early Diagnosis Team } & - & 5 & 5 \\
\hline other & & 6 & 6 & 12 \\
\hline
\end{tabular}

\section{Level of handicap}

Documentation of the level of ID was provided in 140 cases (44\%). For $178(56 \%)$ cases, only the estimation of the level of handicap by the GP was provided. About half of the sample was estimated to have mild ID.

Results regarding the skills of the people with ID as asked for in the checklist are shown in Table 2. About half of the sample had problems in ADL functions and/or a notion of time. Problems in using or understanding language and in handling money were reported in $75 \%$ of the people with ID.

Documentation of IQ was mentioned for 22 persons (7\%) with ID. Sixteen persons (5\%) out of those with ID were reported with an IQ above 70. Only one of these cases had no limitations in language, ADL, money handling or time awareness skills. For four of these 16 subjects, the questions about skills were not completed. 
Table 2 The skills of persons with ID $(\mathrm{N}=318)$ in $\%$

\begin{tabular}{lcccc}
\hline \multicolumn{1}{c}{ Skills } & no problem & slight problem & severe problem & not completed \\
\hline language active/passive & 24 & 49 & 18 & 10 \\
ADL functions & 48 & 30 & 12 & 1 \\
handling money & 26 & 36 & 22 & 17 \\
notion of time & 53 & 22 & 9 & 16 \\
\hline
\end{tabular}

\section{People without intellectual disability or with unclear diagnoses under the selected codes}

For the 294 persons who were not labeled as having ID, the questionnaire asked for reasons as to why people were coded under one of the three selected codes.

The reasons were: learning and /or language problem, 165 cases $(56 \%)$; neurologic condition, 60 cases $(20 \%)$; psychiatric condition, two cases $(1 \%)$; functioning after initial problems, 10 cases $(3 \%)$; environmental problems, 21 cases ( $7 \%$ ); too young (under 5 years of age), three cases $(1 \%)$; and not completed, 33 cases $(11 \%)$.

From those who were initally labeled as unclear diagnoses, one person appeared to have a clear $\mathbb{I D}$, but the parents of this 12 -year old child refused to accept the diagnosis. For eight persons, the diagnosis had become clearly not ID in the 6 months between completing the questionnaire and the phone-call by the first author. One 12-year-old boy with school problems improved after the divorce of his parents. A diagnosis that remained uncertain was the case of an 18-year old girl with severe epilepsy: the side-effects of medication may have further impeded her or impacted upon other causes of slowness.

\section{Differences in demographic characteristics}

The differences in age and gender stucture and other demografic characteristics between the group with ID and the other people in the same practices are shown in Table 3. The differences were remarkable. The age structure of the people with ID showed fewer persons over 50 years than in the other group, the male/female ratio was different, income and socioeconomic status of those with ID were inferior. Far fewer people with ID married. In the living arrangements section, group homes were mentioned in $15 \%$ of the cases. The difference in single-parent families was striking: there were $16 \%$ in the group with ID against $5 \%$ in the group without ID. 
Table 3 Demographic characteristics (\%) of people with ID $(\mathrm{N}=318)$ compared to other people in the same practices $(N=48443)^{i}$

\begin{tabular}{|c|c|c|c|c|c|}
\hline & IDt & ID- & & ID $\div$ & ID \\
\hline age groups & & & insurance status & & \\
\hline $0415 \mathrm{yt}$ & 21 & 18 & public health care & 92 & 70 \\
\hline $16-30 y r$ & 22 & 20 & insurance & & \\
\hline $31-50 y \mathrm{r}$ & 37 & 33 & private health care & 8 & 30 \\
\hline$>50 \mathrm{yr}$ & 20 & 30 & insurance & & \\
\hline gender & & & marital status & & \\
\hline male & 62 & 49 & married $^{3}$ & 16 & 54 \\
\hline \multirow[t]{2}{*}{ female } & 38 & 51 & single & 80 & 39 \\
\hline & & & other & 4 & 6 \\
\hline \multicolumn{6}{|l|}{ level of education } \\
\hline low & 70 & 42 & living arrangements & & \\
\hline moderate & 1 & 25 & familly ${ }^{3}$ & 47 & 76 \\
\hline high & - & 7 & alone & 12 & 10 \\
\hline \multirow[t]{3}{*}{ not completed } & 29 & 27 & group home & 15 & 1 \\
\hline & & & single parent family & 16 & 5 \\
\hline & & & other & 10 & 9 \\
\hline
\end{tabular}

'Peason's chi-square test: all differences between people with en without ID were significant at a level of $P<0.001$.

${ }^{7}$ including divorced, widowed and living together unmarried

${ }^{3}$ this category includes pairs with or without children.

\section{ICPC-codes}

A methodologically important question was under which of the three selected ICPC codes were the people with ID registered? Table 4 shows the relationship between diagnosis and ICPC code. Some $52 \%$ of the selected cases appeared to be false positives and had no intellectual disability. Furthermore, 15 persons ( $2 \%$ ) that were registered under other than the selected codes were added to the sample by the GPs. This regarded primarily people with Down's syndrome, coded under A90 (multiple congenital anomalies).

Table 4 ICPC codes in the sample in relation to diagnosis of $I D(N=661)^{*}$ (in $\%$, of column)

\begin{tabular}{|c|c|c|c|c|c|c|}
\hline \multirow[t]{2}{*}{ diagnosis } & \multirow[t]{2}{*}{ Abs $\mathbb{N}$} & \multicolumn{5}{|c|}{ code } \\
\hline & & P85 & $\mathrm{P} 24$ & N85 & other & total \\
\hline Abs. N & 661 & 296 & 266 & 79 & 4 & \\
\hline $\mathrm{ID}+$ & 318 & 84 & 20 & 18 & 50 & 48 \\
\hline ID & 294 & 11 & 75 & 79 & 50 & 45 \\
\hline ID? & 33 & 6 & 5 & 4 & - & 5 \\
\hline missing & 16 & - & - & - & - & 2 \\
\hline
\end{tabular}

* Legend: ID+ =people with intellectual disability

ID- =people without intellectual disability

ID? =people with uncertain diagnosis

P85 =mental retardation

P24 =specific learning disorder

N85 =congenital disorder of the nervous system 
It is clear that the majority of the people with ID are coded under P85 (mental retardation), although $17 \%$ of the people under this code either not did have ID or had a questionable diagnosis.

Under the other selected codes, P24 (specific learning disorder) and N85 (congenital disorder of the nervous system), the percentages of people with $\mathrm{ID}$ were $20 \%$ and $18 \%$, respectively.

\section{Home care facilities}

The question as to whether or not a person with ID used any form of home care, was answered positively for eight persons with ID. Four of them received household help and/or assistance in ADL, and two of them received help from a nurse. Three people received assistance from either a kindergarten or a retirement home.

\section{DISCUSSION}

To the best of the present authors' knowledge, this is the first study in which cases of people with ID were determined in a GP database.

An indication for the accuracy of the data is that the results were in line with the population study on the prevalence of people with ID in the Netherlands (Maas 1988). He collected information on people with ID living with their families and residentially and found $0.75 \%$ of the sample population had ID. One-quarter of those with ID lived in residential facilities. The present study collected information on people living at home and found that $0.65 \%$ of the population had ID. Assuming that this is three-quarters of the total population of people with ID, one might estimate that the total prevalence of people with ID is $0.82 \%$.

In Maas' (1988) study the age range was 4-70 years. His male:female ratio was 59:41; the present study results regarding male:female ratio were $62: 38$. Maas found that $20 \%$ of his sample in the 4-15-years-old age group and that $9 \%$ were in the 50 years and older age group. In the present study, $21 \%$ were under 15 years of age, and $20 \%$ were older than 50 years. Since the present study had no cut-off for older people, the results might be considered to be in line with Maas' (1988) results.

A limitation of the results might be that these could be biased by the fact that an overlap with other forms of handicap (e.g. psychiatric problems), especially in the group with mild mental handicap, will be present.

The question is whether or not GPS should be better trained to recognize people with ID. The opinion of the present authors on this point is, that there should be an agency to which people who are suspected of having ID can be referred. It is unnecessary to create a new facility. In the Netherlands, the expertise to perform these assessments is available in doctors and psychologists/educationalists working in centres for people with ID. These experts should be consulted to assess both the cause of the ID and the level of handicap. If necessary, advice regarding health problems which may occur with the established cause of ID should be given. Furthermore, in GP training and other postgraduate medical training, more attention should be given to the medical aspects of ID. 
Regarding home care, the results of this study indicated that GPs quite often do not know if their patients with $\mathbb{I D}$ use home care facilities. Some GPs referred to home care organizations (e.g. for help with dressing and grooming). Registration of these referrals in a GP database were rare. In group practices GPs quite often discussed their patients who did use home care facilities in so-called "home-teams". A home team is a bi-weekly or monthly meeting of doctors nurses and all other home care providers at which clients and their problems are discussed. Minutes of these meeting were not added to the GPs database. The present authors have the impression that the availability of care support affects the well being, if not of the person itself, at least of her/his family members (Penninx 1996). The higher percentage of single parents' families in families with a member with ID found in this study might indicate that the burden is heavy.

Therefore, it would be helpful if the GP at least had all information regarding handicaps and use of care facilities for people with ID in his practice at his disposal. A simple method to find all candidates in a GPs case load thus might be desirable. An easy way of doing this would be a special code for people with ID in the patient data base.

A further study is necessary to develop an adequate coding system for people with ID and to determine how this should be implemented. Health care for people with ID living in the community can be improved by having easy access to data that indicate which people are entitled to extra attention: This will be even more desirable when the relatively small group of people with severe and profound ID found in general practice in this study was will be expanded by the group of people who will leave the institutes and be housed in living facilities in the community in the near future. 


\section{REFERENCES}

AAMR (1992) Mental retardation. Definition, classification and systems of supports. AAMR, Washington DC USA.

Berkum H.W. van \& Haveman M.J. (1995) Zorg aan huis. Behoefie aan zorg. gebrik wan zorg en discrepantie inssen waag en aanbod ander ouders wan versiandelijk gehandicapten in Zuid- Nederland. Department of Epidemiology, University of Limburg, Maastricht.

Carey J.C. (1992) Health supervision and anticipatory guidance for children with gentetic disorders (including specific recommendations for trisomy 21 , trisomy 18 and neurofibromatosis 1). Pediatric Chinics of North America 39, 25-53.

Day K.A. \& Jancar J. (1994) Mental and physical health and ageing in mental handicap: a review. Jow nal of Invellectual Disability Research 38, 241-56.

Dixon W.J., Brown M.B., Engelman I. \& Jennrich R.I. (1990) BMDP statistical soffware manual. Volume II. University of California Press. Berkeley/Los Angeles/ Oxford.

Howells G., Barker M. (1990) Primary care for people with a mental handicap. Occasional Paper 47. Royal College of General Practitioners, London.

Kerr M., Dunstan F. \& Thapar A. (1996) Attitudes of general practitioners to caring for people with learning disability. British Journal of General Practice 46, 92-4.

Lamberts H. \& Wood M. eds. (1987) ICPC International Classification of Primary Cafe Oxford University Press, Oxford.

Maas J.M.A.G., Serail S. \& Janssen A.J.M. (1988) Frequentie-onderzoek geestelijk gehandicapten 1986. IVA Tillburg.

Metsemakers J.F.M., Höppener P., Knottnerus J.A., Kocken R.J. \& Limonard C.B. (1992) Computerized health information in the Netherlands: a registration metwork of family practices. British Journal of General Practice 42, $102-6$.

Penninx B.W.J.H. (1996) Social support in elderly people with chronic diseases. Does it really help? PhD. Thesis, Free University, Amsterdam, the Netherlands.

Schrojemstein Lantman-de Valk H.M.J. van, Haveman M.J. \& Crebolder H.F.J.M. (1996) Comorbidity in people with Down's syndrome: a criteria-based analysis. Joumal of Intellectual Disability Research $40,385-99$.

Welsh Health Planning Forum (1992) Protocol for Imvestmemt in Health Gain, Mental Handicap (Learning Disabilities). University of Wales, Cardiff. 


\section{HEALTH PROBLEMS IN PEOPLE WTTH INTELLECTUAL DISABILITY IN GENERAL PRACTICE: A COMPARATIVE STUDY}

\section{Summary}

Background: Unmet health needs of people with Intellectual Disability (ID) were reported from several countries. As yet, no study could be found, that compared health problems of people with ID to those of people without ID and registered in the same database.

Aim: To examine the differences in prevalence of health problems in people with and without Intellectual Disability (ID) in general practice.

Method: In an anonymous computerized database of general practices cooperating with the Department of General Practice, Maastricht University, people with ID were detected. There were 318 persons with and 48,443 persons without ID. Both groups were compared as to number and nature of health problems.

Results: People with severe ID had 2.7 times more health problems than people without ID; people with mild ID had 2.2 times more problems.

People with severe ID had more congenital disorders, epilepsy and strabismus. People with mild ID showed a higher prevalence of deafness, adipositas, fractures, skin problems and hemorroids.

Conclusions: Some of the health problems (for example epilepsy, deafness, strabismus) were related to the cause of $I D$, whereas other health problems (obesity, fractures) may be related to external circumstances. Consequences for prevention, early detection and treatment are discussed.

Dementia and gastrointestinal problems, despite the high prevalence rate in people with ID using residential living services, were not reported in this study. This result may change as the closing down of large residential facilities proceeds. Individual health plans for each person with $\mathrm{LD}$ based on the personal risk factors are necommended.

Submitted for publication: Schrojenstein Lantman-de Valk H.M.J. van, Metsemakers J.F.M., Haveman M. J. \& Crebolder H.F.J.M. Health Problems in people with intellectual disability in general practice: a comparative study. 


\section{INTRODUCTION}

At this time in the Netherlands, institutions for people with intellectual disability (ID) are being divided into smaller facilities which are quite often located within villages and suburbs. One of the intentions of this policy is to stimulate community integration (Ministry of Health, Welfare and Sports 1996).

Considerably more people with ID are going to be living within the community. The primary medical care has to be provided by general practitioners (GPs). It is as yet unknown what the impact of this change in workload will be in the future.

Health care researchers from other countries like the US and the UK report that the process of deinstitutionalization which took place in the 1980s has led to unmet health needs of people with ID (Turner \& Moss 1996, Walsh et al. 1997). It is therefore necessary to study the health problems of people with ID to determine the consequences for the GP. Quite a few studies have dealt with the increase of health problems in people with $I D$ in relation to age but they were limited to a sample which consisted exclusively of people with ID (Janicki \& Jacobson 1986, Haveman \& Maaskant 1989, Moss et al. 1993, van Schrojenstein Lantman et al. 1996). No studies could be found that compared health problems of people with and without ID within one sample.

The aim of the present study was to examine the differences in prevalence rates of health problems in people with and without $\mathrm{D}$ who are currently being served by general practices.

\section{PATIENTS AND METHODS}

\section{Data base}

This study was done within the Registration Network Family Practices (RNH) of Maastricht University in the Netherlands. This RNH has been established primarily as an opportunity for researchers to obtain samples. The main goal of this network was to establish an anonymous computerized database which contained various patient characteristics and included all relevant health problems (Metsemakers et al. 1992). A health problem is defined as 'anything that has required, does require or may require health care management and has affected or could significantly affect a person's physical or emotional wellbeing'. Health problems were recorded by the GPs only if they are permanent (no recovery expected), chronic (duration longer than 6 months) or recurrent (more than three recurrences within 6 months). All health problems are coded according to the International Classification of Primary Care (ICPC) (Lamberts \& Wood eds. 1987). The GPs participating in the RNH use computerized systems to store and continuously update the medical records of all patients registered with their practice. The present study was done on the data base on file in January 1996.

The data on health problems and diagnoses in the computerized medical records of the RNH have shown to be reliable (Metsemakers 1994). 


\section{Persons involved in the study}

Case identification of people with ID was achieved by the use of questionnaires defining ID according to the American Association of Mental Retardation (AAMR, 1992). The questionnaires were completed by the GPs for patients identified as possibly having ID based on the ICPC codes P85 (mental retardation), P24 (leaming disability) and N85 (congenital netrologic disorder). The full procedure was described in a previous article (Van Schrojenstein Lantman et al. in press). Three hundred eighteen (318) persons with ID were identified. The data concerning these people were compared to those data on 48,443 persons without ID within the data base. There was a difference in the age range percentages between the people with and without ID. Twenty percent of the people with ID and $30 \%$ of the people without ID were older than 50. There were also differences in the male:female ratio (62\% male:38 \% female for people with ID compared to $49 \%$ male and $51 \%$ female for people without ID). Fifty three percent of the people with ID had a mild disability.

\section{Statistical analysis}

All analyses were performed with the Bio Medical Data Package (BMDP) (Dixon et al. 1990). The people with ID and those without ID were compared to each other as to the number of diagnoses and as to the nature of these diagnoses.

The number of diagnoses was calculated by adding up the number of diagnosis codes each person had been assigned. For the people with ID, the number of diagnoses was diminished by 1 , to account for the code for $\mathbb{I D}$. The differences in health problems were then studied on the level of organ systems, based on chapters in the ICPC system. Subsequently, the differences in prevalence rate per diagnostic code in the ICPC system were analyzed. As a measure of difference the odds ratio (OR) and its $95 \%$ confidence interval was chosen. If the OR did not include 1, backward stepwise logistic regression analyses were performed in order to exclude influences from confounding variables. Here, the presence of a disorder was the dependent variable. As potential confounders, the level of handicap, age and gender were each analyzed as independent variables. As a reference group for ID the people without ID were chosen. The level of handicap was estimated by the GP as mild or severe. In terms of age, the group with the largest number of members (31-50 years of age) was chosen as a reference group. Male was chosen as the refence group for gender.

With regard to logistic regression analysis, only the significant results were included in this report.

\section{RESULTS}

The number of health problems in the people with severe or mild ID and the number of health problems for those without ID are shown in Table 1. For persons with severe $\mathbb{E D}$, the percentage of people with health problems was the largest, followed by people with mild ID. The least health problems were seen in those without $\mathbb{D}$. A backward stepwise logistic 
regression analysis was performed with the presence of health problems as the dependent variable, and the above mentioned as independent variables. It appears that for people with mild disability the risk for health problems is 2.2 times more than for people without $\mathrm{DD}$. For people with severe ID the risk is 2.7 times greater than for people without ID.

Table 1 Total number of health problems* in people with mild or severe ID or without ID (column \% )

\begin{tabular}{ccccc}
\hline $\begin{array}{c}\text { Number of health problems } \\
\text { A.bs.N }\end{array}$ & $\begin{array}{c}\text { without ID } \\
48443\end{array}$ & mild ID & severe ID & total \\
\hline none & 21 & 169 & 135 & 48747 ** \\
\hline 1 & 22 & 21 & 10 & 21 \\
$2-5$ & 43 & 51 & 16 & 22 \\
$>5$ & 14 & 15 & 59 & 43 \\
\hline
\end{tabular}

* the code for ID was excluded from this calculation

* 16 persons had incomplete data; in 14 persons with ID the level of ID was unknown

Table 2 Prevalence rate of health problems ( in \%) per body tract. Crude odds ratios of differences between people with ID $(I D+2 N=318)$ and people without ID $(I D-;=48443)$ in general practices and results of backward stepwise logistic regression analysis ( $95 \%$ confidence interval between brackets).

\begin{tabular}{|c|c|c|c|c|c|c|}
\hline & Tract & $\mathrm{ID}+$ & ID- & crude $O R$ & $\begin{array}{l}\text { mild ID/ID- } \\
* * * *\end{array}$ & $\begin{array}{c}\text { severe ID/ID- } \\
\text { * }\end{array}$ \\
\hline $\mathrm{N}$ & neurological & 22.3 & 8.8 & $3.0(2.3-4.0)$ & $3.0(2.1-4.5)$ & $4.0(2.7-6.0)$ \\
\hline $\mathbf{P}$ & psychological & 16.7 & 7.8 & $2.4(1.7-3.2)$ & $3.1(2.0-4.6)$ & $2.6(1.6-4.2)$ \\
\hline $\mathrm{H}$ & ear & 16.0 & 915 & $1.8(1.3-2.5)$ & $2.0(1.3-3.0)$ & $1.7(1.0 .2 .7)$ \\
\hline F & eye & 11.9 & 7.4 & $1.7(1.2-2.4)$ & $1.8(1.1-3.0)$ & $2.6(1.6-2.4)$ \\
\hline A & general and unspecified. & 22.3 & 15.4 & $1.6(1.2-2.1)$ & $1.5(1.0-2.2)$ & $2.0(1.4-3.0)$ \\
\hline \multirow[t]{2}{*}{$\mathrm{T}$} & endocrine, metabolic and & & & & & \\
\hline & nutritional & 17.9 & 12.9 & $1.5(1.1-2.0)$ & $2.1(1.4-3.1)$ & $2.0(1.3-3.2)$ \\
\hline $\mathrm{L}$ & musculoskeletal & 34.0 & 30.7 & $1.2(0.9-1.5)$ & - & $1.5(1.0-2.1)$ \\
\hline$Y$ & male genital system ** & 11.2 & 9.2 & $1.2(0.8-2.0)$ & $1.8(1.0-3.1)$ & \\
\hline$\$$ & skin & 17.6 & 15.7 & $1.1(0.8-1.5)$ & & \\
\hline $\mathrm{B}$ & blood/bloodorgams & 2.2 & 2.1 & $1.0(0.5-2.3)$ & & \\
\hline $\mathrm{R}$ & respiratory tract & 22.6 & 26.3 & $0.8(0.6-1.0)$ & & \\
\hline $\mathrm{D}$ & digestive tract & 15.1 & $20: 2$ & $0.7(0.5-1.0)$ & & \\
\hline $\mathrm{U}$ & urology & 4.4 & 6.0 & $0.7(0.4-1.3)$ & & \\
\hline$x$ & female genital system* & 13.9 & 19.2 & $0.7(0.4-1.2)$ & & \\
\hline $\mathbf{K}$ & circulatory tract & 15.1 & 20.7 & $0.7(0.5-0.9)$ & & \\
\hline
\end{tabular}


The difference in prevalence rate of health problems per body tract between people with ID and people without ID is shown in Table 2. The results are ranked from high OR to low $O R$. The highest ORs found are for neurological and psychological problems. Lower ORs are found for ear and eye problems, 'general and unspecified" health problems and endocrine, metabolic and nutritional disorders. An OR smaller than 1-meaning that the risk for people with ID is smaller than for those without ID - is only found for diseases of the circulatory tract. People with severe ID appeared to have the highest risk for neurological disorders, eye problems, endocrine and metabolic disorders and general health problems. People with mild ID had a higher risk for psychological problems and ear disorders.

The results for circumscript health problems are shown in Table 3 . Only those disorders that were registered in 10 or more persons with ID, and for which the crude OR did not include 1 were presented. The most striking results are those from the backward stepwise logistic regression analysis. ORs on congenital anomalies, neurological disorders, musculoskeletal impairments, epilepsy and strabismus are higher for people with severe ID. Perinatal morbidity, deafness, lower leg fractures, obesity and skin problems reflected higher ORs in people with mild ID.

Table 3 Absolute number of patients $(\mathrm{N})$ in people with $\mathrm{ID}(\mathrm{ID}+\mathrm{N}=318)$ and prevalence rate $(\%)$ of health problems in people with or without (ID-; $N=48443$ ). Crude odds ratios and results of backward stepwise logistic regression analysis ( $95 \%$ confidence interval between brackets).

\begin{tabular}{|c|c|c|c|c|c|c|c|}
\hline Code & Health problem & $\mathbf{N}$ & $\mathrm{ID}+$ & ID- & crude $\overline{\mathrm{OR}}$ & mild IDID** & severe ID/D-* \\
\hline$\overline{A 90}$ & $\begin{array}{l}\text { multiple congenital } \\
\text { anomalies }\end{array}$ & 16 & 5.0 & 0.4 & $14.7(8.3-25.4)$ & $6.2(2.3-17.1)$ & $25.8(13.9-47.7)$ \\
\hline N88 & epilepsy & 35 & 11.0 & 0.8 & $15.0(10.2-21.9)$ & $13.9(8.3-23.3)$ & $19.3(11.6-32.1)$ \\
\hline L28 & $\begin{array}{l}\text { disability/impairment } \\
\text { musculo-skeletal }\end{array}$ & 19 & 6.0 & 0.5 & $\mathbb{1 1 . 8 ( 7 . 0 - 1 9 . 5 )}$ & $12.5(6.3-25.0)$ & $15.4(7.7-30.0)$ \\
\hline Fo5 & strabismus & 17 & 5.3 & 1.1 & $5.0(3.0-8.5)$ & $3.1(1.4-7.0)$ & $7.5(4.0-14.2)$ \\
\hline A.93 & $\begin{array}{l}\text { premature/immature } \\
\text { liveborn infant: }\end{array}$ & 13 & 4.1 & 0.9 & $4.7(2.6-8.5)$ & $5.1(2.4-10.8)$ & $3.9(1.5 \sim 9.8)$ \\
\hline N99 & other disorders CNS & 14 & 4.4 & 1.1 & $4.0(2.2-7.0)$ & $3.6(1.6-8.1)$ & $6.1(3.0-12.5)$ \\
\hline A94 & all perinatal morbidity & 17 & 5.3 & 1.5 & $3.7(2.1-6.1)$ & $3.7(1.9-7.4)$ & $2.7(1.1-6.3)$ \\
\hline H86 & deafness & 20 & 6.3 & 2.3 & $2.8(1.7-4.5)$ & $3.8(2.0-6.9)$ & $2.2(1.0-5.1)$ \\
\hline$\llcorner 73$ & fracture lower leg & 16 & 5.0 & 1.9 & $2.8(1.6-4.7)$ & $4.0(2.2-7.3)$ & - \\
\hline $\mathrm{T} 82$ & obesity $\mathrm{Ql}>30$ & 28 & 8.8 & 3.5 & $2.6(1.8-4.0)$ & $4.1(2.5-6.9)$ & $2.6(1.4-5.0)$ \\
\hline L82 & $\begin{array}{l}\text { congenital anomalies } \\
\text { musculo-skeletal system }\end{array}$ & 10 & 3.1 & 1.3 & $2.4(1.2-4.8)$ & - & $3.3(1.5-7.6)$ \\
\hline$\$ 96$ & acne & 13 & 4.1 & 1.6 & $25(1.4-4.6)$ & $3.2(1.6-6.3)$ & - \\
\hline$\$ 88$ & $\begin{array}{l}\text { contactdematitis or } \\
\text { other eczema }\end{array}$ & 18 & 5.7 & 2.9 & $2.0(1.2-3.3)$ & $2.5(1.4-4.7)$ & - \\
\hline$k 96$ & hemorroids & $1 \|$ & 3.5 & 1.8 & $2.0(1.0-3.6)$ & $2.2(1.0-5.1)$ & - \\
\hline T83 & overweight $Q \mathrm{l}>25$ & 13 & 4.1 & 2.3 & $1.8(1.0-3.2)$ & - & $2.6(1.2-5.7)$ \\
\hline R90 & $\begin{array}{l}\text { hypertrophy/chronic } \\
\text { infection tonsills/adenoid }\end{array}$ & 35 & 11.0 & 7.0 & $1.6(1.1-2.3)$ & $=$ & - \\
\hline
\end{tabular}

* these columns refer to the results of backward stepwise logistic regression analysis 


\section{DISCUSSION}

It was logical to expect that perinatal problems, motor handicap and epilepsy would be found more often in people with ID. Perinatal problems may have caused the brain dysfunction, which manifested itself as ID, motor handicap and/or epilepsy.

However, there are some other results of this study that require further attention.

In this present study, the prevalence rates of sensory impairments for people with ID were much higher than in people without ID. Most studies which were restricted exclusively to people with ID (van Schrojenstein Lantman et al. 1996, Evenhuis 1995, Warburg 1994), reported yet higher prevalence rates for both visual and hearing problems. Routine screening for sensory impairments is often not feasible for children or adults with severe ID (Warburg 1995). There is a need for adjusted diagnostic methods to assess these impaiments in people with severe disabilities. Providing necessary hearing aids and visual appliances will result in a health gain for this group.

While the above health problems are clearly related to the cause of $\mathrm{ID}$, the following conditions seem more related to external circumstances, such as lack of exercise, poor mobility, poor eating habits, medication use etc. (Prasher 1995, Tannenbaum et al. 1989), that are presently characteristic for people with ID.

This is an applicable assumption for obesity (Q1>30). It seems contradictory that this condition is more often observed in people with mild ID. This might be due to the fact that these people - being more mobile than people with severe ID - have more opportunities to obtain additional foods. For those with severe ID weight monitoring is more difficult, especially in wheelchair-bound people or people who are less ambulatory.

The high prevalence rate of fractures, especially lower leg fractures could have similar causes for the higher frequency for people with mild ID. This might again be correlated to being less restricted in mobility than people with severe ID, but being more prone to accidents. Haemorrhoids most often are reported in combination with constipation. Risk factors such as medication use or dietary insufficiency (Stewart et al. 1992) are again more frequent in this group.

Preventive activities for people with ID would focus on lifestyle change and patient education using basic language with an ample use of drawings, comics and videos with the goal of reducing morbidity due to lifestyles and external circumstances.

Skin problems (acne, contact dermatitis) appeared to be a problem more often in people with mild ID than in those with severe ID. This is probably caused by overshadowing: people with severe ID have so much other problems that these minor health problems are overlooked.

Although people with ID in this study appeared to have a lower risk for circulatory problems than people without ID, no single disorder was found that was represented in at least 10 cases and could therefore be included in our study. The low prevalence of hypertension and other cardiovascular problems was also found in a study on residential living people with ID (van Schrojenstein Lantman et al. 1996). In contrast to these results, a study in the US reported a higher risk for cardiovascular disease in a group of people with ID (Rimmer et al. 1994). 
Some health problems which were reflected in high prevalence rates in residential living people with ID (van Schrojenstein Lantman et al. 1996) were not found in this study. There were no cases of dementia in people with ID in the present study. This might mean that dementia was either not present in this sample with few people older than age 50, or was not experienced as an additional problem in people with ID living at home.

The absence of gastro-intestinal problems in this present study is also striking. Risk factors for these disorders are being non-ambulatory, having a more severe level of $I D$, cerebral palsy and using anticonvulsants (Böhmer 1996). If most people with ID having these diagnoses are still to be found in large residential facilities in the Netherlands, this data will change in the near future.

\section{CONCLUSION}

The present study showed that people with ID have twice as many health problems as people without ID. The number of health problems may be higher for the people with ID who are leaving residential facilities and returning in the community.

This fact, combined with the communication problems experienced by people with ID both in expressing their concern about their own health and in cooperating with examination techniques (Day \& Jancar 1994), and, due to the nature of their handicap, having limited insight in regard to their own health, justifies a more proactive attitude towards this group by the GPs'. Special training will be necessary both for GPs and their practice personnel.

In a recent study evaluating the medical, psychiatric and dental status of 41 elderly people with ID living in the community, a mean number of two additional diagnoses, that were not recorded before in the patient files, for each person was found. This regarded primarily treatable disorders (Carlsen et al. 1994). It seems worthwhile, to develop individual health plans for each person with ID based on the personal risk factors as identified in a medical assessment of the person and in consultation with his family and caregivers.

\footnotetext{
'Given these communication problems, it is conceivable that underreporting occurs more frequently in people with ID than in other people
} 


\section{REFERENCES}

AAMR (1992) Mental retardation. Definition, classification and systems of supports. AAMR, Washington DC. Böhmer C. (1996) Gastro-oesophageal reflux disease in intellecrually disab̆led individuals. Ph.D. Thesis, Free University Amsterdam.

Carlsen W.R., Galluzi K.E., Forman L.F. \& Cavalieri T.A. (1994) Conprehensive Geriatric Assessment: Applications for Community-Residing, Elderly People with Mental Retardation/ Developmental Disabilities. Mental Retardation 32, 334-40.

Day K.A. \& Jancar J. (1994) Mental and physical health and ageing in mental handicap: a review. Jowrnal of Intellectual Disability Research 38, 241-56.

Dixon W.J., Brown M.B., Engelman I. \& Jennrich R.I. (1990) BMDP statistical soffrare manual. Volume II. University of Califormia Press, Berkeley/Los Angeles/Oxford.

Evenhuis H.M. (1995) Medical aspects of ageing in a population with intellectual disability: I1. hearing impairment. Journal of Intellectual Disability Research 39, 27-33.

Haveman M.J.\& Maaskant M.A. (1989) Defining fragility of the elderly severely mentaliy handicapped according to mortality risk, morbidity, motor handicaps and social functioning. Joumal of Mental Deficiency Research 33, 389-97.

Janicki M.P. \& Jacobson J.W. (1986) Generational trends in sensary, physical and behavioral abilities among older mentally retarted persons. American Journal of Mental Deficiency $90,490-500$.

Lamberts H. \& Wood M. (eds) (1987) ICPC Imternational Classiffcation of Primary Care. Oxford University Press, Oxford.

Metsemakers J.F.M., Höppener P., Knotnerus J.A., Kocken R.J. \& Limonard C.B. (1992) Computerized health information in the Netherlands: a registration network of family practices. British Journal of General Practice 42, $102-6$.

Metsemakers J.F.M.(1994) Unlocking parients' records in general practice for research, medical education and quality assurance: The Registration Network Family practices. PhD Thesis. Thesis publishers, Amsterdam.

Ministry of Health, Welfare and Sports.(1996) Actualization 1996 of the lang term program for an intersectoral policy an the handicapped 1995-1998: Beyond Limitations. Ministery of Health, Welfare and Sports, The Hague.

Mass S., Goldberg D., Patel P. \& Wilkin D. (1993) Physical morbidity in older people with moderate, severe and profound mental handicap and its relation to psychiatric morbidity. Social Psychiatry Psychiartic Epictemiology 28, 32-9.

Prasher V.P. (1995) Overweight and obesity amongst Down's syndrome adults. Journal of Invellectual Disability Research 39, 437-41.

Rimmer J.H., Braddock D. \& Fujiura G. (1994) Cardiovascular risks in adults with mental retardation. American Journal on Mental Retardation 98, $510-8$.

Schrojenstein Lantman-de Valk H.M.y. van, Akker M. van den, Maaskant M.A., Haveman M.J., Urlings H.F.J., Kessels A.G.H. \& Crebolder H.F.J.M. (1996). Prevalence and incidence of health problems in people with intellectual disability. Journat of Intellectual Disability Research 40,535-43.

Schrojenstein Lantman-de Valk H.M.J, van, Metsemakers J.F.M., Soomers-Turlings M.S.J.G., Havernan M.J. \& Crebolder H.F.J.M. People with Intellectual Disability in general practice: case definition and case finding. Journal of Intellectual Disability Research 41, 373-79

Stewart R.B., Moore M.T., Marks R.G. Hale W.E. (1992) Correlates of constipation in an ambulatory elderly popullation. American Journal of Gastraenterology 87, 859-64. 
Tannenbaum T.M. Lipworth L. Baker S. (1989) Risk of fractures in an intermediate care facility for persons with mental retardation. American Journal on Mental Retardation 93, 444-51.

Turner S. \& Moss S. (1996) The health needs of adults with learning disabilities and the Health of the Nation strategy. Journal of intellectual Disablity Research 40, 438-50.

Walsh K.K., Kastner T. \& Criscione T. (1997) Characteristics of hospitalizations for people with developmental disabilities: Utilization, costs, and impact of care coordination. American Journal on Mental Retardation 101, 505-20.

Warburg M.(1994) Visual impainnent among people with developmental delay, Joumal of Intellectual Disability Research 38, 423-32. 


\section{CHAPTER 8}

\section{GENERAL DISCUSSION}

This chapter will present a summary of the study, followed by an account of the methodological considerations regarding the study as a whole, a discussion of the results and a list of recommendations regarding health care provision and issues requiring further study. 


\section{SUMMARY OF THE CHAPTERS}

Chapter 1 outlines the framework of this thesis and presents an overview of the changes in the role of the people with intellectual disability (ID) and its resultant impact on service provision, offers a rationale as to why attention to the health problems in people with ID is justified, and presents the study questions. The study questions regard the health problems of people with ID living in residential facilities, the health problems of people with ID living in the community and receiving medical care through the registration in general practice (the means of health care for the general population of the Netherlands) and the phenomenon of multimorbidity. Chapter 2 decribes the prevalence and incidence rate of health problems of people with ID who live in residential facilities. Chapter 3 and 4 discuss in more detail two important health problems in this group, those of sensory impaiment and medication use: Chapter 5 presents the results of a literature analysis on the multimorbidity in people with Down's syndrome. Chapter 6 and 7 deal with the results of a study on people registered with general practices, with chapter 6 offering the case definition and the casefinding of people with ID within the registration system of the cooperating general practitioners (GPs) and chapter 7 describing the differences between health problems between people with ID and those without ID in the same practices. 


\section{METHODOLOGICAL CONSIDERATIONS}

\section{Case identification}

There was no problem identifying the people with ID receiving services in either group homes or institutes in the Netherlands as assessment of ID was an admission criterion for both. However, as there is no formal registration of people with ID who do not reside in such services, the identificaton of people with ID who were registered in general practices was considerably more of a challenge. The Registration Network Family Practices (RNH), the database which served as the basis of the general practices study, registers health problems according to the International Classification Primary Care (ICPC) (Metsemakers et al. 1992). This classification contains no exclusive code for ID.

In the pilot study, it was recognized that the ICPC codes selected because they would detect the majority of the people with ID, would not, in fact identify everyone. For this reason, participating GPs were asked to include other patients known to have ID who were not identified by the preselected codes.

To ascertain the cases of people with ID, questionnaires were developed that had to be completed by the GPs for patients registered under preselected codes. The questionnaires for assessment of ID in people registered in general practices were designed with the help of experts and were based on the new AAMR definition (1992). With the help of a few reminders, the response rate in the definitive study was $100 \%$. Cooperation of the participating GPs was optimal.

Three hundred and eighteen (318) out of the 661 selected cases were identified as having ID. 294 persons out of this sample had no ID. Most of these 294 had language or learning disorders or neurological conditions. The prevalence of ID resulting from this study was $0,65 \%$ people with $\mathrm{ID}$ in this population. This was in line with the earlier study of Maas (1988). Therefore, it was concluded that the casefinding method was adequate. However, the casefinding may have overlapped some people with mild ID and people with psychiatric conditions resulting in this group being incorrectly included or excluded.

\section{Reporting health problems}

The results of the residential facility study were all based on questionnaires. Health problems mentioned in the patient files that did not fit into the formulated questions, may have remained unnoticed. Furthermore, completion of the questionnaires was dependent on the quality of the patient tiles, which was not assessed.

The results of the GP study were based on the diagnosis codes registered in the RNH. Health problems at the level of complaints, which also may be registered in the RNH, were not included in this study. This was done in order to maximize the potential for comparing the results of the GP study to that of the residential study which was only based on diagnoses. A possible source of incompleteness is the fact that GPs only register health problems presented to them by either the patient, a farnily member, the caregiver or other medical specialists. Health problems that are not recognized, such as sensory impairments, would not be stored in 
the database. A certain degree of underreporting of health problems must also be assumed. Since the RNH data base contained no data on prescriptions, medication use of the people receiving services from the GP was not studied.

\section{DISCUSSION OF THE MAIN RESULTS}

\section{Health problems of people with ID}

Quite a few health problems were reported in both studies. Rather than discussing the health problems of people with ID in residential facilities versus those of people with ID registered in a general practice, it seemed more sensible to discern health problems which were related to the disability and those due to external conditions. After a discussion of both types of health problems, differences between people living in residential facilities and people with ID who live with their families or on their own were highlighted.

Comparing the results from the people living in residential facilities and from people with ID receiving services from general practices had its limitations, since the study methodology and populations were different. On the other hand, the health problems questionnaire used for those living in residential facilities and the ICPC code system that was used in the study of those people living in the community and registered in general practices were both based on the same ICD-9 system.

In respect to health problems related to the nature of the disability, all manifestations of brain dysfunction other than intellectual disability were considered. Most striking in both the study of residential facilities and the study of GPs were the sensory impairments. The prevalence rate of visual impairment in the study of people with ID living in residential facilities was $19 \%$ compared to $12 \%$ of the people with ID receiving medical care from GPs in the community. The prevalence rate of hearing impairment was $12 \%$ and $16 \%$ respectively. Epilepsy was also frequently reported in both studies, with a prevalence of $16 \%$ in the study of residential facilities and $11 \%$ in the study of people with ID receiving medical care from community GPs. In the study of residential facilities, cerebral palsy, which bad a distinct code in this study was reported as a frequent problem with a prevalence of $12 \%$, while in the study of people with ID served by GPs in the community the code reflecting congenital anomalies of the musculoskeletal system (which might refer to the same problem) showed a prevalence of $3 \%$. In the study of residential facilities, psychiatric disorders were mentioned in $25 \%$, compared to $17 \%$ in the study of people being served in the community. Health problems caused by external conditions reported in the residential facility study were mainly gastrointestinal $(7 \%)$ whereas in the study of people with ID receiving medical care in the community, obesity ( $9 \%$ ), being overweight $(4 \%)$, lower leg fractures $(5 \%)$, skin problems $(10 \%)$, and hemorrhoids ( $4 \%)$ were reported in this category. In the following paragraphs, the most important health problems will be considered in more detail. 


\section{Health problems related to the nature of the disability}

Sensory impairments deserve far more attention from health care professionals. Having an intellectual disability and an unrecognized sensory impairment is a distinct disadvantage in developing one's intellectual potential. Screening for these impairments may either provide people with adequate glasses or hearing aids, or may make them eligible for treatment as a visually or auditorily impaired person. A recent study of Dutch general practices (Mul et al. 1997) detected 83 of 206 people with ID in the sample as having a hearing impairment. In $80 \%$ of these cases, this diagnosis was unknown to their GP and their caregivers.

The problem in detecting these disorders is that routine screening is often inadequate (Evenhuis, 1995a, 1995b). People with severe or profound ID rarely understand what is being asked of them to participate in an audiometric exam, and are also often unable to identify pictures as is required in a vision exam. In the Netherlands, a consensus protocol as to the diagnosis and treatment of hearing impairment in people with ID has been developed (Evenhuis 1996). A consensus on the diagnosis and treatment of visual impairment is now in progress (NVAZ 1997). Both protocols have not yet been introduced to GPs. The proposed new screening methods are time consuming. Time is also needed to establish rapport and to learn how the person with ID can express himself. Using these methods, however, prevents impairments from having gone undetected. Adequate screening will offer better opportunities for the person's development. Early detection might diminish the functional level of disability and is likely to positively influence the person's capacities to participate in ordinary life.

Other health problems related to the disability which require attention are epilepsy and cerebral palsy or motor problems. Although these conditions could best be monitored by neurologists and rehabilitation physicians, the GP, being the gatekeeper to all other health care facilities, needs to be aware of the key issues. People with epilepsy inevitably have to use medication. Anticonvulsants quite often interact with other medication prescribed by the GP or by another specialist. Regular evaluation of the medication used by each person with ID is mo luxury. Wilson \& Haire (1990) reported that in their sample of people with ID registered in general practice and taking medication, only 11 out of 27 persons had regular prescription evaluations.

In people with cerebral palsy, regular evaluation of motor problems is important. Bax er al. (1988) found lower joint contractures in 61 out of 104 young adults with motor problems. Here, the role of the GP may be that of the family guide (Schade 1996), who maintains the oversight and knows where and how to refer the person with ID and his carers once they are too old for pediatric services.

\section{Health problems related to external conditions}

In obesity, fractures and haemorrhoids, causal factors as lack of exercise, being less mobile, medication use and inadequate food intake play a role. Health gain for people with ID with regard to these disorders can be best achieved by prevention. This can be realized by information, stimulation of exercise and evaluation of medication use. For people with a mild $I D$, generally functioning on the cognitive level of an 8-10 year old child, adequate 
information preferably on his/her level of understanding such as easy-to-read information, comics, videos, etc. may be helpful. Advice given in everyday terms by a dietitian would improve health, well-being and reduce obesity, osteoporosis and all other problems related to poor food intake.

Exercise programs, adjusted in order to develop the capacities of the person with ID rather than focusing on items too difficult for the person, would diminish the lack of movement and thereby positively affect the same conditions. Rimmer (1997) proposed a combination of exercise and informative activities in fitness centres with special classes for people with ID.

Monitoring of medication rarely means that all prescriptions can be withdrawn. However, a regular evaluation of medication use, especially regarding anticonvulsants and psychotropic medications, will reduce overdosage, drowsiness, osteoporosis and fractures caused by these conditions. The GP, having an overview of his patient's health problems, is the most appropriate person to maintain the overview of the person's prescriptions as well. The medication evaluation could best be carried out by the GP in consultation witl the person with ID and/or his main caregiver.

\section{Health problems not reported in the GP study, but frequently reported in the residential study}

A point of concern here is the much lower prevalence rate of gastro-intestinal and psychiatric problems in people with ID registered in general practice, particularly since these conditions are reported frequently in people with ID living in residential facilities. Risk factors for gastrooesophageal reflux disease, being the most frequently met gastro-intestinal problem, include non-ambulation, a more severe level of ID, cerebral palsy and use of anti-convulsants (Böhmer 1996). Given the low percentage of people with severe ID in the GP population, this might be merely a question of chance, or that of selection, while those with more severe problems might more often be living in residential facilities. When more people from residential facilities move into small living facilities in the community, $\mathrm{GPS}$ may encounter this problem more often. Optimal physiotherapy including prevention or treatment of a skoliosis, may positively influence the manifestation of gastro-oesophageal reflux disease. Unfortunately, it is nearly impossible to prevent this disease completely. Medical treatment for gastro-oesophageal reflux is effective in the majority of cases (Böhmer 1996). A serious problem is the effect of this type of medication on the resorption of anticonvulsants.

The situation becomes even more complicated with regard to psychiatric problems. The proposal for a standardized criteria for the diagnosis of psychiatric problems and especially of dementia in people with ID was recently published (Aylward et al.1997) and has clearly not yet been generally implemented. Furthermore, the diagnosis of a psychiatric disorder in a person who is non-verbal is difficult even for the most experienced of physicians (Tuinier \& Verhoeven 1992). Consultant psychiatrists with expertise on ID could be very helpful and improve the quality of life for people with psychiatric conditions by offering adequate treatment. Unfortunately, psychiatrists with expertise in $I D$ are rare. 


\section{Underreporting and communication}

The present study did not focus on underreporting of physical problems (Carlsen et al. 1994). The issue was not studied in people with ID living in residential facilities nor for people with ID registered in general practice. Reasons to assume that underreporting is likely were mentioned by Howells et al. (1993) and Day \& Jancar (1994). Quite a few people with ID experience difficulty in explaining their symptoms and worries about health issues to physicians. At the same time, doctors have not been trained in how to communicate non-verbally, and often experience problems in explaining how to cooperate in examinations, what symptoms to expect once a diagnosis has been made, and how to adjust their professional behaviour to people with ID.

\section{The person with ID as a family member}

A family member with ID has a strong impact on a family. The burden of caring for a family member with ID quite often affects both the physical and emotional well-being of the other family members and especially the mother (Seltzer er al. 1995).

The GP, being the family physician, is the most likely person to watch over the health of all family members and to guide the family with a member experiencing ID during the transitional phases of the life cycle (Schade 1996). The first transitional phase is the initial diagnosis of ID when the family has to make their choices for care provision; the second transition is when adolescence emphasizes the differences between the child with ID and the normal siblings; and finally the third is the phase of adulthood when children normally leave the family and when decisions have to be made by the adult person with ID and his parents about staying together or leading separate lives.

In the Netherlands, in recent years, health care policy has been focusing more and more on keeping families with a disabled or chronically ill family member together in their family environment. To this end, home care agencies were developed to offer house hold help, assistance with activities of daily living, and nursing assistance. This study revealed that GPs do not register families who utilize these services. Improving the communication between physicians and home care providers seems desirable in order to oversee the health of all family members and to see if the available assistance is used to its optimal advance.

\section{Multimorbidity}

Recent literature (Van den Akker et al. 1996) has defined comorbidity as an index disease and additional medical conditions, while multimorbidity has been defined as any co-occurrence of health problems in one person. The question presented in the current study was whether people with a known aetiology, in this case, Down's syndrome, were more at risk for certain health problems. This was difficult to determine with any certainty because few of the articles reviewed provided sufficient statistical information needed to establish a definitive relationship between the aetiology and the health concern. It seems wiser, to use the term 
'multimorbidity' for most combinations of health problems in persons with ID in order to acknowledge the preexisting condition of ID.

One of the results of the study of people with ID receiving services from a GP was that people with $\mathbb{I D}$ had more than twice as many health problems than people without ID which may be interpreted as a proof of the existence of multimorbidity. It is conceivable that part of the multimorbidity in people with ID was related to the disability in itself, the brain dysfunction that may in fact lead to various neurological and sensory impairments. To establish that a high risk for health problems is aetiology-related, such as in people with Down's syndrome, Fragile $\mathrm{X}$ syndrome, Prader Willi syndrome and so many other diagnoses, publications concerning aetiology-related health problems should consider offering documentations of such occurrences with more statistically reliable data.

A relation between the level of handicap and the extent of multimorbidity might be suspected from the fact that people with severe ID receiving services from a GP have more health problems than people with mild $\mathrm{DD}$. People with ID living in residential facilities generally have a more significant level of disability. This likely indicates that they have a greater number of health problems than those people with ID who currently live in the community. When people with ID move from residential facilities into community settings and register with local GPs, one should be aware of the fact that these persons with ID may have more health problems than the people with ID who are now registered in general practices.

\section{RECOMMENDATIONS}

\section{Recommendations for health care provision for people with ID}

The principle of medical care in the Netherlands is, that the GP is the gatekeeper to all other health care facilities. This principle is also applicable to people with ID who live with their family or on their own.

The earlier situation under which people with ID lived in residential facilities and therefore had special GPs may change as these people move into the community (Ministery of Health, Welfare and Sports 1996). More and more, GPs will become involved in the health needs of people with ID. The GPs are not yet equipped for this task (Schadé 1996). Accepting this involvement does not mean that the GPS have to solve all the health problems faced by people with ID themselves. The GP has to maintain the oversight of health related problems of the person with ID and, if this person resides with his or her family, has to pay attention to the impact of long-term care provision on the other family members. It would be helpful if people with ID could easily be identified in the GPs registration system. This will alert the GP so that additional health problems in these people are reason for more attention. It would make it easier to find out which people are eligible for additional health checks. It would also improve the possibilities for research on special health needs in this group.

An important point is the issue of networking: which health services are available to people with ID? To whom can the doctor refer? What can be expected from other disciplines? The role of specialized GPs, currently employed primarily by residential care facilities and 
spending most of their time providing expert medical care for the residents, should change, from a role as GP for those living in a residential facility, to a new role as consultant to people with ID who live within the community, and to the family doctors of these people. The development of this new role can be analogous to that of nursing home physicians in the Netherlands. These nursing home physicians are currently shifting their role from a fulltime residential physician to a combination of a partime consulting function for people who are nursed elsewhere and for these people's GPs, and to a parttime residential function. If the goal is truly that of establishing a new policy of separating the provision of residential services and accomodation and the provision of expert care for people with $\mathrm{D}$, it is then advisable to create such facilities that the residential working physicians, social workers and psychologists can be consulted by all people with ID and their caregivers, whether the person lives in the community or in a residential facility. These experts can also be consulted by primary care workers such as GPs, district nurses, psychologists and all other people who are involved in the earegiving of people with ID. Accessibility of such outpatient clinics and communication with primary care facilities should be easy for all those who may need this service.

The screening activities for sensory impairments recommended earlier could be performed by nursing assistants, speech therapists and other qualified paramedics. Schools for people with ID, only for those under 20 years of age, and residential facilities quite often thave skilled people trained in performing these screening activities. It is a pity that their availability for people with ID who are not students at their school or residents of their institution is limited. In this time of changing visions there is a need for change in making the experts accessible for all people with ID who need their advice.

The issue of providing prevention strategies on an easy-to-understand level is rather new. The 1997 program of the annual meeting of AAMR contained some abstracts regarding this issue. Rimmer (1997) addressed and suggested health information programs in special classes in local fitness centres. The idea of combining preventive and other social activities is challenging, and requires further consideration. Who is primarily responsible for preventive activities, is still a point for discussion. Kerr et al. (1996) reported that GPs in the UK generally accept their roles as primary health care providers for people with ID but were less positive about their roles in health promotion. Unfortunately, weight reduction and limiting prescriptions were among the recommendations of the Welsh Health Planning Forum (1992) which appeared to be scarcely implemented (Fraser 1996).

Another point that needs consideration is the management of psychiatric problems in people with ID. Consultant psychiatrists with expertise in the characteristic symptoms of psychiatric problems in people with ID may be very helpful. In the Netherlands, there are just a few of such people. Although the UK has a postgraduate training program as a further specialisation for psychiatrists for people with ID, here, the demand for people with such training is greater than their availability. Training of all junior psychiatrists in the characteristics of psychic problems in people with ID should be compulsory. 


\section{Recommendations regarding undergraduate and postgraduate training}

The new goals of medical training in the Netherlands (Grundmeijer \& Rutten 1996) state that a future doctor has to deal with patients with problems not with diseases. People with ID have at least two characteristic problems, that of communication, and that of having twice as many; health problems than other people. The results of our study indicate that, including people living in residential facilities, $0.82 \%$ of the Dutch population can be identified as having ID. In an average practice consisting of 2,350 persons, one may expect 16 people with $1 \mathrm{D}$. This means that every GP and his practice personnel regularly will be confronted with the health problems of people with $\mathrm{ID}$.

The most important point for a training program is that of communication. Training for doctors and other health care workers in non-verbal communication, the use of sign language and gestures is virtually non-existent. This should be developed. Points that should be focused upon are getting background information about the complaints, and being able to explain in easy language what will be happening to the person with ID when subjected to blood tests, gynaecological examinations or other fearsome examinations.

The second important point is the issue of networking. Which services are available for people with ID? What can be expected from special services? How should one refer to these services?

Another point is that of the epidemiology of the most frequent health problems. How often do these problems occur, and how important is it to screen adequately for sensory impairments or other preventable disorders or complications. Here, some knowledge on multimorbidity, its consequences for polypharmacy and the risks of overdosage and side-effects should be included as well.

The above issues should be offered to all doctors whether they are GPs, hospital specialists or public health care officers. An exciting example that could be followed is the "distance learning workbook on learning disability' that was developed for GPs in the UK by Howells et al. (1993).

The question remains how we can really change doctor's attitudes and practice organization in such a way that the proposed issues improve the care for people with ID in general practice. Organizational and attitudinal obstacles to change should be identified (Grol 1997, Hulscher et al. 1997) before a strategy to implement changes is selected. Organizational barriers to change may include insufficient staff, equipment, time, or management structures.

Training doctors should take place in small groups, taking into account the learning style of each individual, using peer reviews, personal feedback, specific reminders and tests. The first step in this training program is offering the above described skills and knowledge on communication, networking and epidemiology. Attention should be paid to a more positive attitude with regard to preventive activities. This education should be a stepwise, cyclical process with evaluations at regular intervals. In these evaluations not only the health care workers but also the people with ID and their caregivers should participate. In this way, quality of health care for people with ID can be developed and improved. 
The training for specialized physicians that currently exists in the Netherlands, now focuses mainly on developing expert knowledge and skills in the characteristic health problems of people with ID. This training should turn its focus more towards the problems of people with ID living in the community and should develop a module on consultation, in which trainees can acquire the skills and knowledge necessary to fulfill a consultant role for GPs and people with ID who live within a family.

\section{Recommendations for further study}

Several topics that require more knowledge have already been mentioned in the above section. Priority should be given to the following topics:

1. How should an adequate system be deweloped in order to register people with ID in general practice? What are the advantages and the disadvantages for the individual with $\mathbb{D}$ in being labeled as having an ID ?

2. Implementation of a screening program on sensory impairments. What is the most costeffective screening method? How many of the people in whom sensory deficits are diagnosed at a young age will develop to which level of independence? How will their level of disability and their quality of life improve as a result of those interventions for improving their hearing and/or visual capacities?

3. How to develop easy-language prevention activities for people who are non-verbal that are effective in reducing the problems of obesity and lack of exercise?

4. How can adequate health care provision contribute to an improvement in the physical and emotional wellbeing of people with ID? How can the effect of health care provision on physical and emotional wellbeing be assessed?

5. How to develop a continuous education model for health care workers, which improves the quality of health care for people with ID? 


\section{REFERENCES}

AAMR (1992) Mental retardation Definition, classification and systems of supports. AAMR: Washington DC. Akker M. van den, Buntinx F. \& Knottnens J.A. (1996) Comorbidity or multimorbidity: what's in a name? A review of literature. European Journal of General Practice 2, 65-70.

Aylward E.H. Burd D.B., Thorpe L.U., Lail F. \& Dalton A. (1997) Diagnosis of dementia in individuals with intellectual disability. Journal of Intellectual Disability Research 41, 152-64.

Bax M.C.O., Smyth D.P.L \& Thomas A.P. (1988) Health care of physically handicapped young adults. Brivish Medical Joumal 296, 1153-55.

Böhmer C. (1996) Gastro-oesophageal reflux disease in intellectwally disabled indiwiduals. Thesis; Free University of Amsterdam.

Carlsen W.R, Galluzi K.E., Forman L.F. \& Cavalieri T.A. (1994) Comprehensive geriatric assessment: applications for community-residing, elderly people with mental retardation/ developmental disabilities. Mental Retardation 32, 334-40.

Day K.A. \& Jancar J. (1994) Mental and physical health and ageing in mental handicap: a rewiew. Joumal of $/ \mathrm{m}$ tellectual Disability Research 38, 241-50.

Evenhuis H.M. (1995a) Medical aspects of ageing in a population with intellectual disability: I Visual impairment. Journal of Intellectual Disability Research 39, 19-25.

Evenhuis H.M. (1995b) Medical aspects of ageing in a population with intellectual disability: II Hearing impairment. Journal of Intellectual Disability Research 39, $27-33$.

Evenhuis H.M. (1996) Dutch consensus on diagnosis and treatment of hearing impairment in children and adults with intellectual disability. Journal of Intellectwal disability research 40, 451-6.

Fraser B. \& Kerr M. (1996) National Health gain targets in mental metardation. Presentation at loth IASSID conference, Helsinki Finland August 1996.

Gennep A.Th.G van (1997) Paradigmaverschuiving in de visie op zorg voor mensen met een werstandelike handicap. Inougurale rede, Maastricht University.

Grol R.P.T.M. (1997) Beliefs and evidence in changing ciin ical practice. British Medical Journal 315, 418-21

Grol R.P.T.M., Everdingen J.J.E. wan \& Casparie A.F. (1994) Invoering van richlijnen en veranderingen. Een handleiding voor de medisehe, paramedische en verplegghumdige praktijk. De Tijdstroom, Utrecht.

Grundmeijer H.G.L.M. \& Rutten G.E.H.M. (1996) Leerdoelen in de huisarsgeneeskunde. De invulling van her Raamplan 1994. De Tijdstroom; Utrecht.

Howells G. Kerr M. \& Lervy B. (1993) Learning disability (mental handicapl. Distance learning workbook for general practitioners. University of Wales College of Medicine.

Hulscher M.E.J.L., Drenth B.B. van, Mokkink H.G.A., Wouden I.C. van der \& Grol R.P.T.M. (1997) Barriers to preventive care in general practice. The role of organizationai and attitudinall factors. British Journal of General Practice 49, 711-4

Kerr M.P., Dunstan F. \& Thapar A. (1996) Attitudes of general practitioners to caring for people with learning disability. British Joumal of General Practice 46,92-4.

Maas J.M.A.G., Serail S. \& Janssen A.J.M. (1988) Frequentie-onderzoek geestelijk gehandicapten 1986. Tilburg: IVA, Instituut voor sociaal-wetenschappelijk onderzoek van de Katholieke Universiteit Brabant.

Metsemakers J.F.M., Hoppener P., Knottnerus J.A., Kocken R.J \& Limonard C.B. (1992) Computerized health information in the Netherlands: a registration network of family practices. British Journal of Gerneral Practice 42. $102-6$. 
Ministery of Health Welfare and Sports (1996). Actualization 1996 of the long term program for an intersectoral policy on the handicapped 1995-1998: Beyond limitations. Ministery of Heatth, Welfare and Sports, The Hague.

Mul M, Veraart W. \& Bieman A. (1997) Slechthorendheid bij mensen met een verstandelijke handicap in de huisartspraktijk. Huisarts en Wetenschap 40, 301-4.

NVAZ, Nederlandse Vereniging wan Artsen in de zorg woor mensen met een verstandelijke handicap (1997) Richtlinen woor diagnostiek en behandeling van visuele stoornissen bij werstandelijk gehandicapten. Utrecht.

Rimmer J. (1997) Physical fitness in people with mental retardation. Presentation at Roundiable on ageing. University of Illinois at Chicago.

Schade E. (1996) En dan is er nog de huisarts. De huisarts als gezinsarts voor verstandelijk gehandicapten. Huisarts en Wetenschap 39, 513-6.

Schrijvers A.J.P. (ed). (1997) Heatth and health care in the Netherlands. a critical self-assessmemt by Dutch experts in the medical and health sciences. De Tijdstroom, Utrecht.

Seltzer M.M., Kraus M.W., Walsh P., Conliffe C., Larson B., Birkbeck G., Hong J. \& Choi S.C. (1995) Crossnational comparisons of ageing mothers of adults with intellectual disabilities. Jaurnal of Intellectwal Disability Research 39, 08-18.

Tuinier S. \& Verhoewen W.M.A. (1992) Psychopathology in mental retardation: a multidisciplinary approach. Integrative Psychiatry 8, 252-63.

Wilson D.N. \& Haire A. (1990) Health care screening for people with mental handicap living in the community. British Medical Journal 301, 1379-81.

Welsh Health Planning Fonm. Protocol for investment in health gain. Mental handicap (learning disabilities). Welsh Office, Cardiff 1992. 


\section{Summary}

This thesis has described a study of the health problems of people with intellectual disability (ID) in the Netherlands and consisted of three parts.

The impetus for this study was a growing concem for the ageing of people with ID. The increasing longevity of these people brought to light ageing problems in a group of people who were already experiencing health problems related to the cause of their ID. This original concern generated a 5-year prospective cohort study on the changes in the care needs and provision of care for 1602 people with ID living in residential facilities in the Netherlands. The study was conducted between 1990 and 1995. Among the aspects considered in this ageing study were health problems. These data formed the basis of the first part of this thesis. The issues highlighted were prevalence and incidence of health problems. Sensary impairments and medication use were studied in more detail.

When reviewing the data of this study it became clear that, although the results were representative for all people with ID living in residential facilities in the Netherlands, there appeared to be two remaining issues. These issues were dealt with in the second and third part of this thesis.

The first issue is based on the assumption that all health problems of people with ID are aaetiology-related. To get the needed insight into the health problems of people with ID, one should study a group of people with ID due to the same aaetiology. The group of people with ID as a whole was considered to be too heterogeneous to give any useful study results. This led to the second part of this thesis, a literature review of the health problems of people with Down's syndrome.

The second issue was, whether or not the results could be considered to be representative for non-residential people with ID. People with ID living in residential facilities constitute a selective group who have possibly left their families because they have greater health problems than people with ID currently living with their families or on their own. Perhems these people are much healthier than those people with ID who lived in residential facilities. Furthermore, there were some important changes in the governmental policy regarding care for people with ID. From 1970 onwards there was a growing concern for the family relations of people with ID. Particularly for children with ID, there was an increased awareness of offering children a more balanced development when they remained with their family than when placed in residential facilities. The consequence of this was a growing capacity of day care facilities for children with ID to enable them to remain with their families as long as possible. By the middle of the $1990^{\prime}$ 's governmental policy further focused on discharging people with ID from the larger residential facilities into smaller living facilities which were more integrated in the community. The question of the health problems of people with ID living with their families was addressed in the last section of this study. 
In chapter 1 the changes in the philosophical vision of ID and the related changes in definition of ID and subsequent changes in care provision in the Netherlands over the past 40 years are described. The vulnerability of people with ID such as the health problems related to the aetiological diagnosis and frequent medication use were discussed. The increasing lifeexpectancy was described as well as the communication problems which were partly caused by the level of disability but also quite often further hampered by sensory impairments. Against this background, the study questions were formulated.

The key questions of this study were:

\section{Health problems of people with ID in residential facilities.}

- What are the prevalence and incidence rate of the most frequent health problems?

- What is known about two important health problems i.e. sensory impairments and medication use?

2. Which multimorbidity is found in people with ID due to a circumscript aetiology such as Down's syndrome?

\section{Health problems of people with ID in general practice.}

- To what extent are people with ID living with their families or living on their own registered with general practitioners?

- What are their characteristics?

- Do people with ID have different health problems from people without ID?

In chapter 2 the prevalence and incidence rates of the most frequent health problems are discussed. The highest prevalence rates were found for visual and auditory impairment, epilepsy, cerebral palsy and psychiatric disorders. Visual and auditory impairment appeared to be more prevalent in older age groups, and were more often reported for people with Down's syndrome than for people with $\mathrm{D}$ due to other aetiologies. Epilepsy and cerebral palsy were found more often in younger people. Dementia was reported more often in people with Down's syndrome above age 40 than in people with ID due to other aetiologies.

The highest incidence rates in three years were reported for visual and anditory impairment, in addition to gastrointestinal problems, affective disorders and, in people older than age 50, chronic obstructive pulmonary diseases (COPD) and cardiovascular disorders. It was concluded that a more proactive attitude of physicians is justified, at least with regard to sensory impairments and with regard to gastrointestinal problems. Assistance by specially trainted health care personnel should be considered.

In chapter 3 the results regarding sensory impairments are studied in more detail.

For people with ID living in residential facilities, $30 \%$ of the people with Down's syndrome were reported as having a visual impairment, whereas for people with ID due to other aetiologies, $12 \%$ had visual impairment. Hearing loss was reported in $15 \%$ of the people with Down's syndrome, and in $8 \%$ of the people with ID due to other aetiologies. The most common eye condition was cataract, and the most frequent cause of hearing impairment was infection. This chapter underlined the conclusions of the previous chapter regarding sensory impairments, and indicated that even more attention should be given to people with Down's 
syndrome, and people with ID older than age 50 . Both cataract and ear infections are treatable conditions if diagnosed in time. Health gain can be obtained by an early diagnosis and treatment of these conditions.

Chapter 4 is dedicated to another important health problem experienced by people with ID living in residential facilities, that is medication use.

$57 \%$ of the people with ID living in residential facilities used medication. The number of drugs used was significantly related to increased age and severity of handicap. Younger people used more anticonvulsants, older people used more antipsychotics, laxatives and cardiovascular medication. More severely disabled people used anticonvulsants, antipsychotics, laxatives and antacids. People with ID who live in large residential facilities did not receive more medication than people with ID living in small group homes. Since people with ID rarely complain about side effects or symptoms of drug interaction, and since epilepsy, psychiatric problems and gastrointestinal problems proved to be frequent in these people with $I D$, alertness of the prescribing physician is warranted. Regular evaluation of the medication use of each person with ID by the person himself, his primary caregiver and his physician appears to be necessary.

In chapter 5 the focus is on the second key question of this thesis: what is known about multimorbidity in people with Down's syndrome? This part of the study was performed by a criteria-based analysis of the literature on the subject.

Recent literature defines "multimorbidity' as any combination of health problems in one person. The term 'comorbidity' is reserved to an index disease and its interrelated health problems. In the present study health problems were defined as a comorbidity if an odds ratio (OR) equal to or greater than 2 could be calculated. In that case the risk for this certain health problem was (more than) twice as much for people with Down's syndrome than for people in the reference group.

Down's syndrome was chosen as the aetiology used to study the multimorbidity or comorbidity in people with ID due to circumscript aetiology since it has a high prevalence within the group of people with ID and it has been studied frequently. Publications were only selected for inclusion in this study which compared data of people with Down's syndrome to data of other people and on which calculations could be performed. Calculations of OR's based on more than one article revealed a higher risk for congenital heart defects, hypothyroidism, hearing impairments and hepatitis B. Calculations of a higher risk for obesity, epilepsy and degenerative spine disorders were based on only one article. Calculations on dementia, visual disorders, hyperthyroidism and psychiatric disorders resulted in an OR and confidence intervals that included 1, and thus, made the results unclear. It was conclucled that data to establish a relation of comorbidity, that is an interrelation of the described health problems to the index problem i.e. Down's syndrome were scarce. Further studies in which epidemiological data on groups of people with ID due to a known diagnosis such as Down's syndrome, Prader Willi syndrome or other more frequently found aetiologies of ID will be compared to a reference group might support the coneept of syndrome-related comorbidity. 
Chapter 6 and 7 are dedicated to the health problems of people with ID receiving medical care from GPs in the community.

In chapter 6 the case definition and case finding of people with ID registered in a general practice are discussed as well as the demographic characteristics of the people with ID and the extent to which their use of home care services were registered in their GPs database.

Identifying people with ID receiving medical care from general practices appeared to be difficult. There appeared to be no exclusive code for ID in the registration system of the common database used by the cooperating GPs. A sample of people who were registered in the database under preselected codes was constructed. The assessment of the individual's ID was done with the help of a questionnaire which was completed by the person's GP. The reported prevalence rate of $\mathrm{ID}$ of $0.65 \%$ was in line with the results of an earlier study on the prevalence rate of ID in the Netherlands.

The male:female ratio and the age structure of the group of people with ID appeared to be different: the group of people with ID consisted of many more males than females and the mean age of people with ID was lower than that of people without ID. Fifty-three percent of the people with ID had a mild disability, while $47 \%$ were more severely disabled.

GPs did not register as to whether or not their patients with ID received home care. In the Netherlands, home care means assistance with activities of daily living, nursing assistance and household help. Incidentally, GPs referred their patients to these facilities, but a regular evaluation of the effects of such services was rare.

Chapter 7 deals with the health problems of the people with ID registered with a general practitioner.

It appeared that people with mild ID had 2,2 times more health problems than people without ID. People with severe ID had 2,7 times more health problems than those without ID.

The disorders reported most frequently for people with ID served by GPs were either related to the nature of their handicap, such as congenital anomalies, musculoskeletal impairments, epliepsy, strabismus and deafness, or they were related to external conditions. This applied to obesity, fractures and haemorrhoids. These last conditions are all related to poor food intake, lack of movement and medication use. Exercise may be difficult for people with ID. The same holds true for healthy nutrition. Medication quite often is obligatory for disability related disorders such as epilepsy and psychiatric conditions. Nevertheless, health benefit is expected from an optimal prevention policy towards these conditions.

In chapter 8 there was an attempt to put the conclusions of the previous chapters into one more or less coherent picture. After a discussion of some methodological restrictions of this study regarding the casefinding of people with mild ID and the limitation of registration of health problems which were registered in either database or patient files, it is concluded that basically, people with ID have two different types of health problems: those related to the nature of their disability, and those related to lifestyle. Health benefit should be expected from the development of a policy of information on prevention and lifestyle issues. 
Sensory impairment may remain unnoticed because of the shortcomings of the present screening methods and may result in unnecessary communication problems and the individual functioning may be poorer as a result of this deficit. The development and implementation of screening methods to evaluate visual and auditory capacities adjusted to the level of disability of the person with ID is absolutely necessary.

The relocation in the near future of people with ID currently living in large residential facities to community-based homes, might confront the GP with a new challenge of encountering people with ID with their inherently formerly unmet conditions within their general practices. This applies to gastrointestinal problems and psychiatric disorders, which, in this study, were reported primarily in people with ID living in residential facilities.

The training of GPs and their health care personnel in communicating with people with ID and providing them with information regarding the most prevalent health problems and the use of screening methods and easy-language health information is recommended. Cooperation between GPs and specialized physicians and paramedical staff who are now mainly employed by residential facilities could benefit both the persons with $I D$ and GPs and health care staff in general practice and in institutions. 


\section{SAMENVATTING}

Dit proefschrift beschrijft de resultaten van een reeks onderzoeken naar de gezondheidsproblemen van mensen met een verstandelijke handicap in Nederland en bestaat uit drie delen. Het eerste deel kwam voort uit de zorg om het toenemend aantal gezondheidsproblemen bij ouder wordende mensen met een verstandelijke handicap. In het kader van een onderzoek naar de veranderingen in zorgvraag en zorgaanbod in relatie tot leeftijd bij mensen met een verstandelijke handicap, werd van 1990 tot 1995 een prospectief cohortonderzoek verricht naar deze veranderingen bij een gestratificeerde steekproef van 1602 mensen in instellingen en gezinsvervangende tehuizen in Nederland. De resultaten van dit onderzoek betreffende gezondheidsproblemen vormen de basis van het eerste deel van dit proefschrift. Hierin stond de prevalentie en incidentie van gezondheidsproblemen centraal. Nader werd ingegaan op zintuigstoornissen en medicijngebruik.

Hoewel de resultaten van dit onderzoek representatief geacht moeten worden voor alle residentieel wonenden met een verstandelijke handicap in Nederland, richtte de discussie zich met name op twee aspecten. Deze worden uitgewerkt in het tweede en derde deel van dit proefschrift.

Het eerste aspect berust op de aanname, dat er een relatie is tussen gezondheidsproblemen van verstandelijk gehandicapten en hun etiologie: Verder onderzoek naar gezondheidsproblemen zou zinvol zijn bij verstandelijk gehandicapten met een etiologisch bepaalde oorzaak. De groep met verstandelijk gehandicapten als geheel zou te heterogeen zijn voor bruikbare studieresultaten. Dit werd de aanleiding voor het tweede deel van het onderzoek: een literatuurstudie naar de gezondheidsproblemen bij mensen met het syndroom van Down.

Het tweede aspect kwam voort uit de vraag, of de resultaten van dit onderzoek bij mensen die in instellingen woonden, ook representatief zijn voor thuiswonende mensen met een verstandelijke handicap. In het verleden waren gezondheidsproblemen vaak de reden om mensen met een verstandelijke handicap in instellingen op te nemen. Mogelijk is de groep mensen met een verstandelijke handicap die thuis wonen veel gezonder dan mensen in residentiele voorzieningen.

Bovendien hebben zich in de afgelopen jaar op het terrein van de zorg voor mensen met een verstandelijke handicap een aantal belangrijke beleidswijzigingen voorgedaan. Vanaf 1970 is er in toenemende mate aandacht voor de gezinsrelaties van kinderen met een verstandelijke handicap. Kinderen die langer in het gezin blijven, blijken zich veel beter te ontwikkelen dan wanneer zij jong uit huis geplaatst worden. Dit leidde tot een enorme uitbreiding van de capaciteit van dagvoorzieningen voor kinderen met een verstandelijke handicap, die daardoor veel langer in het gezin konden blijven.

Vanaf ongeveer 1990 begint in onze maatschappij het beleid zich er op te richten, dat mensen met een verstandelijke handicap mensen met mogelijkheden zijn, die recht hebben op ondersteuning bij een optimale integratie in de maatschappij. Het overheidsbeleid wordt dan 
gericht op het sluiten van grote instellingen, en het stimuleren van geintegreerd wonen van kleine groepen mensen met een verstandelijke handicap in aangepaste huizen in dorpen en stadswijken.

Het vraagstuk van de gezondheidsproblemen van mensen met een verstandelijke handicap die bij familie of op zichzelf wonen, leidde tot onderzoek, dat wordt behandeld in het derde deel van dit proefschrift.

Hoofdstuk 1 geeft een beschrijving van de veranderingen in de visie op verstandelijke handicap en de daarmee samenhangende veranderingen in de definiering van verstandelijke handicap gedurende de laatste 40 jaar en de hieruit voortvloeiende veranderingen in zorgaanbod. Er wordt nader ingegaan op de kwetsbaarheid van mensen met een verstandelijke handicap. Deze kwetsbaarheid wordt onder meer bepaald door de gezondheidsproblemen die samenhangen met de oorzaak van de handicap, en door het veelvuldige medicatiegebruik. Andere factoren die een rol spelen zijn de toenemende levensverwachting, en de communicatieproblemen. De communicatie wordt nadelig beinvloed door het niveau van de handicap van de persoon, en ook vaak door niet onderkende gezichts- en/of gehoorstoornissen. Binnen dit kader worden de onderzoeksvragen geformuleerd.

\section{Gezondheidsproblemen van mensen met een verstandelijke handicap in instellingen} en gezinsvervangende tehuizen.

- wat is de prevalentie en incidentie van de meest voorkomende gezondheidproblemen?

- wat is er bekend over zintuigstoornissen en medicijngebruik bij mensen met een verstandelijke handicap die in deze voorzieningen wonen?

2. Welke multimorbiditeit wordt er gevonden bij mensen met het syndroom van Down?

3. Gezondheidsproblemen bij mensen met een verstandelijke handicap die zijn ingeschreven in huisartspraktijken.

- In hoeverre zijn mensen met een verstandelijke handicap die bij een huisarts zijn ingeschreven als zodanig bekend bij hun huisarts?

- Hoe oud zijn zij en wat is hun niveau van functioneren?

- Hebben mensen met een verstandelijke handicap andere gezondheidsproblemen dan de mensen zonder verstandelijke handicap in dezelfde huisartspraktijken?

Hoofdstuk 2 gaat nader in op de prevalentie en incidentie van de meest voorkomende gezondheidsproblemen van mensen met een verstandelijke handicap in instellingen en gezinsvervangende tehuizen.

De aandoeningen met de hoogste prevalentie bleken visus- en hoorstoornissen, en verder epilepsie, cerebral palsy en psychiatrische aandoeningen. Stoornissen in het zien en horen bleken meer voor te komen bij ouderen, en ook vaker bij mensen met het syndroom van Down, dan bij mensen met een verstandelijke handicap ten gevolge van andere oorzaken. Epilepsie en cerebral palsy werden vaker gerapporteerd bij jongeren. Dementie werd vaker gemeld bij mensen met het syndroom van Down ouder dan 40 jaar dan bij mensen met een verstandelijke handicap door andere oorzaken. 
De aandoeningen met de hoogste incidentie in drie jaar, dat wil zeggen het aantal nieuwe gevallen van mensen met een bepaalde aandoening in deze tijd, waren zintuigstoomissen, maagdarmaandoeningen, affectieve stoornissen, en chronische aandoeningen van de luchtwegen en hart-en vaatziekte bij mensen ouder dan 50 jaar. Dit leidt tot de conclusie dat een actiever beleid van artsen met betrekking tot opsporing van zintuigstoornissen en van maagdarmaandoeningen gewenst is. De inzet van goed getrainde verpleegkundigen kan hierbij nuttig zijn.

In hoofdstuk 3 worden de zintuigstoornissen bij mensen met een verstandelijke handicap die in instellingen wonen, nader beschouwd. Het bleek dat in deze populatie $30 \%$ van de mensen met het syndroom van Down, en $12 \%$ van de mensen met een verstandelijke handicap door andere oorzaken problemen hadden bij het zjen. Hoorproblemen werden gemeld bij $15 \%$ van de mensen met het syndroom van Down, en bij $8 \%$ van de mensen met andere oorzaken van hun handicap.

De meest voorkomende oogaandoening was cataract; de meest voorkomende ooraandoening was infectie. Dit hoofdstuk bevestigt de conclusies van het vorige hoofdstuk, en geeft aanwijzingen, dat mensen met het syndroom van Down, ouder dan 50 jaar, en mensen met een verstandelijke handicap door andere oorzaken nog meer dan anderen nauwgezet gevolgd moeten worden. Cataract en oorinfecties zijn bij een tijdige diagnose en behandeling goed behandelbare aandoeningen. Dit levert een duidelijke gezondheidswinst op.

In hoofdstuk 4 wordt een ander belangrijk probleem betreffende de gezondheid bij mensen met een verstandelijke handicap die in instellingen wonen nader onderzocht, namelijk het medicijngebruik. $57 \%$ van de instellingspopulatie bleek bij onderzoek medicatie te gebruiken. Ouderen en mensen met een ernstiger handicap gebruikten meer medicijnen. Jongeren kregen vaker anti-epileptica, ouderen daarentegen meer antipsychotica, laxeermiddelen, en middelen tegen hart-en vaatziekten. Mensen met een ernstiger handicap gebruikten vaker anti-epileptica, antipsychotica, laxeermiddelen en antacida. Er werd geen verband gevonden tussen medicijngebruik en het wonen in grote instellingen of veel kleinere gezinsvervangende tehuizen. Omdat mensen met een verstandelijke handicap zelden klagen over bijwerkingen of over symptomen van medicijninteracties, en omdat epilepsie, psychiatrische aandoeningen en maagdarmproblemen veel voorkomen, moet de voorschrijvende arts op zijn hoede zijn. Regelmatige evaluatie van alle medicijngebruik wordt aanbevolen. Deze moet uitgevoerd worden door de arts, de persoon met een verstandelijke handicap en zijn ouder of verzorger, bijvoorbeeld eens per drie of zes maanden.

Hoofdstuk 5 behandelt de tweede onderzoeksvraag: wat is er bekend over multimorbiditeit bij mensen met het syndroom van Down? Deze vraagstelling werd onderzocht met behulp van een systematische analyse van de literatuur over dit onderwerp. Recente literatuur geeft aan, dat de term 'comorbiditeit' gereserveerd moet blijven voor alle bijkomende aandoeningen die horen bij een index-ziekte. Alle andere combinaties van aandoeningen waarbij de samenhang. of oorzaak en gevolg niet duidelijk zijn, worden betiteld als multimorbiditeit. 
Voor dit onderzoek naar multimorbiditeit bij een groep mensen met een verstandelijke handicap ten gevolge van eenzelfde etiologische diagnose is gekozen voor mensen met het syndroom van Down, omdat dit syndroom een hoge prevalentie heeft binnen de groep mensen met een verstandelijke handicap, en omdat hierover veel is gepubliceerd.

Alleen die publicaties, waarin gezondheidsproblemen van mensen met het syndroom van Down werden wergeleken met dezelfde aandoeningen bij een andere groep, kwamen in aanmerking voor onderzoek. De publicaties moesten data bevatten die nagerekend konden worden. Als maat voor comorbiditeit kozen we een odds ratio (OR) $>2$; dat wil zeggen dat het risico op een bepaalde aandoening twee keer zo groot is bij mensen met het syndroom van Down als bij de mensen uit de vergelijkingsgroep. Uitgangspunt is, dat bij een $O R>2$ de beschreven aandoeningen meer dan door het toeval bepaald voorkomt bij de indexaandoening, in dit geval het syndroom van Down. Op grond van meerdere publicaties bleek een dergelijke berekening alleen mogelijk voor aangeboren hartgebreken, hypothyreoidie, hoorstoornissen en hepatitis B.

Een hoger risico voor vetzucht, epilepsie en degeneratieve afwijkingen van de wervelkolom kon berekend worden op grond van de data van steeds 1 artikel. Voor dementie, visusstoornissen, hyperthyreoidie en psychiatrische aandoeningen werden publicaties gevonden op grond waarvan een OR berekend kon worden.Omdat het betrouwbaarheidsinterval de 1 omvatte kunnen hieraan geen conclusies worden verbonden.

Geconcludeerd moet worden, dat er maar weinig gegevens zijn om met statistische zekerheid vast te stellen of er sprake is van comorbiditeit. Er is meer epidemiologisch onderzoek nodig bij mensen met vaker voorkomende syndromen zoals het syndroom van Down, fragiele $X$ syndroom en Prader Willi syndroom om zekerheid te geven over het bestaan van syndroomgebonden comorbiditeit.

Hoofdstuk 6 en 7 gaan in op de gezondheidsproblemen van mensen met een verstandelijke handicap die in een huisartsenpraktijk zijn ingeschreven.

Hoofdstuk 6 behandelt de definitie van verstandelijke handicap, en hoe mensen met deze handicap opgespoord kunnen worden in een registratiesysteem van huisartspraktijken. Het opsporen van de doelgroep bleek niet gemakkelijk. Er was geen exclusieve code voor verstandelijke handicap in het classificatiesysteem dat door huisartsen gebruikt wordt. In een vooronderzoek werden een aantal codes geselecteerd waaronder de meeste mensen met een verstandelijke handicap in het systeem geregistreerd waren. Voor deze geselecteerde groep werd door de huisartsen met behulp van vragenlijsten al dan niet de diagnose verstandelijke handicap gesteld. Op deze manier werden 318 mensen met een verstandelijke handicap gevonden, hetgeen overeenkomt met de uitkomsten van eerder gepubliceerd prevalentieonderzoek (prevalentie 0,65\%) naar mensen met een verstandelijke handicap in Nederland.

De man-vrouw verhouding in de groep mensen met een verstandelijke handicap was verschillend van die van de rest van de populatie. De groep mensen met een verstandelijke handicap bestond uit meer mannen dan vrouwen. De gemiddelde leeftijd van mensen met een 
verstandelijke handicap was lager dan die van de andere mensen in dezelfde huisartspraktijken. Drie en vijftig procent van de mensen had een lichte verstandelijke handicap en $47 \%$ had een ernstiger handicap.

Ook bleek dat er bij huisartsen weinig werd geregistreerd over de thuiszorg van mensen met een verstandelijke handicap. Onder thuiszorg wordt hier verstaan de huishoudelijke hulp, ADL hulp en verpleging zoals die door de thuiszorgorganisaties in Nederland wordt geboden.

In hoofdstuk 7 worden de gezondheidsproblemen van de mensen met een verstandelijke handicap die bij familie of zelfstandig wonen beschreven. Uit dit onderzoek in de huisartspraktijk bleek dat mensen met een lichte verstandelijke handicap 2,2 maal zo veel gezondheidsproblemen hadden als niet-verstandelijk gehandicapte mensen in dezelfde praktijken. Ernstig verstandelijk gehandicapte mensen hadden 2,7 maal zo veel gezondheidsproblemen.

De aandoeningen die bij mensen met een verstandelijke handicap vaker voorkwamen, bleken voor een deel samen te hangen met de aard van de handicap, zoals zintuigstoomissen, epilepsie en motorische problemen. Daarnaast werden er aandoeningen gevonden die met de levensomstandigheden van deze mensen te maken hebben. Dit gold met name voor adipositas, botbreuken en aambeien. Deze laatste groep aandoeningen ontstaan of verergeren door een onverstandig voedingspatroon, gebruik van medicatie, en te weinig lichaamsbeweging. Zowel het stimuleren van beweging als het geven van voedingsadviezen vragen een geheel eigen deskundigheid. Medicatie, met name bij epilepsie en psychiatrische aandoeningen, dient te bestaan uit zo weinig mogelijk verschillende middelen in een adequate dosering. Wellicht kan een deel van de problematiek met een adequate aanpak, gericht op de doelgroep voorkomen worden.

In hoofdstuk 8 worden de onderzoeksresultaten in hun onderlinge samenhang beschreven.

Op de methode van het onderzoek in de huisartspraktijken zijn twee aanmerkingen te maken. Mogelijk zijn niet alle mensen met een verstandelijke handicap opgespoord; uitgangspunt zijn de gezondheidsproblemen, voorzover ze geregistreerd zijn. Een aanpak waarbij alle mensen op systematische wijze een diagnostisch onderzoek moeten ondergaan ('screenen'), had andere uitkomsten wat betreft de prevalentie van aandoeningen opgeleverd.

In het algemeen kan gezegd worden, dat het surplus aan gezondheidsproblemen bij alle mensen met een verstandelijke handicap, of ze nu thuis of in instellingen wonen, in feite terug te brengen is tot aandoeningen die bij de handicap horen, of tot aandoeningen die door omstandigheden bepaald worden. Voor het verbeteren van de gezondheid is vooral de laatste groep aandoeningen van belang: gebrek aan lichaamsbeweging, ongezonde voedingspatronen en medicatiegebruik dat niet regelmatig geëvalueerd wordt, zijn punten waar een voorlichtings- en preventiebeleid voor ontwikkeld kan worden.

Een groot probleem vormen de visus- en hoorstoomissen die vaak niet onderkend worden doordat de huidige screeningsmethoden te complex zijn voor ernstig gehandicapte mensen. Dit leidt tot onnodige communicatieproblemen tussen mensen met een verstandelijke handicap en hun omgeving, en het leidt er ook toe dat mensen op een lager niveau 
functioneren dan ze zouden kunnen doen met adequate hulpmiddelen, of na een tijdige behandeling van de gevonden aandoeningen. Het ontwikkelen en implementeren van aangepaste screeningsmethoden woor zien en horen is daarvoor absoluut noodzakeiijk.

Het feit dat in de nabije toekomst mensen met een verstandelijke handicap uit instellingen verhuizen naar gewone huizen in de wijk, betekent dat de huisarts bepaalde aandoeningen vaker zal tegenkomen, die nu voornamelijk bij mensen met een verstandelijke handicap in residentiele voorzieningen worden waargenomen. Dit geldt met name voor maagdarmproblemen en psychiatrische aandoeningen.

Ten aanzien van de opleiding van artsen en hun praktijkpersoneel wordt systematische aandacht aanbevolen voor de communicatie met mensen met een verstandelijke handicap en de hier beschreven meest voorkomende aandoeningen. Samenwerking tussen huisartsen, paramedici en artsen voor verstandelijk gehandicapten die nu bijna uitsluitend werken voor mensen met een verstandelijke handicap in instellingen of gezinsvervangende tehuizen, zal aan alle partijen ten goede komen. 
APPENDIX

Questionnaire casefinding 
To the general practitioners participating in

the study of co-morbidity

in the people with intellectual disability

\section{Dear colleague,}

Please find enciosed the questionnaires for the above-mentioned study.

The lists have been marked with a sticker indicating the patient's number and your practice code. This makes it possible for you to retrieve data on the person concerned in your system in order to complete the questionnaires.

You will also find enclosed a number of blank questionnaires, as we suspect that not all people with intellectual disability $(=I D)$ have been registered under one of the three selected codes $(N 85, P 24, P 85)$. Do you know of any persons with ID registered under different codes in the RNH files? Would you please fill out a list for these persons? Pay special attention to A90 (multiple congenital disorders). People suffering from Down's syndrome may be coded here. Also pay attention to P28 (handicap through psychological problems). In such cases, please also add the patient number and practice code.

Do you know of any people with ID among your patients who are not yet included in the RNH file? Would you please complete a questionnaire for these persons, a problem list in the RNH file, and also add the personal background variables, in order that they may be included in the next output file?

If you need more blank questionnaires, or if you have any questions, please call the telephone number listed below.

You may return the completed questionnaires in the enclosed envelope.

I would like to ask you to return the questionnaires no later than the 15 th December.

Many thanks for your co-operation

HMJ van Schrojenstein Lantman-de Valk

Medical researcher

Telephone Monday, Tuesday, Wednesday and

Thursday momings: 0475-479666 


\title{
GENERAL PRACTITIONER QUESTIONNAIRE
}

Patient no.

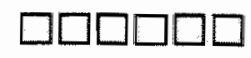

Date of birth

\section{$\square \square \square \square \square \square$}

Postal code

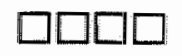

Gender

MEMIC reg.no.

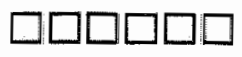

Practice code

\section{$\square \square \square$}

1. This person

\author{
$\square$ has nowed \\ $\square$ has deceased \\ $\square$ cannot be found on file
}

If you marked any one of the three answers above, you need not complete this questionnaire. However, would you be so kind as to retum it?

Please also read the instructions in the accompanying letter.

2. Patient has ICPC code $\square$ N85

$\square$ P24

口P85

3. Is this person mentally handicapped?

3.1 $\square$ Yes. What ICPC code have you used to register this?

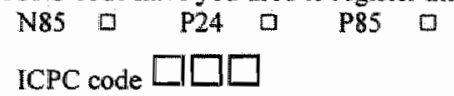

3.2 $\square$ No. What is the patient suffering from then?

If necessary, correct the ICPC code $\square \square \square$

3.3 $\square$ Doubtful. Why?

Have you any documentation?

D $\mathrm{No}_{*}$ there is no documentation.

[ Y Yes, there is documentation from:

$\square$ VTO team

口Paediatrician

$\square$ Neurologist

$\square$ Psychiatrist

$\square$ School Guidance Agency

DOther: 
4. Has the levell of intellectual functioning been recorded?

$\square$ No

$\begin{aligned} \text { QYes } & \text { IQ: } \square \square \square \\ \text { Or: } & \square \text { severely mentally handicapped } \\ & \text { Qseriously mentally handicapped } \\ & \square \text { moderately mentally handicapped } \\ & \square \text { slightly mentally handicapped }\end{aligned}$

Checklist

Please complete this section for each patient.

Indicate, on the basis of the data you have on fille, which points (1 to 11) in your opinion apply to this person. It is possible to mark more than one option!

It concerns a person:

1. ㅁ whose intellectual/mental development is clearly below average,

2. in whom the above-mentioned problem was manifest before the age of 18 ,

3. W who attendis, has attended, or is on a waiting list for, a school for children with very serious leaming difficulties, or - in the case of senior citizens - who has in the past, with great difficulty, managed to take part in primary education for a few years,

4. who visits, has visited, or is on a waiting list for, a day-care centre for mentally handicapped children (KDV) or adults (DVO),

5. $\square \quad$ is lliving in, has lived in, or is on a waiting list for, an institution for the mentally handicapped or an alternative family facility,

6. who makes use of a day and/or weekend facility in an institute or lodging home,

7. who makes use of practical pedagogic home guidance.

8. whose problems with active and/or passive use of language can be classified as

9. who has problems looking after himself/herself

10. who has problems with money/shopping

11. who has problems understanding the concept of time

12. indicate the level of intellectual functioning, in your opinion:

$\square$ severely mentally handicapped

$\square$ seriously mentally handicapped

$\square$ moderately mentally handicapped

a slightly mentally handicapped

If there has been no contact with the home care agency, or contact for any other reason than the mental handicap within the past six months, then you need not answer question 1.3.

13. this person has received care in connection with his/her mental disability, within the past year

a for a short period ( $<1$ month)

for a long period ( $1-6$ months)

$\square$ continually ( $>6$ months)

by:

b home help

$\square$ district nursing

$\square$ other home help agency: 
Een proefschrift kan alleen maar geschreven worden als veel mensen je daar bij helpen. Er waren nogal wat mensen die mij op allerlei manieren geholpen hebben, en ik ben hen allen dankbaar voor hun bijidrage.

Harry Crebolder, ik ben je dankbaar voor je steun, het feit dat je geloofde in mijn onderwerp en voor alles wat ik gaandeweg van je geleerd heb. Als je mij niet gebeld had op de dag dat ik besloten had ermee te stoppen, zou dit proefschrift er nooit gekomen zijn. Meindert Haveman, jij was de eerste die mij wegwijs maakte in het formuleren van onderzoekswiagen en het vinden van een antwoord op de gestelde vraag. Ik heb daar veel aan gehad. Job Metsemakers, de discussies over de huisarts, zijn werk en de plaats van de persoon met een verstandelijke handicap naast alle andere complexe zorgvragers, heeft me geleerd de zaken in een context te plaatsen. Ik heb genoten van al die discussies. In de eerste fase van mijn onderzoek heeft ook prof. Dr. F. Sturmans mij op weg geholpen. Prof Dr. M. Niermeijer gaf mij op het juiste moment een duwtje in de rug met zijn commentaar bij mijn eerste artikel over visus- en gehoorstoornissen.

De leden van de leescommissie, Prof. Dr. A.C. Nieuwenhujizen Kruseman, Prof. Dr. J.A. Knottnerus, Dr. J. Diederiks en Prof. Dr. E Schadé ben ik dankbaar voor hun opmerkingen die ik graag gebruikt heb on de tekst te verbeteren. Prof. W.I. Fraser, thank you very much for your remarks which helped me greatly.

$\mathrm{Bij}$ het eerste deel van het onderzoek, het vergrijzingsprojekt, was het vooral Marian Maaskant die veel voorstructureerde, mij wegwijs maakte in de geheimen van BMDP en Medline. Marian, wat was het leuk om met je te werken. Gelukkig kunnen we op Pepijn nog op diverse manieren onze samenwerking voortzetten.

Fons Kessels van de vakgroep Epidemiologie: bedankt dat je mij de eerste beginselen van de statistiek bijbracht. En verder was je ook onmisbaar bij het invoeren van en werken met het medicijn-programma van de KNMP. Marijke Claessens hielp in de eerste drie jaar van het vergrijzingsonderzoek met het invoeren van de data. Veel collega-artsen, werkzaam in instellingen voor mensen met een verstandelijke handicap of verbonden aan gezinsvervangende tehuizen, vooral in Noord Brabant en Limburg, vulden vier jaar lang telkens de checklist medische anamnese van het vergrijzingsproject in. Zonder hun medewerking zou ik het eerste deel van mijn onderzoek nooit hebben kunnen uitwoeren.

Maarten Kamper en Sonja van Hout hielpen in hun wetenschapsstage bij het literatuuronderzoek. Rens Evers, dank je wel voor je hulp bij het selecteren van de artikelen voor het onderzoek naar comorbiditeit en voor je assistentie bij het rekenwerk.

Binnen de vakgroep Huisartsgeneeskunde ben ik velen erkentelijk voor hun steun. Het was vooral Marjan van den Akker, lange tijd mijn kamergenoot, die mij hielp bij praktische problemen. $\mathrm{Zij}$ wist altijd de fouten in het databestand op te sporen, al duurde het soms wel een hele dag voordat we die gevonden hadden. Ook in de laatste jaren van het vergrijzingsproject was je behulpzaam met data-invoer en data-analyse. Marjan, dank voor je eindeloze geduld en voor al je steun. 
Paula Rinkens, je hebt me enorm geholpen bij het bewerkbaar maken van de RNH-gegevens. Sjef Roos van de afdeling Medische Statistiek schreef het computerprogramma dat nodig was om de onderzoeksgegevens en het RNH bestand te koppelen. Gregor Franssen en Jan Bergers van het MEMIC hielpen bij het ontwerpen en verwerken van de vragenlijsten. Marianne Soomers-Turlings, huisarts in Kerkrade, dank je wel voor je enthousiaste hulp bij het selecteren van de ICPC-codes waaronder mensen met een verstandelijke handicap in het databestand wan de RNH-praktijken geregistreerd zouden kunnen zijn.

Alle huisartsen die deelnamen aan dit onderzoek: Ph. Govaert, R. Leclerq, G.J. Dinant, V. Zwietering, B. Huijnen, P. Castermans, P. Stalenhoef, M. Maaskant, B. Schilten, R. Helmers, M. van Nunen, H. Paas, B. Bruls, P. Voorhoeve, G. van Schendel †, P. Janssen, G. de Koning, H. van Dam, H. Vlek, T . van Kessel, H. Ypma, J. Eussen, C. Stuurman, H. Schönberger, J. van Putten, W. van den Broek, F. Guldemond, V. Kaiser, J. Veldhuizen, H. van der Ploeg, F. Soomers, M. Soomers-Turlings en J. Stoffers ben ik dank verschuldigd voor de tijd en energie die zij gestopt hebben in het invullen van de vragenlijsten, en het geduld waarmee ze mij te woord stonden als ik weer eens belde om verduidelijking.

Op Pepljn zijn er erg veel mensen aan wie ik veel te danken heb. In de eerste plaats de bewoners en hun ouders, bij wie ik gezondheidsproblemen tegenkwam en die mij inspireerden en mijn nieuwsgierigheid stimuleerden om uit te zoeken waar de echte problemen zaten.

Ben Zegwaard, die de omslag voor dit proefschrift tekende: je hebt het perfect begrepen en ik ben erg blij met de manier waarop je mijn onderwerp in beeld hebt gebracht.

Mijn collega Anneke Schoonbrood, met wie ik al bijna 18 jaar samenwerk: heel hartelijk bedankt voor je steun door dik en dun, voor de diensten die je overnam en spoedpatienten die je opving op momenten dat ik elders aan dit proefschrift zat te werken. Ook heb ik het zeer gewaardeerd, dat je als diensthoofd de kaders wist aan te passen aan wat ik nodig had.

Samen met Harry Urlings als collega pedagoog van Pepijn ben ik in het kader van het vergrijzingsprojekt begonnen aan de samenwerking met de Universiteit van Maastricht. Je was mijn maat uit de praktijk, en je nuchterheid en het vermogen om moeilijkheden te verwoorden hebben me vaak verder geholpen.

De pauzes, die ik samen met Trudy Beijk, collega maatschappelijk werk van Pepijn, heb doorgebracht, waarin we ons lief en leed deelden, hebben me zeer goed gedaan.

Ook alle andere collega's in de begeleidingsteams: dank voor jullie meeleven en ondersteuning.

Sandra Driessen en Marjo Creusen: jullie waarneming van een deel van mijn huisartsenwerk op Pepijn in 1996 maakte het mij mogelijk harder door te werken. Intussen heb ik ook veel geleerd van jullie frisse inbreng bij al jaren bestaande gezondheidsproblemen bij bewoners. De dames van het algemeen secretariaat, en vooral Els van Riet en Ans Lommertzen hebben in de eerste fase met eindeloos geduld teksten getypt, tabellen ingevoerd en alles persklaar gemaakt.

De leden van de raad van bestuur van Pepijn ben ik dankbaar voor hun stimulans en voor de financielle ondersteuning van dit werk. 
Vele collega-artsen in de zorg voor mensen met een verstandelijke handicap hebben bij de wording van dit proefschrift meegeleefd. Dank woor al jullie bemoedigende woorden. Marijke Cremers, inmiddels in een heel andere functie werkzaam, wil ik met name bedanken voor haar ondersteuning in de beginfase, voor de contacten die ik via haar gelegd heb en voor alle keren dat ik mijn problemen met haar kon bespreken. Ook de andere collega's, die ik mocht ontmoeten in de wetenschappelijke commissie van de NVAZ, dank ik voor hum stimulerende bijdragen.

De mensen van de NSPH, vooral Joke Meulmeester en Jose van Kuik: dank voor jullie steun en begrip bij de laatste fasen van dit werk. De deelnemers aan de AVG-opleiding 1996: dank voor jullie kritiek op mijn ideeèn. Sommige van jullie commentaren heb ik dankbaar verwerkt in mijn laatste hoofdstuk en in de stellingen.

Writing an English text is a job in itself. Dana Henning, thank you so much for all your work, not only in checking my English, but also for being my language police, and thank you even more for everything 1 leamed from you about cultural differences. I had no idea that cultural differences even more than language barriers are the determinants of miscommunication between people. I learned with pleasure. Patricia Walsh: thank you for your comments on my introduction and conclusion chapter. Bob Wilkinson from Worldneth in Maastricht is thanked for his prompt assistance in translating chapter 4 and the Appendix which were originally published in Dutch.

All language errors that remained are the consequence of the fact that I kept on changing things and words until the last moment, and sometimes forgot to check if the language was correct.

Alle vrienden en familieleden die mij de laatste tijd wat minder vaak gezien hebben, wil ik bedanken voor hun begrip en voor hun steun op gezette tijden.

Esther, Merel en Jonas: jullie hebben mij met beide benen op de grond gehouden met jullie nuchterheid, met jullie levenslust, en niet te vergeten de telefonische adwiezen vanuit Enschede en Zeist, vooral als het tekstverwerkingsprogramma niet deed wat ik wilde.

Wat de steun van Ren heeft betekend, is nauwelijks in woorden uit te drukken. Dat je in de laatste fase ook nog de rol van secretaris op je nam, heeft het proces zeker versneld, en dat is maar goed ook. 
Henny de Valk werd geboren op 24 november 1948 te Anna Paulowna.

$\mathrm{Na}$ het eindexamen gymnasium $\mathrm{B}$ aan het lyceum Mater Dei te Nijmegen ging zij geneeskunde studeren in dezelfde stad.

Na het artsexamen 'oude stijl' in 1974, werkte zij van 1974-1977 als arts-coordinator bij de Ederhorst te Ede, destijds een observatiecentrum voor kinderen met leer- en ontwikkelingsstoornissen. Van 1977 tot 1979 werkte zij als huisarts bij huize Boldershof te Druten, een woonvoorziening voor mensen met een verstandelijke handicap. Van 1980 tot heden is zij werkzaam in een soortgelijke functie bij de Pepijnklinieken te Echt.

In 1984/1985 volgde zij de eerste jaargang van de opleiding voor artsen voor mensen met een verstandelijke handicap, die toen nog Zwazo-opleiding heette, aan de Stichting voor Sociale Gezondheidszorg (SSG) te Utrecht.

In 1986 deed zij op uitnodiging van de Nederlandse Vereniging van Artsen in de Zorg voor mensen met een verstandelijke handicap (NVAZ) onderzoek naar de relatie tussen het ouder worden van mensen met een verstandelijke handicap en de kosten van de gezondheidszorg voor deze mensen.

Van 1990 tot 1995 was zij verbonden aan het project vergrijzingsonderzoek, een samenwerkingsverband van de Vakgroep Epidemiologie van de Universiteit van Maastricht en de Stichting Pepijnklinieken.

$\mathrm{Zij}$ was betrokken bij de oprichting van de International Roundtable on Ageing, inmiddels omgedoopt tot Special Interest Research Group on Ageing van de International Association for the Scientific Study of Intellectual Disability (IASSID), en van ENIDA, het European Network on Intellectual Disability and Ageing.

Vanaf 1994 werkte zij aan dit proefschrift over de gezondheidsproblemen bij mensen met een verstandelijke handicap. Sinds 1995 doet zij dit werk vanuit een honoraire aanstelling bij de Vakgroep Huisartsgeneeskunde van de Universiteit Maastricht.

Sinds 1996 is zij opleidingscoördinator van de opleiding voor artsen voor mensen met een verstandelijke handicap aan de Netherlands School of Public Health (NSPH) te Utrecht.

$\mathrm{Zij}$ is gehuwd met Ren van Schrojenstein Lantman.

Zij hebben 3 kinderen: Esther, Merel en Jonas. 